\title{
Competency in shaping one's life : autonomy of older adults with type 2 diabetes mellitus who are treated in a nurse-led clinic
}

Citation for published version (APA):

Moser, A. (2009). Competency in shaping one's life : autonomy of older adults with type 2 diabetes mellitus who are treated in a nurse-led clinic. [Doctoral Thesis, Maastricht University]. Maastricht University. https://doi.org/10.26481/dis.20091023am

Document status and date:

Published: 01/01/2009

DOI:

10.26481/dis.20091023am

Document Version:

Publisher's PDF, also known as Version of record

\section{Please check the document version of this publication:}

- A submitted manuscript is the version of the article upon submission and before peer-review. There can be important differences between the submitted version and the official published version of record. People interested in the research are advised to contact the author for the final version of the publication, or visit the DOI to the publisher's website.

- The final author version and the galley proof are versions of the publication after peer review.

- The final published version features the final layout of the paper including the volume, issue and page numbers.

Link to publication

\footnotetext{
General rights rights.

- You may freely distribute the URL identifying the publication in the public portal. please follow below link for the End User Agreement:

www.umlib.nl/taverne-license

Take down policy

If you believe that this document breaches copyright please contact us at:

repository@maastrichtuniversity.nl

providing details and we will investigate your claim.
}

Copyright and moral rights for the publications made accessible in the public portal are retained by the authors and/or other copyright owners and it is a condition of accessing publications that users recognise and abide by the legal requirements associated with these

- Users may download and print one copy of any publication from the public portal for the purpose of private study or research.

- You may not further distribute the material or use it for any profit-making activity or commercial gain

If the publication is distributed under the terms of Article $25 \mathrm{fa}$ of the Dutch Copyright Act, indicated by the "Taverne" license above, 


\section{Competency in shaping one's life}

Autonomy of older adults with type 2 diabetes mellitus who are treated in a nurse-led clinic 
Copyright 2009, Albine Moser, Maastricht / Krakauebene ISBN: 978-90-9024387-0

\section{Printed by Datawyse}

Cover Design by Len Dumont, www.designbydumont.nl

The graphic on the cover is derived from a picture representing a nautilus shaped staircase. The nautilus shell consists of multiple layers and chambers and the shape of the structure becomes more complex as the nautilus matures. The analogy with the title 'Competency in shaping one's life' is apparent, since both the nautilus shell and people with diabetes shape their lives to the best of their abilities. Also competency is a multi-layered concept and therefore it is reflected seamlessly by the layered complexity of the nautilus shell's structure. 


\title{
Competency in shaping one's life
}

\author{
Autonomy of older adults with type 2 diabetes \\ mellitus who are treated in a nurse-led clinic
}

\section{PROEFSCHRIFT}

Ter verkrijging van de graad van doctor aan de Universiteit Maastricht, op gezag van de Rector Magnificus,

Prof. mr. G.P.M.F. Mols

volgens het besluit van het College van Decanen,

in het openbaar te verdedigen

op vrijdag 23 oktober 2009 om 12.00 uur

door

\section{Albine Moser}




\section{Promotores}

Prof. dr. G.A.M. Widdershoven

Prof. dr. C. Spreeuwenberg

\section{Copromotor}

Dr. K. Cox

\section{Beoordelingscommissie}

Prof. dr. J. Hamers (voorzitter)

Dr. A. Beurskens (Hogeschool Zuyd)

Prof. dr. C. Gastmans (Katholieke Universiteit Leuven, België)

Prof. dr. N. Schaper

Dr. T. van der Weijden

The research presented in this dissertation was conducted under the auspices of the School for Public Health and Primary Care (CAPHRI). CAPHRI was acknowledged by the Royal Dutch Academy of Science (KNAW) in 1995.

Parts of the research was financially supported by CAPHRI. 
The real voyage of discovery consists not of seeking new lands, but seeing with new eyes.

M. Proust 



\section{Table of Content}

$\begin{array}{lll}\text { Chapter } 1 & \text { Introduction }\end{array}$

Chapter 2 Overview of theoretical and empirical literature 23

Chapter 3 Competency in shaping one's life. Autonomy of 41 people with type 2 diabetes mellitus

$\begin{array}{lll}\text { Chapter } 4 \quad \text { Identification } & 63\end{array}$

Chapter $5 \quad$ Self-management and the DSN's and family's role $\quad 79$

Chapter 6 Self-determination, shared decision-making, 99 welcomed paternalism and moral capacities

$\begin{array}{lll}\text { Chapter } 7 & \text { Planned surveillance and motivational factors } & 121\end{array}$

$\begin{array}{lll}\text { Chapter } 8 & \text { Responsive relationships } & 139\end{array}$

$\begin{array}{lll}\text { Chapter } 9 \text { General conclusion and discussion } & 155\end{array}$

$\begin{array}{lr}\text { Summary - Samenvatting - Zusammenfassung } & 187\end{array}$

Acknowledgements - Dankwoord - Dankwort 207

$\begin{array}{ll}\text { Curriculum vitae } & 213\end{array}$

$\begin{array}{lr}\text { Publications } & 214\end{array}$ 

1

Introduction 
CHAPTER 1 
Chronic illness such as diabetes mellitus type 2 may bring about invasive changes in people's lives. Living with diabetes mellitus necessitates taking on tasks to care for the diabetes and simultaneously represents a potential threat to one's autonomy. The term autonomy stems from the Greek: "auto" which means self and "nomos" which means rule [1]. Autonomy is an important value in Western society and is considered to be one of the leading principles of medical [2] and nursing ethics [3]. In ethics, patient autonomy is translated into a whole family of related terms [2]. Collopy [4] considers it as a "notional field". Yet, there is still a considerable amount of ambiguity surrounding this concept. To understand patient autonomy better we need to look at the patients themselves.

\subsection{What is patient autonomy?}

Mr. Limpens ${ }^{1}$

I was diagnosed with diabetes seven years ago. I inject insulin four times a day and visit the diabetes nurse regularly. I became her patient when my physician decided to hand over the diabetes care to the nurse. The goal is that we keep an eye on the diabetes. She taught me several skills to deal with the diabetes. Let me give you an example. She gave me a diabetes computer program. I prick my finger and I type it (sugar level) into the computer program. Before I see my nurse I make a print-out with all the data and graphs of my sugar levels. We have a look at it and depending on the data my nurse asks questions such as "Why do you think your sugar level is so high?" "Can you remember something that was different that day?" We look at the peaks and evaluate them. In the beginning I had some difficulties. When I had a peak I did not know if I should adjust the units of insulin. Should I inject more or less units than she told me? I have learned how to do that. If I eat more, I inject more. Recently, the nurse adjusted the units because I had some hypo's (hypoglycaemia) before lunch time. Until then, I had adjusted the units myself. Once when my sugar level was low I omitted six units and, of course, it did not work out well. Now I know how to alter the units myself - if it is only a few units. My nurse always says that if I want something else I should tell her. She lends a hand, but not in a forceful way. She says, "I give you advice, but if you don't like my advice and want to

\footnotetext{
${ }^{1}$ In our translation we wanted to stay as close as possible to the language people with diabetes use.
} 
do things differently, you tell me." Once, she said that I should use "new" medication for my high cholesterol. I did not agree and I did not take it. I had not experienced any problems with my normal medication and the "new" medication had some side-effects which I wanted to avoid. We also speak about other things like, when I bike home I feel that I have a low sugar level. I ask her, "Should I inject fewer units in the morning or should I eat a snack in between?" She provides me not only with information about why these things happen, but also recommends and teaches me certain strategies to handle the situation. In the meantime, I think that I can manage my diabetes quite well. I do not really need the nurse, but seeing her regularly motivates me to take care of my diabetes properly. She tells me to come back every three months for a follow-up. It sounds crazy, but when I am going to see her I feel I have to prove that I take good care of the diabetes. Let me give you an example. Some time ago I had some meetings with a dietician because my nurse wanted me to go there. The dietician taught me what to eat and how to cook. I did not adjust my cooking pattern and eating habits. A few weeks later when I saw my nurse I started taking care of my diet. The visits have a control function that makes me take better care of myself. My nurse also encourages me to contact her if I need something. She emphasizes that I do not need to wait until the next consultation - "Just give me a call". Diabetes is a fussy disease since one cannot feel it. But if I do not take care of it I will have more health problems in about ten years, like problems with my eyes. That's so risky. I'm more and more aware of this since I am getting older. The perfect thing is that my body tells me if something is wrong with the sugar level. I wake up during the night and then I measure my blood sugar and eat a snack. I do take care of the diabetes myself. The diabetes requires me to make decisions daily. It already starts in the morning. On weekdays I inject my insulin around 7.30 a.m. On the weekend I prefer to sleep longer. Then I decide to get up at 10 a.m. and to inject at a later moment. My wife supports me a lot. She is quite engaged. She has become a sort of co-patient. After I work on the computer and we have dinner she often asks "Have you injected the insulin?" She just knows that I tend to forget about it since I am occupied with other things. When we go out she asks "Did you bring the insulin?" - "No, no," and then I have to go back to the apartment to fetch it. She is closely involved in the diabetes thing. What happens if I become unconscious? Then she needs to know what to do. We do not speak about the diabetes a lot. It is much more like. "Oh, the sugar is high I am going to inject some extra units". We do not make a drama out of it. It has become automatic. Diabetes is something I have to deal 
with. It is not a sickness I chose. Rather, it just happened to me. In the beginning I was rebellious and I could not understand why it happened to me. I did not like it. Now I know how to live with it. Honestly, I do not deal with the diabetes in the same way every day. Most of the time I try to do everything correctly. Still, there are periods when I have setbacks. Over the course of the years, I have learned to master my diabetes.

What does autonomy mean to Mr. Limpens? The autonomy of Mr. Limpens can be interpreted in several ways. In medical ethics patient autonomy is most often understood as the people's right to decide for themselves without interference by others [2]. Mr. Limpens exercises his right to self-determination. He does not let others decide for him, but does what he wants to do. He rejects the advice to use another medication for his cholesterol which the nurse proposed. He wants to continue with the medication he already takes for this. On the weekends, he decides to inject insulin later in the morning without consulting the nurse or his wife. Mr. Limpens' autonomy fits Berlin's account of negative freedom [5]. Negative freedom highlights freedom of decision-making and action and freedom from interference from others.

Mr. Limpens does not only exercise his right to self-determination, he also experiences that he is the author of his own life [6]. Mr. Limpens considers options that suit his personal situation. In this sense, positive freedom [5] refers to people's capacity to make their own choices and direct their life according to their personal convictions and goals. In positive freedom, people recognize and respond to external circumstances. Mr. Limpens does this as the following examples show. Mr. Limpens deliberates with the nurse about the peaks in his glucose profile. They review them and the nurse tries to find out what is going on and what issues are important. Here, Mr. Limpens was insecure about the adjustment of insulin. They agreed that Mr. Limpens may decide on the number of units of insulin he injects within a range of a few units. In addition, the nurse encourages Mr. Limpens to deliberate about the care and treatment regimen by emphasizing that he should indicate if he wants things to be handled differently. In this fragment autonomy in communication is at the core. In communicative ethics patient autonomy stresses the processes of negotiation and sharing decisions. Autonomous decision-making takes place in deliberation $[7,8]$ with others.

From a self-management view on autonomy, people manage their chronic condition themselves [9]. Mr. Limpens enhances his abilities to self-manage his diabetes by being educated on the subject and by asking the nurse for selfmanagement solutions. Mr. Limpens' self-management abilities include: observ- 
ing body cues, measuring his blood sugar level and knowing what decisions and actions are necessary when he encounters problems with the sugar levels.

According to the theory of care ethics, autonomy is best realized within the context of social relationships with others [10]. Autonomy can only develop in caring relationships in which mutual responsiveness and human interdependence are recognized in the process of care [11]. These elements can also be found in the story of Mr. Limpens. He assumes certain care responsibilities in the relationship with the nurse. He goes regularly to the follow-up visits. He consulted with the dietician to improve his diet and eating behaviour, and he tries to adapt his lifestyle to meet the requirements of his diabetes. Though the latter is not easy, he assumes that responsibility, too. The nurse is responsive to Mr. Limpens. She reflects on the blood glucose levels to evaluate the life-style modifications which might be indicated/desirable to improve his health and encourages him to contact her at any time (during or after office hours). Mr. Limpens also has a responsibility to his wife. His responsibility is to take her concerns seriously and to take care of himself. In addition, Mr. Limpens has to keep his wife up-to-date about the treatment regimen. His wife observes him and reminds him to carry out the tasks appropriate to the care of his diabetes. She knows about the treatment needed in case of an emergency.

Agich [12] defines the concept of actual autonomy as concrete human actions in a social world which people display. Persons become autonomous as their actions display a developed pattern based on habits and routines. Actual autonomy is developmentally determined. Personal development is ongoing because people are always open to new influences and might change. Mr. Limpens' autonomy is continuously developing. He accommodates himself to new situations. Over time he has learned to master the diabetes. Mr. Limpens is also open to the future. He accepts his ageing and tries to alert himself to changes in his health and how to manage them in an attempt to avoid and minimize long-term complications and their consequences.

From a nursing perspective, patient autonomy is particularly supported in the nurse-patient relationship. Patient autonomy includes collaborative working between nurses and patients to achieve certain goals [13]. Mr. Limpens has developed a long-term relationship with his nurse and is learning appropriate skills on an on-going basis with the goal to monitor the diabetes properly. The nurse trained his self-monitoring skills (of the glucose profile), taught him how to alter the units of insulin injected depending on the glucose levels, and took the initiative to refer Mr. Limpens to a dietician. 
We used a range of theories and concepts to explain the ways Mr. Limpens exercises his autonomy. We looked from an ethical, decision-making, selfmanagement, caring, developmental, and nursing perspective. These theories and concepts are diverse in nature and, as this example shows, autonomy has many faces. This diversity illustrates the complexity of autonomy. Most theories are constructed top-down, while a few authors, such as Agich [12] and Koch [9], start from the patient's perspective. Each theory explains patient autonomy from a certain perspective and, as we have illustrated in the case of Mr. Limpens, do cover a certain aspect of the whole picture. Clearly the concept of autonomy is dynamic and determined by situational factors. On the one hand, Mr. Limpens wants to make his own decisions and, on the other hand, he mentions more than once that he needs the support of his diabetes nurse and wife. In this respect it is not clear what autonomy means for patients and nurses. A critical concern is whether these theories and concepts fit to the way older adults with type 2 diabetes understand and exercise their autonomy and how nurses can most effectively support it.

\subsection{Nurse-led diabetes clinics as embedded in the Maastricht shared care model}

In the late 1990s, diabetes specialist nurses (DSN) became part of diabetes teams in the Netherlands and nurse-led diabetes clinics in primary care were established [14]. Of course, they are still involved in traditional care as well. A variety of healthcare professionals are involved in the care of diabetics and the addition of the DSN required a substitution of tasks [15] which happened within existing shared care models but evoked the development of nurse-led clinics as an answer to the rising number of chronically ill people.

This development is based on a series of policy decisions. Already in 1989, the National Council of Public Health [16] which advises the Dutch government on health policy issues, published a report about the substitution of tasks in health care. Task or functions should be transferred to the lowest level of expertise and competence as possible to control costs and to increase the efficiency of care. In 1991, the release of the governmental report " A policy document for the chronically ill. Don't keep chronic patients out of it" [17] formulated three goals of a health policy for chronically ill people: to promote an effective and efficient approach of chronic diseases and their consequences, to stimulate an environment in which chronically ill people experience an improved quality of life, and to promote a liveable societal climate for the chronically ill. In this report, it was explicitly formulated to install a new function - that of the specialist nurse. A specialist 
nurse should provide nursing as well as medical care, coordinate care, improve the expertise in primary care and reinforce the integration of care between hospital and primary care. In the same year, the National Commission of Chronically III was established to help to initiate and implement these efforts and to strengthen the societal position of the patient [18]. In 1994 the Maastricht University Hospital implemented a policy to improve the cooperation between family physicians and medical specialists which resulted in a transfer of tasks from specialists to primary care physicians [19]. Additionally, to reduce the workload of physicians (but also medical specialists) it was decided to transfer tasks to specialist nurses. It was assumed that specialist nurses function as the main care giver for patients with a chronic disease in a stable phase [19]. DSN were implemented. In the meantime, DSN have developed into indispensable professionals, administering complex care [20].

Besides the substitution of tasks another movement is a patient-centric view in shared-care [21]. A shift of paradigm has emerged: from traditional care to collaborative care [22]. Traditional care regards physicians as experts, with patients bringing little to the table besides their chronic illness. Collaborative care includes that physicians and other health professionals are the experts about the disease and patients are experts about their lives. This new paradigm means that care provision is directed at the wishes, wants and needs of chronically ill people. One of the cornerstones of the Maastricht shared care model is to encouraged people with diabetes to participate more actively in selecting the nursing and medical interventions which they consider appropriate $[18,23]$. There is also the desire to be more sensitive to the personal circumstances and wishes of the individual patient [21]. The aim is to enhance the autonomy of patients with regard to their own care. For older people with diabetes coping with type 2 diabetes is a complicated matter [24]. The condition is complex and involves, among other things, comorbidity and potential long-term complications. Moreover, the responsibility for the day-to-day care shifts from the professional to the individual [25]; in this case from the DSN to the older adults with type 2 diabetes. This places a large burden on patients [26] and forces them to rely on their own knowledge and skills to manage their care in the absence of the healthcare professional. This shift requires these older adults to be responsible for their diet, skin care, medication intake, insulin administration, exercise, rest, monitoring of blood glucose levels, and maintaining contact with the DSN and other health professionals.

As already mentioned, in the Maastricht shared care model, DSN have taken over tasks from medical specialists and general practitioners. In effect, DSN have an intermediate position between that of the medical specialist and the general practitioner. Diabetes patients are allocated to one of three care pathways: a) 
patients with complicated health problems that may require radical medical decisions are referred to a medical specialist, such as an endocrinologist, b) patients with less complex cases are referred to general practitioners who provide basic care and to home care nurses who provide the essential daily diabetes care and (diabetes) education, and c) patients with a complex health status, in a stable phase, are referred to the DSN as the main care provider [19]. This group of diabetes patients require medium-intensity care [14]. Autonomy issues of people with type 2 diabetes differ in primary and tertiary settings. Specialist-care patients have acute and very complicated health problems that may require radical medical decisions. General practitioners provide basic care for the less complex cases of diabetes in the primary care setting, and home healthcare nurses provide the essential daily diabetes care. The result is that autonomy concerns in a nurse-led, shared care setting are characterized by a mix of specific medical and advanced nursing issues.

DSN see their patients frequently, offer quarterly follow-up consultations [27], and, are available for appointments, as needed. The patient sees the medical specialist for an annual check up in the hospital and the DSN and general practitioners have regular meetings to discuss and evaluate the medical and nursing treatment of individual patients [19].

Most DSN have a Bachelor Degree in Nursing with a Post-Bachelor training in diabetes care [27]. DSN work in a multidisciplinary team. In addition to medical specialists and general practitioners, there are dieticians, home care nurses, podiatrists and several coordinators of care networks in Maastricht and South Limburg [28]. DSN function in both hospital and primary care settings. This nurse-led clinic consists of a diabetes outpatient department at Maastricht University Hospital and specialty clinics in general practice. DSN are assigned to a specific group of general practitioners and are able to provide on-going care to their patients which enable them to enter into long-term relationships with them.

DSN follow agreed upon guidelines based on national treatment guidelines (Dutch Association of General Practitioners and Dutch Diabetes Association) [29] and local guidelines in which tasks, activities and targets are formulated [30]. DSN provide a mix of advanced nursing practice and medical care. That includes: a) direct patient care: taking nursing and medical history, making care plans, b) organization and coordination of care of the individual patient: organizing additional health services if necessary and participation in multidisciplinary meetings, c) consulting: giving advice to other professionals involved in the diabetes care $\mathrm{d}$ ) promotion of professional expertise: giving courses to other professionals involved in the shared-care model, participating in national DSN networks and e) 
innovation and research, and establishing nurse-led clinics, In addition, DSN need to take on the task of supporting patients in their efforts to realize their autonomy.

\subsection{The role of DSN in fostering patient autonomy}

The aim of nursing care for chronically ill people is to assist and guide them in dealing with the consequences of their illness in their daily lives and to maintain their autonomy as long as possible [31, 32]. Nurses can offer support in four ways by: a) helping the chronically ill cope with their illness, b) easing the struggle of daily life, c) helping with the therapeutic regime, and d) assisting with care management [32]. DSN, too, have an important role to perform in supporting patient autonomy and, therefore, they need the appropriate competencies. The Dutch Association of Diabetes Nurses [33] defines competencies as "a combination of skills, knowledge and attitude to practice adequately, effectively and efficiently in a particular work situation" (p. 14). They state that DSN should assess the degree of dependency, responsibility and autonomy of the patient [33]. They do not provide information about what competencies are needed to promote patient autonomy. As a consequence DSN might ineffectively train that competencies, they might not know what competencies exactly they need to train and most importantly, there might be great variation in the way DSN support patient autonomy in daily practice. The question what DSN in particular, can do to support the autonomy of their patients remains unclear.

\subsection{The research project}

\subsubsection{Aims}

The aim of this research is threefold: to develop a substantive theory of patient autonomy, to conceptualize the essence of complex interactional processes related to the patients' realization of autonomy and to formulate recommendations for the DSN to support patient autonomy on the individual as well as policy level.

\subsubsection{Research questions}

1. How do older adults with type 2 diabetes mellitus who are treated by DSN view their autonomy?

2. How do these older adults realize their autonomy?

3. How can DSN support the autonomy of their patients? 


\subsubsection{Theoretical orientation}

The theoretical orientation of the dissertation is symbolic interactionism [34]. According to Blumer [34] symbolic interactionism rests on three basic premises:

1. Human beings act toward things on the basis of the meanings that the things have for them. These things may be objects, other human beings, institutions, guiding ideas and activities of others or a combination of these.

2. The meaning of such things is derived from, or arises out of the social interaction that one has with others.

3. These meanings are handled in, and modified through, an interpretive process used by people in dealing with the things they encounter.

The reality or meaning of a situation in a natural environment is created by people and leads to particular actions and consequences. Meaning is derived from the social interaction and experience that people have with others and the environment, as well as with the history of similar interaction. Symbolic interactionism contends that people act rather than just respond to others and that human conduct is purposeful.

The human being is not a mere responding organism, only responding to the play of factors from this world or from himself; he is an acting organism who has to cope with and handle such factors and who in doing so has to forge and direct his line of action (p. 55) [34].

Behaviour is a self-directed process. The meanings are continually interpreted and revised in social actions and interactions with others through the use of symbols such as language. Symbolic interactionism is a theoretical orientation to study people's social actions and interactions in search of understanding the process of meaning-making with regard to a particular phenomenon in a specific social context. Our focus is on the perception and understanding of patient autonomy by older adults with type 2 diabetes mellitus and their exercise of it.

\subsubsection{Research design}

To answer the research questions a qualitative descriptive and exploratory research project has been designed. We approached older adults with type 2 diabetes mellitus and interviewed 15 participants, in-depth, to explore their perspectives and experiences regarding autonomy. We used the grounded theory method [35], which is based on social interactionism. Grounded theory is an inductive from-the-ground approach that uses everyday behaviours to generate a theory about a particular phenomenon [35]. 


\subsection{Outline of the dissertation}

In Chapter 2 we present a review of the theoretical and empirical literature addressing patient autonomy and how nurses can support it. In Chapter 3 we portray how older adults with type 2 diabetes mellitus, who are being cared for by DSN in a nurse-led clinic, view their autonomy. Competency in shaping one's life was found to be the most prevalent description of this phenomenon. It consists of seven categories which we consider to be dimensions of autonomy. These are: identification, self-management, self-determination, shared decision-making, welcomed paternalism, planned surveillance and responsive relationship. Chapters 4 to 8 present the processes that underlie these dimensions. In Chapter 4, we describe the process of identification. Chapter 5 outlines the processes that characterize self-management. In this chapter, we also pay attention to the involvement of DSN and family members in patient self-management. Chapter 6 explains the decision-making processes of the dimensions self-determination, welcomed paternalism and shared decision-making. We also present moral capacities, which older adults with diabetes consider important in the DSN's support of autonomous decision-making. In Chapter 7, we explain the processes that underlie the dimension planned surveillance and the patient's motivation to remain under continuous surveillance. In this chapter we also examine the use of literature as data in a grounded theory analysis. In Chapter 8, we describe the processes that shape autonomy in responsive relationships with others. Chapter 9 provides a general conclusion and discussion. 


\section{References}

1. Dworkin, G., The theory and practice of autonomy. 1988, Cambridge: Cambridge University Press.

2. Beauchamp, T.L. and J.F. Childress, Principles of biomedical ethics. 5 th ed. 2001, New York: Oxford University Press.

3. Fry, S.T. and M.-J. Johnstone, Ethics in nursing practice: a guide to ethical decision making. 2 nd ed. 2002, Geneva: Blackwell Science Ltd.

4. Collopy, B., Autonomy in long term care: some crucial distinctions. The Gerontologist, 1988. 28, Suppl: p. 10-17.

5. Berlin, I., Twee opvattingen van vrijheid. 1996, Amsterdam/Meppel: Boom.

6. Raz, J., The morality of freedom. 1990, Oxford: Clarendon Press.

7. Widdershoven, G.A.M., Ethiek in de kliniek: Hedendaagse benaderingen in de gezondheidsethiek. 2000, Maastricht: Boom.

8. Widdershoven, G.A.M., Care, cure and interpersonal understanding. Journal of Advanced Nursing, 1999. 29(5): p. 1163-1169.

9. Koch, T., P. Jenkin and D. Kralik, Chronic illness self-management: locating the 'self'. Journal of Advanced Nursing, 2004. 48(5): p. 484-492.

10. Mackenzie, C. and N. Stoljar, Relational autonomy: feminist perspectives on autonomy, agency, and social self. 2000, Oxford: Oxford University Press.

11. Tronto, J.C., Moral boundaries: a political argument of an ethic of care. 1993, New York: Routledge.

12. Agich, G., Dependence and autonomy in old age. 2003, Cambridge: Cambridge University Press.

13. Peplau, H., Interpersonal relations in nursing. 1988, Hampshire and London: Macmillan Education Ltd.

14. Vrijhoef, H.J.M., C. Spreeuwenberg, I.M.J.G. Eijkelberg, B.H.R. Wolffenbuttel and G.G. Van Merode, Adoption of disease management model for diabetes in the region of Maastricht. British Medical Journal, 2001. 323: p. 983-985.

15. Vrijhoef, H.J.M., J.P.M. Diederiks, C. Spreeuwenberg, B. Wolffenbuttel and L.J.G.P. Van Wilderen, The nurse specialist as a main care-provider for patients with type 2 diabetes in a primary care setting: effects on patient outcomes. International Journal of Nursing Studies, 2002. 39: p. 441-451.

16. Volksgezondheid, N.R.v.d., Substitutie in de gezondheidszorg: discussienota. . 1989: Zoetermeer.

17. Ministerie van Welzijn, V.e.C., Notitie chronisch ziekenbeleid, chronische pateinte niet buiten spel. 1991: Den Haag.

18. Spreeuwenberg, C. and P. Pop, Transmurale zorg, in Handboek tansmurale zorg., C. Spreeuwenberg, et al., Editors. 2000, Elsevier Gezondheidszorg: Maarssen. p. 17-36.

19. Vrijhoef, H.J.M., Is it justifiable to treat chronic patients by nurse specialists? Evaluation of effects on quality of care. 2002, Maastricht: Datawyse.

20. Van den Berg, T.I.J., H.J.M. Vrijhoef, G. Tummers, J.A. Landeweerd and G.G. Van Merode, The work setting of diabetes nursing specialists in the Netherlands: A questionnaire survey. International Journal of Nursing Studies, 2008. doi:10.101/j/ijnurstu.2007.12.003.

21. Kodner, D. and C. Spreeuwenberg, Integrated care: meaning, logic, applications, and implications a discussion paper. International Journal of Integrated Care, 2002. 2(14 November).

22. Bodenheimer, T., K. Lorig, H. Holman and K. Grumbach, Patient self-management of chronic disease in primary care. Journal of the American Medical Association, 2002. 288(19): p. 2469-2475.

23. Wolffenbuttel, B., Het Matador - project (Maastrichtse transmurale diabetesorganisatie), in Tranmurale zorgvormen van diabetes mellitus - een verkenning van de situation anno 2000., $\mathrm{H}$. Bilo and $\mathrm{F}$. Van Nunen, Editors. 2000, Isala Clinics: Zwolle. p. 204-219.

24. Van den Arend, I.M., R.P. Stolk, H.M.J. Krans, D.E. Grobbee and A.J.P. Schrijvers, Management of type 2 diabetes: a challenge for patient and physician. Patient Education and Counseling, 2000. 40: p. 187-194.

25. Barlow, J., C. Wright, J. Sheasby, A. Turner and J. Hainsworth, Self-management approaches for people with chronic conditions: a review. Patient Education and Counseling, 2002. 48: p. 177-187. 
26. Reed, J.A., J.M. Lawrence, S. Hollinghurst and E.R. Higgs, Diabetes self-management: how are we doing? Practical Diabetes International, 2003. 20(9): p. 318-322.

27. Denis-Thissen, E. and M. Frederix, Rol van de diabetesverpleegkundige: nu en in de toekomst, in Transmurale zorgvormen van diabetes mellitus: een verkenning van de situatie anno $2000, \mathrm{H}$. Bilo, et al., Editors. 2000, Isala Klinieken: Zwolle. p. 98-113.

28. Maastrichtse transmurale diabetesorganisatie, Protocol: het MATADOR project. 1999, Maastricht: University Hospital Maastricht.

29. Maastrichtse transmurale diabetesorganisatie, Beleidsdocument 2007. Diamand. 2007, Academisch Ziekenhuis Maastricht: Maastricht.

30. Frederix, M., Gespecialiseerde verpleegkundigen nemen taken van specialist over. Tijdschrift voor Verpleegkundigen, 1998. 108(13): p. 416-419.

31. Pool, A., P.-T. C, F. Veltman-Van Vugt and S. Vogel, Met het oog op de toekomst. Beroepscompetenties van HBO-Verpleegkunidgen. 2001, Utrecht: NIZW.

32. Grypdonck, M., Het leven boven de ziekte uittillen. De opdracht van de verpleegkunde en de verplegingswetenschap voor chronisch zieken. 1996, Leiden: Spruyt, van Mantgem en de Does.

33. Eerste Associatie van Diabetes Verpleegkundigen, Diabetesverpleegkundige. 2004, Utrecht: AVVV.

34. Blumer, H., Symbolic interactionism. 1969, New York: Englewood Cliffs.

35. Strauss, A. and J. Corbin, Basics of qualitative research: grounded theory procedures and techniques. 1990, Newbury Park: Sage. 


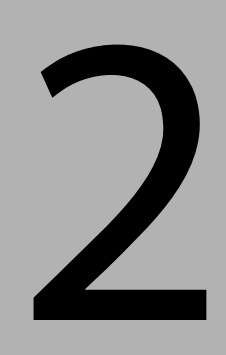

\section{Overview of theoretical and empirical literature}




\section{Abstract}

This chapter presents a review of the theoretical and empirical literature addressing patient autonomy and how nurses can support patient autonomy. Nurse-led, shared-care settings provide needs-based care to patients who are encouraged to participate actively in their care. Patient autonomy is a complex ethical concept with many different meanings. As a result, nurses must solve various problems to foster patient autonomy successfully. Two methods were used to identify literature for the review: (a) a search of the Medline, Embase, CINAHL and Online Contents databases and the Dutch Central Catalogue for material published from 1966 to 2005; (b) a selection of ethical and nursing literature on the basis of its identification of positive and negative freedom. We reviewed qualitative empirical research to explore the patients' views of autonomy. Negative freedom emphasizes freedom of action and freedom from interference by others. Positive freedom stresses the idea that people should direct their lives according to their personal convictions and individual reasons and goals. The most prominent theories fitting negative freedom are those defining autonomy as self-governance and self-care. Theories fitting positive freedom are those focusing on autonomy in caring, autonomy as identification, autonomy in communication, and autonomy as goal achievement. In the empirical literature, two studies centred on patient autonomy in home care, one in nursing home care, and three in hospital settings. To achieve autonomy, patients prefer a mixed approach that combines features of negative and positive freedom. Nurses cannot rely exclusively on one model of autonomy to foster patient autonomy. Rather, it requires in-depth knowledge of, and interaction with, patients in the context of each particular nursing encounter. The practice of nurse-led, shared care remains to be investigated in this respect.

This Chapter is based on the publication:

Moser, A., R. Houtepen, and G.A.M. Widdershoven, Patient autonomy in nurse-led shared care: a review of theoretical and empirical literature. Journal of Advanced Nursing, 2007. 57(4): p. 357-365. 


\subsection{Introduction}

Shared care models define needs-based care for chronically ill people [1]. In these models, specialist nurses play a significant role because they are the main professional caregivers for people with chronic conditions which require continuing care [2]. One of the key aims of this type of care is encouraging patients to take an active role in management of their condition [3]. Patient autonomy is a cornerstone of nurse-led, shared care.

We address patient autonomy from an ethical perspective derived from the moral ideal of autonomy. This ideal is linked to life as a whole, not only to decisionmaking, and stresses the notion that people should run their own lives. Autonomous people are authors of their own lives. The ideal of personal autonomy is that people should control their own destiny, fashioning it through successive decisions [4]. However, patient autonomy is an ethical concept that is open to empirical investigation. Empirical ethics integrates ethics and empirical research [5]. By 'integrated empirical ethics' we mean that empirical research methods are directly related to ethical theory and vice versa [6]. Integrated empirical ethics is based on the assumption that descriptive and prescriptive sciences are interwoven [7] and should augment one another [8]. Nurses are becoming more and more aware of the ethical dimension of their practice; consequently, empirical research into this ethical dimension is now being carried out [9].

Patient autonomy is a term that is often used in nursing literature, although its meaning is often ambiguous [10]. Autonomy is translated into a whole family of related terms: individual liberty, privacy, free-choice, self-governance, selfregulation, and moral independence [11]. In biomedical ethics, patient autonomy is the core of the concept of informed consent and dominates the relationship between patients and healthcare professionals. Some theorists, however, emphasize the importance of the healthcare context [12-14], highlighting the significance of individual circumstances, and ways in which interaction between participants constitutes part of the context [15]. As a result, it is not clear what fostering patient autonomy consists of in daily practice. Given these difficulties, we want to answer the question: how can patient autonomy be supported? To do this, we examine relevant ethical and nursing concepts of autonomy and empirical research on patients' views of autonomy. In this paper, we aim to present a review of theoretical and empirical literature addressing patient autonomy and how nurses can support patient autonomy. 


\subsection{Method}

We used two methods to locate relevant literature: (a) ethical and nursing literature based on the interpretation of freedom and (b) empirical literature cited on computerized databases.

With respect to the first method, Berlin's [16] distinction between negative and positive freedom was the starting point for our selection of theories. Our rationale for starting with a theory addressing freedom is that autonomy is the concrete form of freedom [4]. Negative freedom refers to freedom of action and freedom from interference by others. People are expected to decide matters for themselves without any intrusion from others. The role of professionals in promoting negative freedom is primarily to provide sound information and leave patients to make their own decisions. We included autonomy as self-governance and selfcare because these two theories focus on patient self-determination as related to negative freedom. Positive freedom, however, highlights people's capacity to make their own choices and direct their life according to deeply held convictions and personal reasons and goals. The role of professionals in positive freedom is therefore different: they take an active part in patients' realization of autonomy. In positive freedom, people are socially embedded, and autonomy is realized within the context of social relationships [17]. This is an important point, as the nursepatient relationship is considered the foundation of nursing care [18]. We therefore opted for theories that view relational issues as a prerequisite to the successful realization of autonomy. We selected theories which, first of all, relate to the nursing context; second, appear in the nursing literature; and third, illustrate various ways in which nurses are involved in fostering patient autonomy. These theories are autonomy in caring, autonomy as identification, autonomy as communication, and autonomy as goal achievement.

Our second strategy was to search the online databases Medline, Embase, CINAHL, Online Contents, and the Dutch Central Catalogue. We used the keyword 'patient autonomy' in combination with 'nursing', which allowed a broad exploration of the published literature. The search yielded 1236 articles. First, we included all papers that matched the keywords. The literature thus identified related to professional autonomy and the work context of nurses, and patient autonomy. We included only qualitative studies because we wanted to study people's own views of autonomy. Quantitative research reports and papers on patient autonomy related mainly to end-of-life care and mental health care and were excluded because they usually analysed autonomy issues in relation to specific settings (for example, autonomy and competency in mental healthcare). The 
search yielded two studies of home care, one of nursing-home care, and three of hospital care.

We included theoretical and empirical articles in English, German, and Dutch published from 1966 to 2005. Furthermore, we checked reference lists and citations of included papers to ensure that we accessed as much relevant literature as possible. A total of 1865 references were reviewed.

\subsection{Findings}

\subsubsection{Ethical and nursing theories}

\subsubsection{Negative freedom}

Autonomy as self-governance. In the nursing literature, autonomy is often referred to as self-governance. In healthcare ethics, however, these and related concepts are more finely dissected. Beauchamp \& Childress [19], for example, distinguish between personal autonomy and autonomous choices. They define personal autonomy as personal rule of the self that is free from any controlling interference by others and from personal limitations that prevent meaningful choices. Autonomous choices, on the other hand, refer to acts such as consent or refusal. Autonomous choices are viewed as actual governance, rather than the capacity for governance. A person with diminished autonomy is, in some respect, controlled by others, or incapable of deliberating or acting on the basis of his/her desires. Three conditions are necessary if people are to make autonomous choices: liberty, agency, and the capacity for intentional action. In the case of patients, informed consent (an individual's authentic authorization of an intervention) is fundamental to the exercise of autonomy; they must be competent, informed, and act voluntarily to be considered autonomous. Autonomous actions cannot, therefore, include controlling constraints of others. At the clinical level, this means that nursing care interventions can only be carried out if the patient gives informed consent.

Autonomy as self-care. Orem's [20] theory of self-care is widely used by nurses. According to Orem, self-care is a human regulatory function where people must act for themselves on the basis of deliberation. Self-care as deliberate action is action to achieve a foreseen result, preceded by investigation, reflection and judgement to appraise the situation, and by deliberate choice about what should be done. Deliberate action is always self-initiated, self-directed, and selfcontrolled. Orem emphasises the concept of self-care agency, highlighting that self-care is fundamentally affected by the presence or absence of power. Self-care 
agency is related to physical, cognitive, and psychosocial development, including development of self-direction, and is demonstrated through the capability to engage in the investigative and decision-making phase of self-care (phase 1) and in self-care action (phase 2). Orem conceptualizes dependent care as activities that people initiate and perform on behalf of a dependent person to meet their self-care demands as, for example, when family members take over self-care responsibilities. Nursing care is only provided when someone (who could also be a family member) needs help to protect or regulate the exercise of self-care agency. Orem [20] (p. 65) clearly states that 'people are capable of self-determined actions even if they feel an emotional pull in the opposite direction'. Autonomy means that people make self-determined decisions and deliberately carry out self-care actions. Nurses have a pivotal role to play in fostering patient autonomy by facilitating resumption of self-care and supporting self-care agency by providing information and resources that enable patients to make deliberate, self-directed choices which result in carrying out self-care activities.

\subsubsection{Positive freedom}

Autonomy in caring. This concept of autonomy in caring stems from an ethical theory where care is at the core. This is of particular relevance to nurses because caring lies at the very heart of nursing. Autonomy can only develop in caring situations where mutual responsiveness and human interdependence are recognised as the basis of the personal and social context [13]; in other words, the care process must be seen as reciprocal. According to Tronto, care is an ongoing relational process consisting of four phases: caring about, taking care of, care-giving, and care-receiving. The four phases are intertwined in the actual care process. The first phase, caring about, involves the recognition that care is necessary: there is a need which should be met. The second phase, taking care of, indicates that someone has to be responsible for meeting the care need. The third phase, care giving, implies direct care interventions, while the fourth phase, care receiving, means that people who receive care respond to the care which they have received. Without an adequate response from care receivers, the care process is not completed. From these four phases, Tronto identifies four moral qualities which are essential to the process. The first is attentiveness which means being open to the needs of others. The second, responsibility, implies that someone has to be responsible for a care action, while the third, competence, suggests they must be capable of meeting a need. The final quality, responsiveness, refers to the active response of the care receiver and highlights the fact that responsiveness requires attentiveness. Autonomy is viewed as a process in which nurses and patients are engaged and to which they give shape as the care process develops. Thus, autonomy is characterized by openness and responsiveness towards each other's 
contributions, resulting in the choices made by one party being nourished by others.

Autonomy as identification. Agich [14] developed this theory in the context of long-term nursing settings. He presents the concept of actual autonomy and defines it as concrete human actions in a social world. A person becomes identifiably autonomous as their actions display a developed pattern. In other words, it is not thinking about their actions, but carrying them out, which makes people autonomous agents. According to Agich, actual autonomy is developmental and socially determined. Personal development is never finished because people are always subject to new influences and change; thus, autonomy is dynamic rather than static. Because autonomous people are always situated in concrete social contexts, decisions and choices are always contextual and autonomy therefore develops in the context of relationships with others. Thus, people can still be considered autonomous if they can identify those people and things on which they are dependent, as the exercise of autonomy requires supportive relationships throughout life. Similarly, decisions are not always rational and reflective, but are formed by everyday experience, routines, and habits. In the nursing context, autonomy for people in long-term care consists of choices that are meaningful to them and that will allow them to sustain their own individuality.

Autonomy as communication. Another view of positive freedom and relational autonomy stresses processes of communication and negotiation. This definition of autonomy was worked out in a nursing-home setting by Moody [12] who defines autonomous functioning as being built on shared dialogue: communication and negotiation within the social environment. Decision-making takes place within social communication processes. He introduced the notion of negotiated consent, which is grounded on social interaction including communication, clarification, and consensus building. Negotiated consent is characterized by balancing competing interests, and requires that patients or their surrogate actively take part; all parties with an interest in the decision co-operate; ethical and legal rights of the weaker are taken into account; the process allows higher authorities to enforce those rights; and, finally that the negotiation process is open to public scrutiny. Moody states that negotiations are appropriate for situations where the ideal outcome is unattainable, so that all participants have to make the best of the situation by focusing on shared goals. He distinguishes four interventions based on negotiated consent: advocacy, empowerment, persuasion, and making decisions for others. Advocacy involves caregivers supporting and defending the legitimate wishes of patients, while empowerment includes facilitating interventions through which patients can maintain their own values. Persuasion means offering arguments to influence patients in order to change their minds, and 
making decisions for others means that decisions are made on their behalf. Negotiated consent focuses on a group process to seek agreement on necessary care interventions. Encouraging the patient to be actively involved in the process of negotiated consent supports patient autonomy.

Autonomy as goal achievement. Peplau [21] places the nurse-patient relationship at the very centre of her nursing theory of interpersonal relationships. She emphasizes the importance of relations with others, and thus the context of nursing practice. According to Peplau, the relationship of nurses to patients is a continuum: at one end are two people with separate goals and interests, and at the other end, two people working together to solve a health difficulty about which there is a common understanding. She perceives four phases, which overlap and occur over time: orientation, identification, exploitation, and resolution. Nurses assume various roles in these phases, such as teacher, resource, counsellor, leader, technical expert, and surrogate. In the orientation phase, patients express a need. Nurse and patient then collaborate to define the problem. The identification phase follows, where patients react to nurses who can meet their needs. Patients' responses take one of three forms: participation or interdependence with the nurse, independence or isolation from the nurse, and helplessness or dependence upon the nurse, either singly or in combination, starting with one pattern and moving through the other two as a co-operative relationship develops. Peplau defines the ideal relationship as a democratic one in which all involved are active participants. In the exploitation phase, patients make use of the nursing services offered while, at the same time, beginning to orientate towards new goals. They develop skills to reach a certain goal, learning these skills in the context of the nurse-patient relationship. In the resolution phase, the nursepatient relationship ends as the goals are achieved through the collaborative efforts of nurses and patients. Successful resolution flows directly from successful completion of the other phases. Peplau [22] stresses that everyone is dependent upon someone or something, in some degree, for a very large proportion of their lives. Autonomy therefore means, not isolation, but collaborative working between nurses and patients to achieve certain goals with nurses supporting patients' autonomy by promoting skills that enable patients to learn how to deal with their health problems.

Each ethical and nursing theory provides a different perspective on patient autonomy, but all have implications for nurses. The diversity of theories of autonomy draws attention to the fact that there are several approaches nurses can use to facilitate patient autonomy. These theories could be compared from a theoretical perspective, which might lead to theoretical integration. However, we 
adopt another approach by investigating empirical studies on autonomy, and looking for a way to integrate theory into practice.

\subsubsection{The patient's view of autonomy}

\subsubsection{Home care}

Pool [23] conducted in-depth interviews with 30 chronically ill, elderly people, who received nursing care at home, and 30 community-based nurses in the Netherlands. The aim of the study was to shed light on (a) life with a chronic disease and, as a consequence, care dependence, and (b) the relationship between nurses and chronically ill clients, concentrating on issues of autonomy. The dominant strategy for remaining autonomous, despite the burden of a chronic illness, was 'adjusting one's lifestyle'. Chronically ill people balanced: 'what do I have to give up and what can I keep.' To keep their identity, they reconstructed their personal and social identities to rehabilitate themselves and regain a personal lifestyle of their own. The nurse-patient relationship was defined as the core element in patient autonomy. It consisted of four phases: orientation, identification, consolidation and co-ordination. In the orientation phase, nurses and patients acted with a view to their own goals, accepting each other's boundaries and creating a situation where negotiation could take place. In the identification phase, nurses and patients together identified nursing care goals and, in the consolidation phase, found the most productive ways to interact with one another. In the coordination phase, both parties compared their goals, and mutual goal-setting occurred. Two concepts of autonomy were dominant: 'care' and 'having one's say'. Care implied that nurses and patients were attached to each other and offered opportunities for realizing autonomy in partnership with others. Having one's say meant that chronically ill patients were able to control certain elements of their lives while nurses supported them by providing alternative views about how they might handle situations. The nurse-patient-relationship was successful if both parties adhered to one approach. Pool concludes that nurses' ideas about autonomy and provision of care played an important role in the realization of patient autonomy. This study puts nurse-patient interaction at the core. Respect for, and the rehabilitation of, autonomy are considered as the aim of home care nursing, indicating that autonomy is a process and not a static condition. However, the author did not investigate whether different phases in the nurse-patient relationship require different approaches in order to foster patient autonomy.

Heimerl and Berlach-Pobitzer [24] conducted in-depth interviews with 19 elderly, chronically ill people who received care at home in Vienna. The aim of this study was to find out what fears care-dependent, elderly people who live at home experienced and what factors increased their feelings of trust and safety. Loss of 
autonomy was their greatest fear. Respondents described three kinds of autonomy: (1) autonomy as the ability to do a lot of things independently, (2) autonomy through symbiosis with their spouse, and (3) autonomy as the ability to organize necessary help oneself. The first kind of autonomy implied that they were autonomous if they could live independently with little or no help from social or professional sources, even when this meant accepting hardship to function independently. The second kind of autonomy was portrayed as organizing as much informal help as possible in order to remain independent of professional care. Some participants were very care-dependent, and their spouse took a central role. In this situation, they realized their autonomy by trusting and relying on others, seeing staying at home and avoiding institutionalization as preserving their autonomy. In the third kind of autonomy, elderly people organized professional and informal help to control the circumstances of their lives. In all three kinds of autonomy, nurses were described as facilitators because their professional services supported patients in remaining as autonomous as possible in the home environment. In general, respondents wanted to be as autonomous as they had been all their lives, and the authors emphasize that autonomy should always be seen in relation to life history, the situation at hand, and social context. As the authors themselves mention, theoretical sampling did not yield complete diversity in the sample as people who did not receive home care, single men, and women who received care from their husbands were not included. The findings are, however, important for nursing practice because they show that autonomy is perceived as vital by extremely care-dependent, older people.

\subsubsection{Nursing home care}

Proot [25] carried out a longitudinal study into autonomy in stroke survivors in Dutch nursing homes. She conducted 58 in-depth-interviews with patients who were temporarily admitted to nursing homes for rehabilitation, and 27 with healthcare professionals. The aim of the study was to identify areas that need special attention regarding patient autonomy during the various phases of rehabilitation. She identified two main concepts: 'changing autonomy' and 'partial paternalism'. Changing autonomy identified the process stroke survivors went through to regain their autonomy. Proot contended that a social concept of autonomy is important to stroke survivors, since autonomy also depends on a person's environment. A social concept of autonomy includes support from healthcare professionals and informal caregivers. The process of autonomy included three dimensions, each related to the others: self-care, independence, and self-determination. Self-care included skills, such as mobility or communication, and activities of daily living necessary for functioning. Independence required planning, taking responsibility, and organizing one's own life. Self-determination indicated making choices and decisions about one's own life and health, and 
included freedom of choice. The second theme, partial paternalism, showed that stroke survivors did not strive for an 'either...or' situation where all decisions were made either by the patient or by professionals. Instead, they preferred a 'both...and' approach where some decisions were made by patients and others by professionals. Stroke survivors were willing to share decisions with others involved. They mainly wanted to decide about self-care issues, but left treatment decisions to the professionals. The author provides no information on possible differences in approach between nurses and other members of the multiprofessional team involved in rehabilitation. Nevertheless, the study provides a first glimpse of autonomy as perceived by people themselves in the nursinghome setting, and presents nuanced knowledge about a specific patient group.

\subsubsection{Hospital care}

In the UK, Biley [26] interviewed eight people recovering from surgery 7 to 10 days after discharge from hospital. The aim of the study was to explore patient participation in decision-making about nursing care in hospital, and identified three types of situations that have an effect. These were: 'If I am well enough', 'If I know enough', and 'If I can'. In the category 'If I am well enough' respondents spoke about how much participating in decision-making depended on how well they were. The continuum ranged from 'being too ill' to 'being well', with 'being too ill' seen as a reason for not being involved in decision-making. Improvement in physical condition led to an increased desire to choose, which led to the other end of the continuum - 'being well'. In the category 'If I know enough', participants spoke about the amount of information they had, needed, or requested in order to be able to make decisions. The continuum ranged from 'Nurse knows best' to 'I know best'. 'Nurse knows best' described situations where patients did not have enough information to make a decision and occurred most often when there were medical, surgical or technical issues. Patients accepted a passive role, displaying trust and confidence in the nurse. 'I know best' occurred when patients felt they knew what was right and could control what happened to them as, for example, in daily living activities. Autonomy in self-care activities was very important to them. In the category 'If I can', respondents spoke about organizational constraints or freedom that had an impact on involvement in decision making. The continuum ranged from 'it is not the nurse's fault' to 'organizational freedom'. 'It is not the nurse's fault' described the feeling that respondents had to fit into the hospital environment. 'Organizational freedom' described how patients could have some, if not most, of their individual needs met, despite organizational constraints, and centred on activities of daily living. Biley concludes that the patients were autonomous when they were well enough, had sufficient information and enjoyed organisational freedom. This study has some methodological limitations: it involved a small sample and the categories did not reach saturation. 
However, it provides an indication that patients' desire to participate in decisions about nursing care is affected by a number of factors.

Waterworth and Luker [27] conducted a qualitative study, drawing on grounded theory, using a convenience sample of 12 people from three medical wards within one hospital in the UK. Their aim was to describe from the patients' point of view how they perceived being involved in decisions concerning their own treatment and nursing care. One main theme was identified: 'toeing the line'. Patients did not seem to be eager to participate in decision-making. The key aim was to stay out of trouble, so they abided by hospital rules and exhibited what they believed to be desired patient behaviour, even though this involved relinquishing freedom. Moreover, participants trusted the nurses and had confidence that they would do their best for them. The authors contend that, because patients are willing to toe the line, if nurses adopt practices that encourage involvement, they may unwittingly coerce patients to comply, and conclude that promoting individualized care is not necessarily synonymous with active patient involvement. Although the study is limited by the fact that the authors used a convenience sample and did not provide any specific information about theoretical sampling, the study does provide some thought-provoking insights into patients' views about autonomy.

McWilliam et al. [28] carried out an interpretative study (document review, indepth interviews and observations) in rural and urban hospital settings about the discharge experience of elderly patients in Canada. Participants consisted of 21 patients, 22 informal caregivers, and 117 professionals. The aim of the study was to explore the contribution of patients' mindsets to the interactive experience of professional care and to the experience of threatened autonomy. They identified four categories of mindset and threatened autonomy along a continuum: positive mindset - successful autonomy; fairly positive mindset - slightly threatened autonomy; somewhat negative mindset - moderately threatened autonomy; and negative mindset - severely threatened autonomy. Successful autonomy was achieved when patients had a positive mindset and clarity about their goals. Despite the severity of their physical condition, these patients aspired to active control of their own care after discharge. These people described as strident independence. A positive mindset protected them against threatened autonomy, even when they were cared for in a paternalistic manner. Patients with slightly and moderately threatened autonomy accepted their life circumstances, which included some dependence upon caregivers who made it possible for them to remain at home after discharge. These patients were satisfied with their involvement in their care, although they deferred to professional authority. They believed that professionals contributed to their life goals and therefore accepted the 
paternalistic approach of these professionals. The authors concluded that increasing patient autonomy must encompass a patient-centred approach, which includes an understanding of patients' mindset, goals, aspirations, and sense of purpose within a larger life context. Nurses should, however, draw interferences from this study with caution because little specific information is provided about characteristics of the healthcare professionals. The professional sample consisted of people working in hospital and community settings, experts with an overview of the discharge system and home-care programme, and it is not clear how many clinically practising nurses were included. However, the findings suggest that patient characteristics such as positive mindset and goal-setting need to be considered.

Overall, empirical literature on patients' perceptions of autonomy is scarce and has some methodological flaws. However, empirical findings clearly suggest that autonomy is important to patients and that, with support from others, they pursue their autonomy in an individualized manner grounded in their personal convictions.

\subsection{Discussion}

Our overview of the literature reveals an extensive number of theoretical articles on patient autonomy. However, most studies addressing patients' perspectives on autonomy in nursing care are based on self-completed questionnaires, which measure autonomy in the positivistic tradition. Few attempts have been made to observe and elucidate what actually happens, or how people perceive their autonomy in the reality of practice. A few qualitative studies have sought to redress the balance and, despite methodological shortcomings, they give valuable insights in what kind of support patients actually need in order to achieve autonomy.

Ethical concepts of autonomy show clear features of either negative or positive freedom. The same applies to nursing theories although sometimes traces of both negative and positive freedom can be detected. Theorists seem to contend that negative and positive freedom form a polarity: negative freedom opposing positive freedom. We do not agree with this strict division. In interpreting the empirical studies, we applied negative and positive freedom as an analytical tool and found that patients prefer a combined approach. Without interaction and support from others, patients cannot make self-determined decisions. Theories of autonomy based on positive freedom seem to provide a necessary ethical frame- 
work for nurses to support patient autonomy. Within this framework, notions of negative freedom can and should also be addressed.

We assume that the original authors of the empirical studies we reviewed chose a certain perspective of autonomy, grounded in either negative or positive freedom, to interpret their findings. It is therefore not surprising that our analysis of the empirical literature on the basis of both negative and positive freedom leads to findings that are not always in line with the original authors' conclusions. Proot [25] mentions a social approach to the autonomy of stroke survivors temporarily admitted to nursing homes as an important element in her theory. This seems to indicate elements of positive freedom, yet we labelled changing autonomy and its dimensions as negative freedom, since we could only find features of negative freedom. Furthermore, Proot considers situations where stroke survivors make self-determined decisions, and simultaneously delegate decisions to professionals, as partial paternalism, which she sees as a threat to autonomy as selfdetermination. We, on the other hand, classified partial paternalism as positive freedom because stroke survivors favour a combined approach to realize autonomy successfully. Waterworth and Luker [27] categorize toeing the line as accepting the situation and relinquishing control, which we again see as negative freedom, because people clearly say that they want to stay out of trouble and therefore make a conscious decision not to be involved in making all kinds of decisions regarding nursing care. McWilliam et al. [28] define successful autonomy only in terms of negative freedom. We labelled their notion of slightly and moderately threatened autonomy as successful autonomy in terms of positive freedom. Dependence on caregivers was described as supporting autonomy, and deference to professional authority was not perceived as having a negative impact on autonomy, since people believed that professionals contribute to the achievement of their life goals.

Since patients prefer a combined approach of negative and positive freedom to realize autonomy, nurses should master the challenge to provide the support, which is wished and needed. Nurses cannot rely on only one specific perception of autonomy to support patient autonomy. They are faced with a complex task. Ethical codes help to guide nurses to make decisions in their work [29]. The International Council for Nurses (ICN) Code of Ethics for Nurses [30] supports both approaches of patient autonomy. On the one hand, the ICN Code of Ethics for Nurses clearly adheres to the notion of negative freedom as informed consent: 'The nurse ensures that the individual receives sufficient information on which to base consent for care and related treatment' (p.208). On the other hand, the Code of Ethics for Nurses states: 'In providing care, the nurse promotes an environment in which the human right, values, customs and spiritual belief of the individual, 
family and community are respected' (p.208) which clearly presents autonomy as positive freedom. Unfortunately, there is no clear ethical guidance regarding the kind of autonomy nurses should adhere to in specific situations and how the different concepts of autonomy are to be combined in practice.

Nursing theories should guide practice [31]. Regarding patient autonomy, this guidance is however problematic. Nursing theories are one-sided, emphasizing either negative or positive freedom. They do not help nurses to find a suitable combination of positive and negative freedom, fitting to concrete nursing situations. As long as nursing theories do not take into account the practical need of patients for a combination of negative and positive freedom, they will not be able to guide nursing practice in an adequate way.

\subsection{Conclusion}

The ethical, nursing, and empirical literature shows that patient autonomy can be realized in many different ways. A variety of factors can facilitate patient autonomy, including support from nurses. Our literature review, however, highlights that providing such support is complex because nurses cannot rely on only one exclusive model of autonomy to enhance the autonomy of their patients. In any situation, the aspects of autonomy at stake, and the kind of action called for, are open to continuous interpretation. In daily practice, nurses have to be sensitive to differences and shifts in patients' needs and wishes relating to their autonomy. Supporting autonomy successfully requires in-depth knowledge of the patient in the context of the particular situation because people actually express their autonomy when they take certain courses of actions. In daily practice, nurses need to ascertain what kind of autonomy their patients pursue; this will help them to become aware of factors that promote the autonomy of their patients, and thus enable them to provide opportunities that support autonomy. The concept of autonomy in ethical codes and nursing theories needs to be refined in order to encompass the needs of patients in practice. The practice of nurse-led, shared care remains to be investigated. 


\section{References}

1. Temmink, D., A. Francke, J.B.F. Hutten, J. Van der Zee and H. Huijer Abu-Saad, Innovations in the nursing care of the chronically ill: a literature review from an international perspective. Journal of Advanced Nursing, 2000. 31: p. 1449-1458.

2. Vrijhoef, H.J.M., C. Spreeuwenberg, I.M.J.G. Eijkelberg, B.H.R. Wolffenbuttel and G.G. Van Merode, Adoption of disease management model for diabetes in the region of Maastricht. British Medical Journal, 2001. 323: p. 983-985.

3. Spreeuwenberg, C. and P. Pop, Transmurale zorg, in Handboek tansmurale zorg., C. Spreeuwenberg, et al., Editors. 2000, Elsevier Gezondheidszorg: Maarssen. p. 17-36.

4. Raz, J., The morality of freedom. 1990, Oxford: Clarendon Press.

5. Borry, P., P. Schotsmans and K. Dierickx, Emprical ethics: a challenge to bioethics (Editorial). Medicine, Health Care and Philosophy, 2004. 7: p. 1-3.

6. Van der Scheer, L. and G.A.M. Widdershoven, Integrated empirical ethics: loss of normativity? Medicine, Health Care and Philosophy, 2004. 7(1): p. 71-79.

7. Molewijk, B., A.M. Stiggelbout, W. Otten, H.M. Dupuis and J. Kievit, Empirical data and moral theory. A plea for integrated empirical ethics. Medicine, Health Care and Philosophy, 2004. 7: p. 5569.

8. Birnbacher, D., Ethics and social science: which kind of co-operation? Ethical Theory and Moral Practice, 1999. 2: p. 319-336.

9. Dierckx de Casterle, B., M. Grypdonck, N. Cannaerts and E. Steeman, Empirical ethics in action: lessons from two empirical studies in nursing ethics. Medicine, Health Care and Philosophy, 2004. 7: p. 31-39.

10. Aveyard, H., Is there a concept of autonomy that can usefully inform nursing practice? Journal of Advanced Nursing, 2000. 32(2): p. 352-358.

11. Beauchamp, T. and J. Childress, Principles of biomedical ethics. 4th ed. 1994, Oxford: Oxford University Press.

12. Moody, H.R., Ethics in an aging society. 1992, Baltimore: The Johns Hopkins University Press.

13. Tronto, J.C., Moral boundaries: a political argument of an ethic of care. 1993, New York: Routledge.

14. Agich, G., Dependence and autonomy in old age. 2003, Cambridge: Cambridge University Press.

15. Douglas-Steele, D. and E. Hundert, Accounting for context: future directions in bioethics theory and research. Theoretical Medicine, 1996. 17: p. 101-119.

16. Berlin, I., Twee opvattingen van vrijheid. 1996, Amsterdam/Meppel: Boom.

17. Mackenzie, C. and N. Stoljar, Relational autonomy: feminist perspectives on autonomy, agency, and social self. 2000, Oxford: Oxford University Press.

18. Hagerty, B.M. and K.L. Patusky, Reconceptualizing the nurse-patient relationship. Journal of Nusing Scholarship, 2003. 35: p. 145-150.

19. Beauchamp, T.L. and J.F. Childress, Principles of biomedical ethics. 5 th ed. 2001, New York: Oxford University Press.

20. Orem, D.E., Nursing: concepts and practice. 2001, St. Louis: Mosby.

21. Peplau, H., Interpersonal relations in nursing. 1988, Hampshire and London: Macmillan Education Ltd.

22. Peplau, H., Interpersonal relations: a theoretical framework for application in nursing practice. Nursing Science Quarterly, 1991. 5(1): p. 13-18.

23. Pool, A., Autonomie, afhankelijkheid en langdurige zorgverlening. 1995, Utrecht: Lemma BV.

24. Heimerl, K. and I. Berlach-Pobitzer, Autonomie erhalten: Eine qualitative PatientInnenbefragung in der Hauskrankenpflege, in Autonomie im Alter: Studien zur Verbesserung der Lebensqualität durch professionelle Pflege, E. Seidl, M. Stankova, and I. Walter, Editors. 2000, Verlag Wilhelm Maudrich: Wien. p. 102-165.

25. Proot, I., Changing autonomy: new perspectives on the care for stroke patients in nursing homes. 2000, Maastricht: University Press Maastricht. 
26. Bailey, B. and A. Kahn, Apportioning illness management authority: how diabetes individuals evaluate and respond to spousal help. Qualitative Health Research, 1993. 3(1): p. 55-73.

27. Waterworth, S. and K.A. Luker, Reluctant collaborators: do patients want to be involved in decisions concerning care? Journal of Advanced Nursing, 1990. 15: p. 971-976.

28. McWilliam, C.L., J.B. Brown, J.L. Carmichael and J.M. Lehman, A new perspective on threatened autonomy in elderly persons: the disempowering process. Social Science and Medicine, 1994. 38(2): p. 327-338.

29. Meulenbergs, T., E. Verpeet, P. Schotsmans and C. Gastmans, Professional codes in a changing nursing context: literature review. Journal of Advanced Nursing, 2004. 46(3): p. 331-336.

30. International Council of Nurses, The ICN Code of Ethics for Nurses, in Ethics in nursing practice: $a$ guide to ethical decision making., S.T. Fry and M.-J. Johnstone, Editors. 2000, Blackwell Publishing: Oxford. p. 207-213.

31. Alligood, M.R. and A. Marriner-Tomey, Nursing theory: utilization and application. 1997, St. Louis: Mosby. 



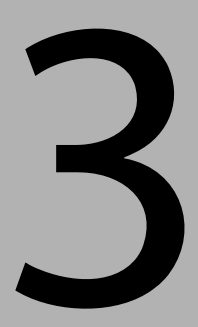

\section{Competency in shaping one's life} Autonomy of people with type 2 diabetes mellitus

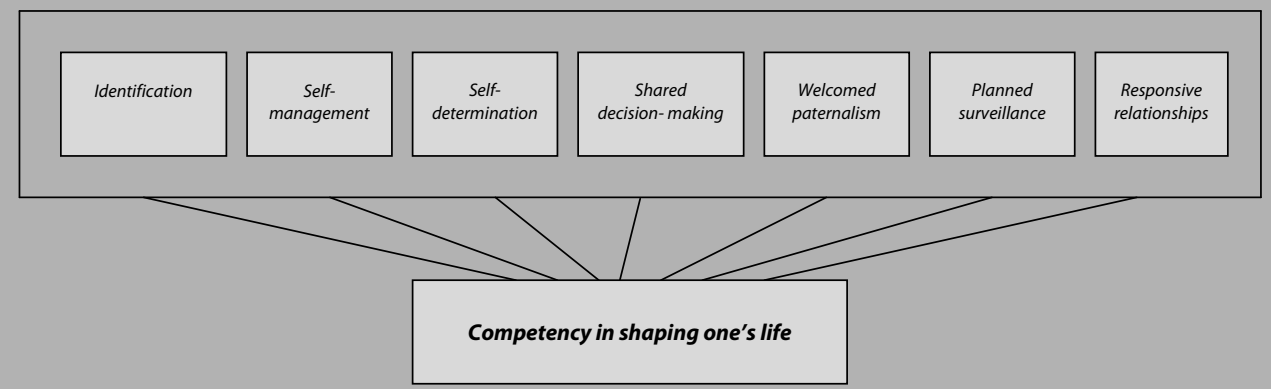




\section{Abstract}

In the Netherlands diabetes specialist nurses play an important role in specialized, long-term care for chronically ill. One of the goals of nurse-led, shared care is to encourage chronically ill people to participate actively in selecting the organisation and interventions of care. We report the findings of a study to determine which concepts of autonomy people with type 2 diabetes use in a nurse-led, shared care setting. The aim is to portray how people with type 2 diabetes mellitus view autonomy who are being cared for by diabetes specialist nurses in a nurse-led clinic. This qualitative study uses in-depth interviews and is carried out in a nurse-led, shared care unit in the Netherlands. The study population consists of 15 people who are enrolled for at least 1 year at the nurse-led, shared care unit and who live independently at home. Data are analysed with the grounded theory method. The core category, 'competency in shaping one's life', describes how people with diabetes exercise their autonomy. Seven categories that emerged are considered dimensions of autonomy. The dimensions were: identification, selfmanagement, welcomed paternalism, self-determination, shared decisionmaking, planned surveillance, and responsive relationships. Autonomy is a multidimensional, dynamic and complex construct. Further research is needed to investigate which decision-making processes patients with type 2 diabetes use in a nurse-led, shared care setting.

This Chapter is based on the publication:

Moser, A., H. Van der Bruggen, and G.A.M. Widdershoven, Competency in shaping one's life: Autonomy of people with type 2 diabetes mellitus in a nurse-led, shared-care setting; a qualitative study. International Journal of Nursing Studies, 2006. 43: p. 417-427. 


\subsection{Introduction}

Diabetes mellitus, a chronic disease that affects many aspects of daily life, compels people to comply with a life-long treatment regime. The management of diabetes is complicated because of the multi-systemic, chronic, and insidious nature of the illness [1]. In the Netherlands, diabetes specialist nurses (DSN) play an important role in specialized, long-term, shared care for chronically ill. These nurses are responsible for the care of patients with type 2 diabetes whose health conditions are stable but complex [2]. Within the nurse-led, shared care model, DSN work independently with their patients; they are involved in medical aspects of care and provide advanced nursing care [3]. The DSN function in both primary and tertiary care and follow the agreed guidelines and protocols in the current approach [3]. Accordingly, autonomy issues of people with type 2 diabetes differ in primary and tertiary settings. Specialist-care patients have acute and very complicated health problems that may require radical medical decisions. General practitioners provide basic care for the less complex cases of diabetes in the primary care setting, and home healthcare nurses provide the essential daily diabetes care. The result is that, the nurse-patient relationship in a nurse-led, shared care setting is characterized by a mix of specific medical care and advanced nursing practice. One of the goals of shared care is to encourage people with type 2 diabetes to participate actively in selecting the organisation and interventions of appropriate care $[4,5]$. Thus, patient autonomy is a cornerstone upon which shared care is built.

\subsection{Literature review}

Various concepts of autonomy can be found in the literature: the paternalistic model [6], self-governance [7], authenticity [8], relational autonomy [9, 10], communicative ethics [11], autonomy as critical reflection [12], actual autonomy [13], shared decision-making [14, 15], autonomy as self-creation [16] and in relation to nursing, self-care and dependent care [17]. Several empirical studies of patient autonomy in non-institutional long-term care have been carried out. Stüssgen [18] interviewed patients with type 1 diabetes and patients with chronic lung diseases in specialist care about autonomy. He identified three kinds of autonomy: self-direction, obedience, and balance between self-direction and obedience. Pool [19] interviewed nurses and chronically ill patients in home care about autonomy. Pool found that autonomy can best be viewed as a process, since illness and physical limitations influence autonomous functioning. The nursepatient interaction is built on two perspectives: 'care' and 'having a say'. Heimerl and Berlach-Pobitzer [20] studied the autonomy of elderly people who lived at 
home and were dependent on formal nursing services. The patients described three kinds of autonomy: autonomy as independence, autonomy as organizing help by oneself, and autonomy as symbiosis with family members.

Theoretical and empirical literature shows that various concepts of autonomy exist and that autonomy in long-term care is difficult to understand. Theoretical literature deals with the kind of autonomy that is usually related to institutional care $[8,11,13]$. Empirical literature deals with specialist care [18] and home healthcare $[19,20]$. A critical question is whether these concepts suit the situation of chronically ill patients in a nurse-led, shared care setting. The reason for doing empirical research on ethical concepts is the assumption that it can identify the ethical issues that actually arise in practice, find out how these are currently resolved, and assesses the consequences of these current solutions [21]. Furthermore, empirical research can identify certain unappreciated ethical issues, focuses attention on theoretical points which, on the basis of empirical data, can lead to problematic consequences, undermines certain theoretical justifications, and evaluates professionals' ability to apply their ethical principles [22]. Additionally, empirical data can support theoretical claims. Most importantly, we seek specific, context-related approaches that are meaningful to nursing practice. The initial focus of interest was the autonomy of chronically ill people in non-institutional long-term care. Patients with type 2 diabetes are good examples for studying autonomy because of the high prevalence, complexity (co-morbidity and secondary long-term complications), large care demand, and amount of responsibility that is placed on the patient. We seek to answer the following research question: which concept(s) of autonomy do patients with type 2 diabetes use in a nurse-led, shared care setting?

We report on a study of people with type 2 diabetes who are being cared for by DSN in a shared care unit. This study is part of a research project concerning the autonomy of type 2 diabetes patients in shared care where the primary care provider is a DSN. The purpose is to portray how people with type 2 diabetes view autonomy in a nurse-led, shared care setting. We give an outline of the dimensions of autonomy that type 2 diabetes patients identified. 


\subsection{Method}

To answer the research question, we designed a research project in which we approached type 2 diabetes patients. We interviewed the participants in-depth to explore their perspectives and experiences regarding autonomy. We chose a grounded theory approach because little is known about autonomy in a nurseled, shared care setting. Grounded theory is an inductive, from-the-ground approach that uses everyday behaviours or organisational patterns to generate a theory about a particular phenomenon [23].

\subsubsection{Setting and sample}

The study was carried out with type 2 diabetes patients who were enrolled at the Maastricht Shared Care Treatment and Care Unit VII Shared Care (MSCTCU VII) at University Hospital Maastricht. The study population consisted of 15 people diagnosed with type 2 diabetes. All respondents were Dutch and lived in or around the city of Maastricht in the province of Limburg in the Netherlands. Patients with a confirmed diagnosis of type 2 diabetes, diagnosed at least 1 year before the study began, with a stable but complex health condition were included. Furthermore, patients who lived independently at home, who had been enrolled for at least 1 year at the MSCTCU VII, and who were able to complete an interview of about 1.5 hours were included too. Type 2 diabetes patients with cognitive impairment and severe geriatric symptoms (diagnosed by a physician), newly diagnosed patients, and those for whom the interview was too heavy a burden were excluded. Elderly type 1 diabetic patients and type 2 diabetic patients who lived in assisted-housing arrangements were also excluded. The researcher, in cooperation with key people (DSN and the project manager) from the MSCTCU VII, selected the participants with the aid of theoretical sampling [23].

\subsubsection{Approaching the participants}

The DSN sent people with type 2 diabetes a letter to ask if they might be approached. The letter included information about the research and asked consent for forwarding personal data to the researcher. After sending this letter, the DSN contacted the patients again to assure that personal data could be given to the researcher. Then, the researcher approached these people to see if they were willing to participate and to make interview appointments. All those contacted by the researcher agreed to participate. 
Table 1.1 Demographic, socio-economic, and clinical characteristics

\begin{tabular}{|c|c|}
\hline Characteristics & $\mathrm{N}=15$ Average \\
\hline Female & 6 \\
\hline Male & 9 \\
\hline Age $55-69$ years & 8 \\
\hline Female & 3 \\
\hline Male & 5 \\
\hline Age 70 years plus & 7 \\
\hline Female & 3 \\
\hline Male & 4 \\
\hline Age sample & 65.4 years \\
\hline Age group 55-69 years & 58.3 years \\
\hline Age group 70 years plus & 72.8 years \\
\hline \multicolumn{2}{|l|}{ Civil state } \\
\hline Unmarried & 0 \\
\hline Married & 13 \\
\hline Registered partnership & 1 \\
\hline Divorced & 1 \\
\hline Widowed & 0 \\
\hline \multicolumn{2}{|l|}{ Educational level } \\
\hline Lower or lower vocational & 0 \\
\hline General secondary or intermediate vocational & 11 \\
\hline University or higher vocational & 4 \\
\hline \multicolumn{2}{|l|}{ Income per month } \\
\hline No income & 1 \\
\hline Less than 649 Euros & 3 \\
\hline Between 650 and 1299 Euros & 4 \\
\hline More than 1300 Euros & 7 \\
\hline Insulin-dependent type 2 diabetes & 8 \\
\hline Non-insulin-dependent type 2 diabetes & 7 \\
\hline Duration of illness & 6.1 years \\
\hline Duration of treatment (by DSN) & 2.4 years \\
\hline Number of visits & 8.7 \\
\hline
\end{tabular}




\subsubsection{Ethical considerations}

The participants gave written informed consent prior to the interviews. The respondents were assured that interview data would be dealt with confidentially. Anonymity was secured by code-numbering the interviews. The ethics commission of University Hospital Maastricht and the University of Maastricht gave ethical approval.

\subsubsection{Data collection}

Fifteen in-depth interviews took place from March to September 2003. All participants were interviewed at home so that the environment was comfortable and familiar to them. We intended to conduct the interviews in the absence of family caregivers, but six participants insisted that a family member be present. In these cases, family members were asked to support the participant only when support was needed.

\subsubsection{Interview guide and procedure}

The interview guide consisted of open-ended questions that the research team themselves developed because of the lack of relevant literature. Members of the project group and selected experts (ethicists, DSN, and researchers) reviewed the interview guide. We pre-tested the guide by interviewing three participants (pilot interviews) and adjusted the guide accordingly. We also obtained a socioeconomic and demographic profile. The interview questions were directed towards aspects of autonomy related to daily life in its broadest sense. These aspects were:

1. Disease and treatment history (How long have you been suffering from diabetes? What medication do you take?)

2. Self-care (What self-care activities do you carry out? What do you do when you have health problems related to diabetes?)

3. The visits to the nurse (Can you describe an appointment with the nurse? Has there been a change in the treatment plan? If so, can you describe that conversation?)

4. The nurse-patient relationship (What things should the nurse do that are is important to you in the nurse-patient relationship? How would you describe your relationship with the nurse?)

5. The family-patient interaction (How deeply involved is your spouse/child in diabetes care? What is your spouse's/child's role in diabetes care?)

6. The impact of type 2 diabetes on one's life (What has changed since you were diagnosed with diabetes? How did this happen?)

7. Autonomy (What does autonomy mean to you? What makes you feel autonomous?). 
During the pilot interviews, we realized that some participants had trouble answering direct questions about autonomy. We sensed that these questions might make respondents feel that they 'looked stupid' to the interviewer. This issue provoked some ethical discussion in the research team. We agreed on the following process: first, direct questions about autonomy were placed at the end of the interview guide. Second, direct questions about autonomy were not pursued if participants had difficulty answering the first of six questions. This was the case in five interviews. Third, we raised issues of autonomy indirectly throughout the interviews by asking for the respondent's actual experiences and thoughts. Participants were encouraged to support their statements with examples that mirrored daily practice. Additionally, the researcher asked follow-up questions to gain more insight. Finally, since grounded theory starts with individual experience, we did not predefine autonomy. The interviews were tape-recorded and transcribed verbatim. Field notes were taken during and after each interview. The first researcher, who is a trained interviewer, conducted all interviews.

\subsubsection{Data analysis}

According to Strauss and Corbin [23], theories and concepts are discovered, developed, and provisionally verified through systematic data collection and analysis of data pertaining to the phenomenon in question. In this approach, theory arises inductively from the interview data and deductively through constant comparison. The interview data and field notes were coded. Codes were grouped, compared, and categorized into concepts. Descriptive coding was used to examine the phenomenon under study. Theoretical coding was employed to develop a theory that clarifies the relationships among concepts. After analysis of 12 interviews, conceptual saturation occurred. The remaining 3 interviews were used to confirm the analyses and concept definitions.

\subsubsection{Trustworthiness}

To prove trustworthiness, four main criteria must be met: credibility, transferability, dependability, and confirmability [24]. Credibility is concerned with the aspect of truth value [24]. To establish credibility, the strategies of prolonged engagement, triangulation, and persistent observation are applied. Prolonged engagement is the investment of sufficient time to learn the culture, to test for misinformation, to build trust, and to learn the data. Several distinctive questions were asked regarding topics related to autonomy. Furthermore, the participants were encouraged to support their statements with examples, and the interviewer asked follow-up questions. Finally, the researcher studied the data from raw interview material until the theory emerged to provide the scope of the phenomenon under study. Triangulation is the use of evidence from different methods, investigators, sources, or theories [25]. To ensure methodological triangulation data were gathered by means of in-depth interviews and field notes. Investigator 
triangulation was assured by involving several investigators as members of the research team. Data triangulation in this study was secured by the various data sets that emerged throughout the analysis process: raw interview material, codes, concepts, and conceptual saturation. Persistent observation means identifying those characteristics and elements that are most relevant to the problem or issue under study and focussing on them in detail. Developing the codes, concepts, and the core category helped us examine the characteristics of the data. We constantly read the data, analysed them, theorized with them, and revised the concepts accordingly. We recoded and relabelled codes, concepts, and the core category. We studied the data until the final theory provided depth.

Transferability concerns the aspect of applicability [24]. Transferability can be proven by thick description. Descriptive data (setting, sample, sample size, sample strategy, inclusion and exclusion criteria, interview procedure, and topics and excerpts of the interview guide) are provided to enable readers to make a transferability judgment.

Dependability includes the aspect of consistency [24]. To prove dependability, one checks whether the analysis process is in line with accepted standards. An academic auditor ( $\mathrm{H}$ vd $\mathrm{B}$ ) examined the analysis process and records for accuracy and dependability.

Confirmability concerns the aspect of neutrality [24]. To prove confirmability, one must secure inter-subjective characteristics of the data and not the characteristics of the enquirer. An academic auditor $(\mathrm{H}$ vd $\mathrm{B})$ reviewed the findings to see if they followed from the data (raw data, analysis notes, code notes, process notes, and report).

\subsection{Findings}

Analyses and coding of the interviews resulted in a core category and seven other categories. The seven categories are considered dimensions of autonomy. The dimensions are identification, self-management, welcomed paternalism, selfdetermination, shared decision-making, planned surveillance, and responsive relationship. The core category 'competency in shaping one's life' describes how people with type 2 diabetes exercise their autonomy. 


\subsubsection{Dimensions of autonomy}

\subsubsection{Identification}

Identification stresses that people with type 2 diabetes identify with their illness. They are aware of the impact of changes in lifestyle on their lives and health. These people work actively towards modifying their behaviour and adapting the limitations imposed on them by the illness. Thus, they are involved in a lively process of development so that the illness fits into their lives. When they succeed, they experience their lives as normal again. However, changes in the treatment plan or health condition may disrupt their lives. People with type 2 diabetes sometimes have to identify with a new treatment and a new health situation. Identification is a never-ending process because they have to deal with changing conditions.

I have been suffering from diabetes for many years. First I took oral medication once a day, then I had to take more and more pills. Now I inject insulin. It took me quite some time to get accustomed to the injections. I really disliked it at first. Twice a day I take my pills and I inject insulin... If there is something new, for example injecting insulin instead of taking pills, I need to get used to it. I have to change my daily routine. I had to do a lot of glucose self-monitoring in the beginning. After some time, my glucose profiles were fine. I make a glucose day-profile every 2 weeks. I always do it on Wednesday. I write it down in my calendar in the kitchen. Otherwise l'd forget to do it. Taking pills, injecting insulin, and glucose self-monitoring are part of my life.'

\subsubsection{Self-management}

This dimension encompasses activities pertaining to taking care of one's health. Self-management includes skills for activities in daily living and the instrumental activities of daily living necessary for the treatment regime. Activities in daily living are related to basic care activities such as taking one's medication or regular foot care. Examples of instrumental activities of daily living are preparing diet meals and gathering and reading information on diabetes. Self-management also refers to decisions about care issues such as communication and knowledge. Skills for care activities and deciding on care issues are intertwined. The dimension self-management is composed of three sub-dimensions: preventive selfmanagement, daily self-management, and off-course self-management.

\subsection{Preventive self-management}

Preventive self-management means that people with type 2 diabetes carry out activities to prevent certain health problems. Diabetes-related health problems 
encompass short-term problems like unanticipated hypoglycaemia and secondary long-term problems like blindness.

'When I go somewhere, like to my daughters', I take care that I have all my diabetes equipment in my bag. This is important because I do not want to go anywhere without my diabetes things, especially if I want to stay away for some time. This is very important to me. I cannot go somewhere and forget about my diabetes. I'm always careful because I do not want to have problems.'

\subsection{Daily self-management}

This sub-dimension is related to daily diabetes care activities such as administrating insulin or exercising and resting. Managing daily diabetes care activities not only includes skills and the execution of care activities that belong to the treatment regime but also activities to stay healthy in general.

'I do everything myself. I inject insulin, I cook, I regularly do my home blood-glucose self-monitoring, and I bike. I also do voluntary work to stay fit.'

\subsection{Off-course self-management}

Off-course events are certain health problems caused by diabetes that occur repeatedly, for example, unanticipated blood sugar levels. Then people with type 2 diabetes take action to fight such health problems.

'My body tells me if something is wrong with my glucose level. And then I take action, I take extra fast-acting carbohydrates or I inject some extra insulin... If I have a hypo' (hypoglycaemia) during the night, I wake up and I measure the glucose level and then, depending on what it is, I take some fast-acting glucose or I inject some short-acting insulin.'

\subsubsection{Welcomed paternalism}

Welcomed paternalism means that people with type 2 diabetes comply with what others tell them to do. This does not mean that people are dominated by others. On the contrary, they are aware that others are in the lead or want others to decide for them in some cases. Welcomed paternalism occurs in the nursepatient relationship as well as in the family caregiver-patient relationship. Within the nurse-patient relationship, the nurse provides treatment information, and the patient accepts the proposed treatment, agrees to the treatment option favoured by the nurse, or delegates the decision to the nurse. Within the family caregiver- 
patient relationship, the family caregivers keep an eye on the health behaviour of the patient. Family caregivers also remind the patient of diabetes-care activities.

Nurse-patient encounter. 'If the nurse tells me do it this way or that way or you have to start with insulin or... Yes, then I will ask: what would you do? Yes, I would do this or I would do that. Yes, then I do as she says.'

Family caregiver-patient relationship. 'My wife reminds me to inject insulin and to monitor my blood glucose. I know how to do all these things. That is not the problem. I do not stick to the treatment plan. She says, "Dinner's ready, and now its time for your insulin injection." She is my commander; otherwise I would end up worse off.'

\subsubsection{Self-determination}

Self-determination stresses making decisions and choosing one's own treatment, health, and behaviour. Within the nurse-patient relationship, people with diabetes receive information from the nurse about treatment choices. The appropriate information enables the patient to compare and select treatment options. The patient makes the decisions him/herself. Regarding self-determination in relation to self-care, people decide self-care issues independently and consciously. People with diabetes compare advantages and disadvantages of certain self-care decisions and behaviour. A prerequisite is that they have a lot of knowledge about diabetes, its treatment, and the resulting consequences.

Nurse-patient encounter. 'I tell the nurse about my problems and she explains certain options. She does not force me to do things. I decide what I want to do. The freedom to choose and to decide is very important to me.'

Family caregiver-patient relationship. 'I decide by myself whether I will comply or not. That's my responsibility. If I eat a piece of cake, then I know that my blood glucose will go up. Then I have a choice: doing it or not doing it.'

\subsubsection{Shared decision-making}

Shared decision-making implies deciding together with others about care and treatment issues. The parties involved share information about personal values and preferences with one another. They take steps to participate in the decisionmaking. All participants involved agree on the decision made. Shared decision- 
making occurs in the nurse-patient relationship as well as in the family caregiverpatient relationship.

Nurse-patient encounter. 'She' (the nurse) 'told me to come in for follow-ups every 6 months. But I want to go every 3 months. Then I am sure that things are okay. Last follow-up, I had to go for a blood analysis and things were okay. I don't need to have it' (blood analysis) 'at the next follow-up. So we will check the blood parameters twice a year and I'll see her four times a year.'

Family caregiver-patient relationship. 'I was told' (by the nurse) 'that my husband was not allowed to help me at all. I talked to my husband. You can ask: what is more important that it works out well or that I forget to inject insulin? We, my husband and I, came to an agreement. Now it's like this: the soup is ready, so now you have to inject insulin.'

\subsubsection{Planned surveillance}

Planned surveillance is the result of the fact that people with type 2 diabetes want to be watched over by DSN. Therefore, they stick to a regular follow-up plan. They assume that planned surveillance offers a degree of control over diabetes. It is also used to prevent or detect secondary long-term complications at an early stage. It means nurses continuously monitoring blood indicators, physical status factors like blood circulation and neurological condition, health behaviour, and adjunct procedures. Surveillance data underlie the actions to be taken - conformity, modifications, and changes of the treatment regime - and they show whether these actions are effective.

'I expect the nurse to keep an eye on me. So that she regularly checks whether additional things are needed or if I have to go see the ophthalmologist or another professional.'

\subsubsection{Responsive relationships}

Responsive relationships develop through social interactions and include reacting to each other's thoughts, feelings, concerns, and habits. Certain behavioural rituals or patterns emerge from these interactions. Insights that flow freely between people with type 2 diabetes and their nurses as well as their family caregivers help guide decisions to outcomes that suit the relationships best. The main point of this concept is that responsibilities towards each other are set.

Nurse-patient encounter. 'When I first saw the nurse, she checked my blood pressure, my abdomen for blue spots, my feet, and this and that. 
My blood pressure was 200 over 100 the first time. The next time I went there, I said, "Everything is okay, don't check on this and that; just check my blood pressure." Then we made a joke of it. And now, every time I go there, she laughs and says, "Oh yes, first the blood pressure.'

Family caregiver-patient relationship. 'My wife is like a mother to me. She went through the same experience of this illness with her mother and now her brother too. She thinks that it shouldn't happen to me. She will end up with a husband who cannot see or walk anymore. Now we do everything together, the whole diabetes thing.'

\subsubsection{The core category - competency in shaping one's life}

The meaning ascribed to autonomy for people with diabetes is 'competency in shaping one's life'. Competency is the individual repertoire of skills that includes recognizing the possibilities and having the abilities, capacities, and expertise that allow people with diabetes to shape their own lives. To shape one's life with diabetes means that a person with diabetes actively strives towards an autonomy that is exactly right for only this particular person; it is based on characteristics that are unique to this person, and it is flexible in changing health conditions and life situations.

Competency implies that people with diabetes initiate and complete various actions daily. From an analytical perspective, these courses of actions are conceptualised as dimensions of autonomy. Each of the seven dimensions outlines differently how people with diabetes realize autonomy. Identification stresses that people with diabetes recognize themselves in new life circumstances. Selfmanagement means that people initiate and complete the necessary diabetes self-care activities. Welcomed paternalism emphasizes the fact that people assent to the opinions of others who determine what is best. Self-determination means that people with diabetes control their own decision-making without coercion from others. Shared decision-making highlights the fact that people share control of their decision-making with others, thus participating in an equal partnership. Planned surveillance allows people with diabetes to exert control by deliberately using the supervision of health professionals. Responsive relationship underlines the fact that people with diabetes achieve interdependence and reciprocity in social networks.

People with diabetes shape their own individual lives by actively taking various courses of actions. From an analytical viewpoint, shaping one's life is a construct of joining various dimensions of autonomy. The synthesis of diverse dimensions of autonomy arises in various ways, depending on health conditions, treatment, 
social context, familial patterns, knowledge, experience and skills, type of relationship, life history, and personal approach. Thus, the combination of the dimensions of autonomy is not fixed, but rather a mix of what seems most appropriate at a given time.

\subsection{Discussion}

This study investigated how people with type 2 diabetes who are being treated in a nurse-led, shared care setting describe autonomy.

\subsubsection{Dimensions of autonomy}

Seven dimensions of autonomy have been discovered. Identification suits Agich's [13] concept of actual autonomy. He defines autonomy as concrete human actions in a social world. A person's actions display a developed pattern. A person identifies with an action, not by thinking about it, but by doing it. A person is never fully formed and an autonomous person develops in an integrative process of accommodating him/herself to new circumstances and adapting the circumstances to his/her unique structure of meaning. In this study, identification is portrayed as a developmental process in which people have to familiarize themselves with changing health conditions or treatment plans.

Self-management as described in this study includes both skills for diabetes care activities and for deciding about diabetes care issues. Self-management is congruous with the dimension of self-care as described by Proot [26] and Orem's [17] concept of self-care. Orem defines self-care as 'the practice of activities that maturing and mature persons initiate and perform, within time frames, on their own behalf in the interest of maintaining life, healthful functioning, continuing personal development, and well-being, through meeting known requisites for functional and developmental regulations.'

Welcomed paternalism within the nurse-patient context fits the paternalistic model [6] and the dimension of obedience [18]. Both state that patients orient themselves toward the medical norms and rules of the professional. The professional decides on the treatment. We could not trace welcomed paternalism within the family caregiver-patient context in theoretical literature. Proot [26] reports that the paternalism that stroke patients describe as over-protectiveness within the family caregiver-patient context is experienced as constraining autonomy. On the contrary, our findings suggest that people with diabetes rarely perceive problems with paternalistic family caregivers. 
Self-determination related to the nurse-patient context agrees with the concepts of self-governance [7], 'having a say' [19], self-determination [26], and selfdirection [18]. Beauchamp and Childress [7] describe autonomy as personal rule of the self that is free of controlling interference and personal limitations. These patients orient themselves toward their own ideas, experiences, and wishes. They have great confidence in their own capacities to make judgments and the right decisions [18]. Self-determination related to the family-patient context is congruous with autonomy as independence [20]. Autonomy as independence is seen as doing everything oneself, independently of the social network. This concept emphasizes the control of personal circumstances without interference from family caregivers or significant others.

Shared decision-making within the nurse-patient relationship matches with the model of shared decision-making $[14,15]$ and the model of balance between selfdirection and obedience [18]. Balancing patients value not only their own experiences and wishes, but also the medical norms and rules of the professional. This leads to an open and critical view of medical advice and rules. These patients follow rules, but not without critical reflection and evaluation of their own wishes [18]. The outcome is a decision based on a deliberation process [14, 15]. We were unable to find mention of shared decision-making in the family caregiver-patient relationship in theoretical or empirical literature.

Planned surveillance partially fits the concept of actual autonomy [13]. Agich notes that a person is still considered autonomous if he/she can truly identify him/herself with people and things on which he/she is dependent. Planned surveillance implies that people with type 2 diabetes depend on a rigorous followup programme. Agich also claims that a person identifies with actions, not by thinking about them, but by doing them. In contrast, people with diabetes purposefully decide to make use of DSN surveillance. Interestingly, people with diabetes expect that planned surveillance offers a certain degree of control over diabetes. This particular dimension of autonomy has not yet been described in either theoretical or empirical literature.

The responsive relationship within the nurse-patient context is congruous with 'care' [19]. A responsive family caregiver-patient relationship is comparable to autonomy as a symbiosis of family members [20]. Tronto's [9] theory of relational autonomy encompasses a broad concept of care that suits the nurse-patient context as well as the family caregiver-patient context. Relational autonomy emphasizes that human beings act autonomously within the social context [9, 10]. These feminist approaches acknowledge that decisions are made in social relationships. Thus, autonomy is seen as an idea of moral competency, which in 
turn is re-conceptualized in relationships [10]. A good care relationship is a relationship in which responsibilities and commitment to each party are set [10]. The responsive relationship in the present study is defined as interpersonal responsibility and mutual understanding that develops as the relationship unfolds.

\subsubsection{Autonomy and competency in shaping one's life}

Husted's [16] concept of self-creation shows some overlap with competency in shaping one's life. Self-creation is a process, and people become what they are by successive choices and actions. Autonomous decisions are decisions and actions that fit into an autonomous life, thus, a life chosen freely. On the one hand, this notion of autonomy fits competency in shaping one's live because someone with diabetes realizes autonomy in a way that suits only him/herself. People with diabetes may take several courses of action simultaneously, which, from a theoretical stance, are apparently contradictory, but this doesn't bother them. In the view of this, Husted stresses that people create valuable options that suit the individual unique situation and that people take responsibility for following certain paths rather than others. On the other hand, Husted provides a general definition of autonomy, but does not consider contextual features. In contrast, competency in shaping one's life accentuates the fact that the autonomy of people with diabetes is context related.

Agich's [13] concept of actual autonomy also comes close to competency in shaping one's life. He states that autonomous people are situated in concrete social contexts so that choice is always contextual. In this sense, autonomy is socially determined. His interpretation of autonomy underscores the fact that the social environment is important to the fulfillment of autonomy. Competency in shaping one's life encompasses numerous dimensions. Some dimensions contradict Agich's concept; for instance, self-determination, where people decide by themselves without intrusion from others. Nonetheless, there are dimensions (for example, shared decision-making) that highlight the importance of the social environment in achieving autonomy. For this reason, DSN and family members support the autonomy of people with diabetes.

The findings indicate that DSN and family caregivers are important in achieving autonomy. Theorists like Moody [11] and Tronto [9] and researchers like Heimerl and Berlach-Pobitzer [20] acknowledge that the formal and informal social context is vital to autonomy. However, much theoretical literature (e.g. [6, 7]), as well as empirical literature (e.g. $[18,19])$ focuses primarily on autonomy within the clinician-patient relationship. The reason may be that ethicists and researchers concentrate mainly on family relations when dealing with incompetent patients and that patient autonomy within the family caregiver-patient relationship has 
received little research attention. This study was not limited to the providerpatient interaction, but focussed on autonomy in its broadest sense.

Life with diabetes encompasses far more than medical issues. It incorporates a complex mix of elements. This research shows that the autonomy of people with type 2 diabetes grows out of the nurse-patient and family caregiver-patient relationships, all aspects of a life with and in spite of diabetes, and facets of chronic care. The mix of these elements implies that life with diabetes is complicated and multi-layered; autonomy is therefore complex and dynamic. Competency in shaping one's life recognizes that there can be a variety of combinations of dimensions of autonomy that will not always be the same. Autonomy entails the necessity of dealing with every single element in the way that is required. In view of this, competency in shaping one's life covers a multidimensional conceptualization of autonomy. Competency in shaping one's life takes into account that several dimensions of autonomy arise simultaneously and that these dimensions are not mutually exclusive. In her research regarding the autonomy of stroke patients in rehabilitation wards, Proot (2001) describes three dimensions of autonomy. Interestingly, she mentions that these dimensions are related, but claims that they occur sequentially and not simultaneously. Heimerl and Berlach-Pobitzer [20], Pool [19], and Stüssgen [18] report several dimensions of autonomy that chronically ill people describe, but they label them as mutually exclusive. In contrast to the views of these authors, competency in shaping one's life is a multidimensional conceptualization of autonomy in which different dimensions are equally relevant at the same time.

\subsection{Limitations}

One limitation of this study is the fact that the formal interviews took place only within a certain geographical area. We tried to compensate for this with theoretical sampling. Diversity in sampling ensured extensive data that covered a variety of behaviour in different situations. Another limitation is the fact that nurses who work at the nurse-led, shared care unit selected the participants. At the time of the study, all the participants were being treated by DSNs. We could not interview patients who were enrolled at the nurse-led, shared care unit, but who did not comply with the follow-up regime. The results might not be applicable to socalled non-compliers, because these people might associate non-compliance with a need for freedom or see it as a way of asserting independence. Thus, the results are comparable to those chronically ill persons who participate in a regular programme, for example, patients who receive diabetes care from DSN, health visitors, or nurse practitioners who work in home care, continuing care, day care 
centres, outpatient clinics, and at the general practitioner's. Because of the diversity of settings and difference in health condition, the various dimensions of autonomy will receive different emphasis, relevance, and importance. It could be that it was easier to get consent from patients who were satisfied with the care they receive. It is also possible that there was a selection bias because an interview requires certain physical, emotional, and cognitive strengths. People with severe diabetes-related health problems were not interviewed. A further limitation is that this study was restricted to interviews. No observations were made to verify whether the participants' comments were applicable in general. We tried to compensate for this by asking participants further questions or by asking for examples to illustrate a statement. Finally, we intended to do a grounded theory analysis. Unfortunately, this was not possible. For logistical reasons, the analyses started after the interviews were completed. However, using the grounded theory approach was essential to developing the core category. For this reason, a modified grounded-theory approach was employed.

\subsection{Implications for practice}

Autonomy as competency in shaping one's life means that people exercise their autonomy in a way that is exactly right for them; autonomy varies from person to person. Some might want to control every detail of their lives, while others confidently carry out self-care activities and have fewer difficulties handing over some decisions to others. The DSNs should be aware that the patient's exercise of autonomy is very personal. They need to understand the patient's perception of autonomy, and they should tailor their approach to autonomy to the needs and beliefs of each individual patient.

Autonomy is not an attribute, but a skill. Autonomy is not an all-or-nothing phenomenon. Everybody is potentially autonomous. Not everybody possesses the same degree of autonomy. Some have all the necessary skills, while others do not. The goal of DSNs should be to facilitate and mobilize these skills; they thereby foster the autonomy of their patients.

The social environment in which people with diabetes live is important to the realization of autonomy. Diabetes is an intrusive illness and this means that the illness itself can become a family affair. Some treatment options may have a serious impact on the patient's family. For some patients, the interests of their families are also their interests. However, not all patients feel this way. The DSN should pay attention to the social background when treating people with diabetes. They 
should facilitate the involvement of family caregivers in healthcare and healthcare decisions when it is appropriate.

Other contextual factors, such as the nature of a health problem, treatment, social environment, familial patterns, experience and skills, life history, type of nursepatient relationship, and personal characteristics of people with diabetes, have an influence how people realize autonomy. Autonomy is rooted in and shaped by the context, thus it is interwoven and complex. The DSN should be alert about and attentive to contextual features. Their concerns should not centre on which approach of autonomy is ideal, but on the approach that best suits the patients' circumstances.

Every DSN has a certain understanding of and mindset about what constitutes patient autonomy. The view of informed consent is the main approach to autonomy in bioethics. Autonomy is far more than freedom of choice or independence. The nurse's vision of autonomy might conflict with the patient's perception of autonomy. What is needed is a compromise or some other means (sometimes temporary) to taking differing notions into account rather than preferring one to the other.

\subsection{Conclusion}

Autonomy for a person with diabetes is competency in shaping his/her life. Competency is the repertoire of individual skills that includes recognizing the possibilities and having the abilities, capacities, and expertise that allow people with diabetes to shape their own lives. To shape one's life with diabetes means that a person with diabetes actively strives towards an autonomy that is exactly right for only this particular person. Autonomy is based on characteristics that are unique to this person, and it is flexible with regard to changing health conditions and life situations. Competency in shaping one's life implies a construct of individual autonomy that joins various dimensions of autonomy; it is a multidimensional and dynamic construct. Each dimension outlines differently how people with diabetes achieve autonomy. The complexity that arises is revealed. The DSN can foster patient autonomy by tailoring their approach to autonomy to each patient individually, acknowledging that autonomy is a skill, and paying attention to the context. The dimensions of autonomy are related to distinctive decision-making processes. Further research is needed to investigate which decision-making processes people with type 2 diabetes use in a nurse-led, shared care setting. 


\section{Acknowledgements}

We express our thanks to Prof. Cor Spreeuwenberg, Maastricht University, and Dr. Frank Verheggen, University Hospital Maastricht, for their helpful comments on an earlier draft of this article. 


\section{References}

1. Van den Arend, I.M., G.E.H.M. Rutten, G.J.P. Schrijvers and R.P. Stolk, Experts' opinions on the profile of optimal care for patients with diabetes mellitus type 2 in The Netherlands. The Netherlands Journal of Medicine, 2001. 58: p. 225-231.

2. Maastrichtse transmurale diabetesorganisatie, Protocol: het MATADOR project. 1999, Maastricht: University Hospital Maastricht.

3. Frederix, M., Gespecialiseerde verpleegkundigen nemen taken van specialist over. Tijdschrift voor Verpleegkundigen, 1998. 108(13): p. 416-419.

4. Spreeuwenberg, C. and P. Pop, Transmurale zorg, in Handboek tansmurale zorg., C. Spreeuwenberg, et al., Editors. 2000, Elsevier Gezondheidszorg: Maarssen. p. 17-36.

5. Wolffenbuttel, B., Het Matador - project (Maastrichtse transmurale diabetesorganisatie), in Tranmurale zorgvormen van diabetes mellitus - een verkenning van de situation anno 2000., $\mathrm{H}$. Bilo and $\mathrm{F}$. Van Nunen, Editors. 2000, Isala Clinics: Zwolle. p. 204-219.

6. Emanuel, E.J. and L.L. Emanuel, Four models of the physician-patient relationship. Journal of the American Medical Association, 1992. 267(16): p. 2221-2226.

7. Beauchamp, T.L. and J.F. Childress, Principles of biomedical ethics. 5 th ed. 2001, New York: Oxford University Press.

8. Miller, B.L., Autonomy \& the refusal of lifesaving treatment. The Hastings Center Report, 1981. August: p. 22-28.

9. Tronto, J.C., Moral boundaries: a political argument of an ethic of care. 1993, New York: Routledge.

10. Verkerk, M., The care perspective and autonomy. Medicine, Health Care and Philosophy, 2001. 4: p. $289-294$.

11. Moody, H.R., Ethics in an aging society. 1992, Baltimore: The Johns Hopkins University Press.

12. Dworkin, G., The theory and practice of autonomy. 1988, Cambridge: Cambridge University Press.

13. Agich, G., Dependence and autonomy in old age. 2003, Cambridge: Cambridge University Press.

14. Charles, C., A. Gafni and T. Whelan, Decision-making in the physician-patient encounter: revisiting the shared treatment decision-making model. Patient Education Counseling, 1999. 49: p. 651-661.

15. Charles, C., A. Gafni and T. Whelan, Shared decision-making in the medical encounter: what does it mean? (or it takes at least two to tango). Social Science and Medicine, 1997. 44(5): p. 681-692.

16. Husted, J., Autonomy and the right not to know., in The right to know and the right not to know., R. Chadwick, M. Levitt, and D. Shickle, Editors. 1997, Aldershot: Avevury. p. 55-68.

17. Orem, D.E., Nursing: concepts and practice. 2001, St. Louis: Mosby.

18. Stüssgen, R.A.J., De nieuwe patient op weg naar autonomie. 1997, Amsterdam: Thesis Publishers.

19. Pool, A., Autonomie, afhankelijkheid en langdurige zorgverlening. 1995, Utrecht: Lemma BV.

20. Heimerl, K. and I. Berlach-Pobitzer, Autonomie erhalten: Eine qualitative PatientInnenbefragung in der Hauskrankenpflege, in Autonomie im Alter: Studien zur Verbesserung der Lebensqualität durch professionelle Pflege, E. Seidl, M. Stankova, and I. Walter, Editors. 2000, Verlag Wilhelm Maudrich: Wien. p. 102-165.

21. Brody, B., Assessing empirical research in bioethics. Theoretical Medicine and Bioethics, 1993. 14: p. 211-219.

22. Pearlman, R.A., S.H. Miles and R.M. Arnold, Contributions of empirical research to medical ethics. Theoretical Medicine and Bioethics, 1993. 14: p. 197-210.

23. Strauss, A. and J. Corbin, Basics of qualitative research: grounded theory procedures and techniques. 1990, Newbury Park: Sage.

24. Guba, E.G. and Y.S. Lincoln, Naturalistic Inquiry. 1985, Newbury Park: Sage.

25. Sim, J. and K. Sharp, A critical appraisal of the role of triangulation in nursing research. International Journal of Nursing Studies, 1998. 35: p. 23-31.

26. Proot, I., Changing autonomy: new perspectives on the care for stroke patients in nursing homes. 2000, Maastricht: University Press Maastricht. 


\section{Identification}

Comprehending

Struggling

Evaluating

Mastering

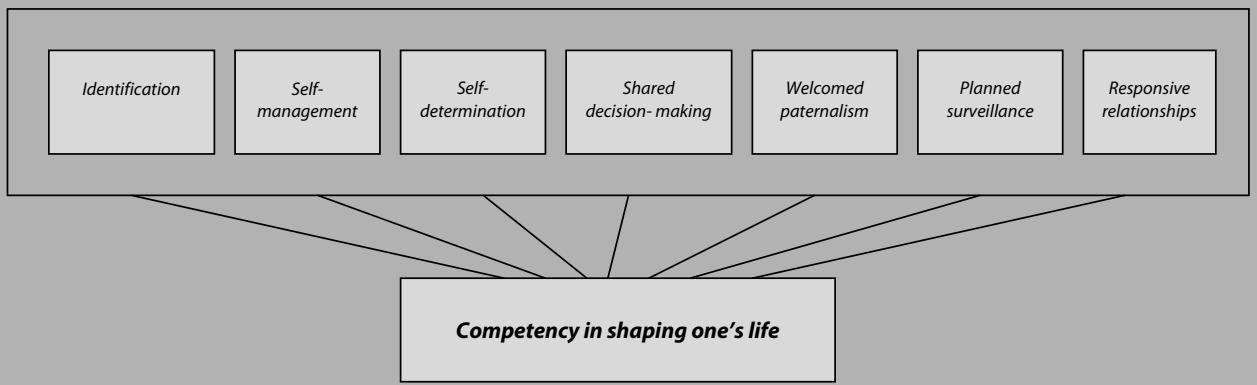




\section{Abstract}

People with type 2 diabetes view autonomy as competency in shaping one's life. This concept of autonomy has seven dimensions, which emerged as categories in prior research. Dynamic processes shape these dimensions of autonomy. One of the dimensions of autonomy is identification. The aim is to clarify the process of identification with diabetes as a dimension of autonomy as described by people with type 2 diabetes. This study has a qualitative descriptive and exploratory design and an inductive approach as described in grounded theory. Data are collected by means of in-depth interviews. The sample consists of 15 people with type 2 diabetes mellitus in a nurse-led, shared care setting in the Netherlands. The phases of identification are comprehending, struggling, evaluating and mastering. Each phase has its own characteristics. Identifying with the diabetes is a nonlinear, cyclical and continuous process because people with diabetes have to deal with changing conditions. The dynamics of identification is directed to a process of identifying with diabetes and its care requirement. Recognizing identification as an element of autonomy enables nurses to adopt a more patient-oriented view of autonomy. Nursing that fosters the process of identification supports autonomy. This implies that a person with diabetes should be able to identify with the nurse's interventions. Hence it is vital that nurses build supportive partnerships when providing care for such a patient.

This chapter is based on the publication:

Moser, A., H. Van der Bruggen, C. Spreeuwenberg, and G.A.M. Widdershoven, Autonomy through identification: a qualitative study of the process of identification used by people with type 2 diabetes. Journal of Clinical Nursing, 2008. 17(17 (7b)): p. 209-216. 


\subsection{Introduction}

The world's diabetic population will increase from an estimated 124 million people to 221 million in 2010 [1]. Approximately $80 \%$ of these patients are diagnosed with type 2 diabetes mellitus and 20\%, with type 1 diabetes mellitus. Type 2 diabetes develops mostly in older adults and the prevalence rises with increasing age [2]. Compared with other chronic illnesses, diabetes care is characterized by its complexity. Diabetes is a life-long challenge that needs continuous adjustment. Most of the care responsibility is placed on the patient. The management of diabetes is complicated because of the multisystemic, chronic and insidious nature of the illness [3].

In the Netherlands, government policy focuses on the improvement of care by encouraging patient-tailored care [4]. Shared care is an approach that provides needs-based care to chronically ill people [5]. Nurse-led, shared care units have been established for people with diabetes. In a nurse-led, shared care model, diabetes specialist nurses (DSN) work independently with their patients and are responsible for the care of patients with diabetes whose health status is stable but complex [6]. One of the goals of nurse-led, shared care is to improve the quality of care by encouraging people with diabetes to be active participants in their own care $[5,7]$.

This study is part of an ongoing research project regarding the autonomy of people with type 2 diabetes in a nurse-led, shared care setting. In a previous article [8], we report how people with type 2 diabetes who are being cared for by DSN in a nurse-led, shared care unit view autonomy. The core category 'competency in shaping one's life' describes how people with diabetes view autonomy. Competency is the individual repertoire of skills that includes recognizing the possibilities and having the abilities, capacities and expertise that allow people to shape their own lives. To a person with diabetes, shaping one's own life means actively striving toward an autonomy that is exactly right for only this particular person; it is based on characteristics that are unique to this person and it is flexible in changing health conditions and life situations. Shaping one's life is a construct of joining various dimensions. The specific way in which the dimensions are combined is not fixed, but is rather a mix of what seems most appropriate at a given time. We found seven dimensions of autonomy. Each of the seven dimensions outlines a different aspect of a person's competency to shape his/her life. Here, we focus on one dimension of autonomy: identification. In this study, we define identification as a process through which people with type 2 diabetes identify with their illness. People work actively toward adjusting their behaviour and adapting to the constraints that diabetes imposes on them. They are engaged in a 
process of development to make diabetes and their lives fit together. They are aware of the impact of life-style changes on their lives and health. When they succeed, they perceive their lives as 'normal' again. However, changes of treatment regimen or health status may disrupt their lives. A person with diabetes sometimes has to identify with a different treatment or a new health situation [8].

In this chapter we extend our previous analysis. We now investigate the phases in the process of identification. The motivation for this inquiry stems from an earlier phase of the research. During the interviews and analysis, we became aware that identification is not static, but dynamic. This awareness guided our research question: what is the process that underlies identification as described by people with type 2 diabetes?

\subsection{Literature review}

Medich et al. [9], who examined a basic life process that people experience during cardiac rehabilitation, found phases of awareness and responding. The basic life process occurs repeatedly over time. Paterson et al. [10] explored the lived experience of diabetes as described in published research and theses. Balance is the metaphor of the experience of diabetes. People learn to balance diabetes through their experience and experimentation with tactics for managing their illness. Learning to balance is a process in which people learn to assume control of diabetes management. The authors do not examine the process of learning to balance. Hernandez et al. [11] discovered a three-phase process when investigating First Nation adults' experience of type 2 diabetes. The phases are having diabetes, turning point and science of one. Paterson et al. [12] researched the process of transformation as experienced of people with type 1 diabetes. The two phases are: challenge that leads to transformation and differentiation of self and body that leads to further transformation. Transformation is an ongoing process where phases occur repeatedly. Paterson [13] designed the shifting perspectives model of chronic illness derived from qualitative reports pertaining to chronic illness. Living with chronic illness is an ongoing and continual process in which people shift between two perspectives dependent on the perceived reality: illness-in-the-foreground or wellness-in-the-foreground. Kralik [14] describes the transition experience of chronically ill women with arthritis in three phases: extraordinariness, transition and ordinariness. She states that the transition experience is nonlinear, cyclic and recurring throughout life. Whittemore et al. [15] also describe a three-phase process model of life-style change in type 2 diabetes: establishing a pattern, embedding a pattern and living a pattern. Hoernsten et al. [16] explain the psychosocial maturity among people with type 2 diabetes. They 
identified three main categories of psychosocial development. They interpret trust as the basis for identity and together they lead to integrity which is the basis for maturity. In relation to long-term care, Agich [17] states that human action can be regarded as free if the individual agent can identify with the elements from which it flows. An autonomous person develops in an integrative process of accommodating him/herself in new circumstances and adopting the circumstances to his/her unique structure of meaning. Agich clearly characterizes autonomy as a process, but does not examine the process phases.

The review of literature indicates that research has been carried out on similar or closely connected concepts. Research concerning the process of identifying with diabetes from the viewpoint of autonomy is limited. The aim of this study is to clarify the process of identification with the diabetes as a dimension of autonomy as described by people with type 2 diabetes.

\subsection{Method}

This study has a qualitative descriptive and exploratory design and an inductive approach as described in grounded theory [18]. We used the grounded-theory approach because little is known about the dynamics that shape dimensions of autonomy in a nurse-led, shared care setting. Grounded theory is an inductive, from-the-ground approach that uses everyday behaviours or organizational patterns to generate a theory about a particular phenomenon [18].

\subsubsection{Participants}

We carried out the study with type 2 diabetes patients who were enrolled at the Maastricht Shared care Unit VII at University Hospital Maastricht. The study population consisted of 15 people diagnosed with type 2 diabetes. They had been diagnosed with type 2 diabetes for 1 - 16 years. The selection criteria included individuals a) who were Dutch and lived in or around the city of Maastricht, b) with a confirmed diagnosis of type 2 diabetes, which was detected at least 1 year before the study began, c) who had stable but complex health condition, d) who lived independently at home, e) who had been enrolled for at least one year at the Maastricht Shared care Unit VII and f) who were able to complete an interview of about 1.5 hours. Participants a) with cognitive impairment and severe geriatric symptoms (diagnosed by a physician), b) newly diagnosed patients, c) those for whom the interview was too great a burden, d) elderly type 1 diabetic patients and e) type 2 diabetic patients who lived in an assisted-housing environment were also excluded. 
The researcher, in cooperation with key people (DSN and the project manager) from the Maastricht Shared care Unit VII selected the participants using the method of theoretical sampling [18]. The DSN forwarded a letter to people with type 2 diabetes to ask if they might be approached. The letter gave information about the research and asked consent for releasing personal data to the researcher. After this letter was sent, the DSN contacted the potential participants again to confirm their permission for personal data to be given to the researcher. Then, the researcher contacted these people to see if they were willing to participate and to make interview appointments. All those approached by the researcher agreed to participate. After receiving detailed information about the research, participants gave written informed consent prior to the interviews. The respondents were assured that interview data would be dealt with confidentially. Anonymity was assured by code-numbering the interviews. The ethics commission of University Hospital Maastricht and the Maastricht University gave ethical approval.

\subsubsection{Data collection and interview procedure}

Fifteen in-depth interviews took place from March to September 2003. All participants were interviewed at home. The interview guide consisted of open-ended questions (e.g., How is your life now compared with the time before you were diagnosed with diabetes? Since you have been diagnosed have you experienced some changes? If yes, how is your life affected?) Members of the project group and selected experts (ethicists, DSN and researchers) reviewed the interview guide. The interviews were tape-recorded and transcribed verbatim. Field notes were taken during and after each interview. The researcher, who is a trained interviewer, conducted all interviews.

\subsubsection{Data analysis}

We analysed the data by applying constant comparative analysis as recommended in grounded theory; according to Strauss and Corbin (1990), theories and concepts are discovered, developed and provisionally verified by means of systematic data collection and analysis of data pertaining to the phenomenon in question. In this approach, theory arises inductively from the interview data and deductively through constant comparison. Codes were grouped, compared and categorized into concepts. Analysis of the interviews resulted in a concept, categories and process phases that shape these categories. Memos were taken and analysed in each step of the analyses, from open coding to writing down the findings and helped to formulate the findings.

\subsubsection{Trustworthiness}

To establish credibility, we used the strategies of prolonged engagement, triangulation and persistent observation [19]. We ensured prolonged engagement by 
learning the culture, testing for misinformation, building trust and learning the data. We asked several distinctive questions regarding topics related to the dynamics underlying the dimensions of autonomy. Furthermore, the participants were encouraged to support their statements with examples and the interviewer asked follow-up questions. Finally, we studied the data from raw interview material until the processes elicited the shape of the dimensions of autonomy to provide the scope of the phenomenon under study. Furthermore, we used method, investigator and source triangulation [19]. We gathered data by means of indepth interviews and field notes. Several investigators were involved as members of the research team. We conducted 15 interviews and used the various data sets that emerged throughout the analysis and a reflexive journal. We ensured persistent observation by developing the codes and categories that examine the characteristics of the data. We repeatedly read the data, analysed and conceptualized them and then we revised them accordingly. We recoded and relabelled codes, process stages and the processes that underlie the dimensions of autonomy. We studied the data until the analysed findings provided depth. We guarantee transferability by providing descriptive data (setting, sample, sample size, sample strategy, inclusion and exclusion criteria, interview procedure, field notes, minutes of the meetings with the project group and other experts and a reflexive journal) on request to enable readers to make a transferability judgment. Dependability was assured by an academic auditor who examined the analysis and records for accuracy and dependability. Confirmability is secured by an academic auditor who reviewed the findings to see that they followed from the characteristics of the data (raw data, analysis notes, code notes, process notes and report) and were not biased by the enquirer.

\subsection{Findings}

On the basis of the analysis of the interviews four phases emerged that shape identification as a dimension of autonomy as perceived by people with type 2 diabetes. The process phases are comprehending, struggling, evaluating and mastering. Although we conceptualize the process of identification in phases it does not progress in a linear fashion. Identifying with the illness is a non-linear, cyclical and continues process because people with diabetes have to deal with changing conditions.

\subsubsection{Comprehending}

When people are confronted with a diagnosis of diabetes, changes in the treatment plan and health condition, they try to comprehend why this happens. Some consult the DSN to help them understanding the situation. People search for 
possible explanations that give meaning to the occurrence of the diabetes. They check family history and past events. A diagnosis of diabetes and the consequences of its treatment are not surprising to some because they have already seen diabetes in their families.

'When I had my first hypo, I knew it was going to happen. My father had diabetes, my brother, everybody in my family has it. Yes and my son too. I knew what was going to happen.'

Some people aim to understand changes in the treatment plan or health condition. For others, the occurrence of diabetes is perceived as something unexpected and strange. They are confused and try to find the cause.

'I think it is very weird that I got it. I have a lot of sisters and brothers and we never talked about diabetes. Never! Nobody in my whole family has that disease. So I ask myself, 'Why did I get it? Did I work too hard? Did I work too long?' These things occupy my mind.'

People with diabetes are also concerned about what the future might bring. They recognize that their life plans need to be changed and that diabetes-related care requirements imposes a lot of restrictions and changes on their daily lives. They are deeply concerned about ways to handle the future despite the diabetes.

'I am 73 years old. Since I was diagnosed with diabetes, my future expectations are somehow different. Somehow I have fewer expectations. Sometimes I think I do not have a life anymore. Damn it, this disease has destroyed my future! I try to think about the future. I try to find ways to give meaning to my future'

\subsubsection{Struggling}

People with diabetes have to learn new behaviours. They struggle with the treatment regimen. They also have problems adapting to their new life-style and behaviour as required by the treatment plan. People feel that it takes a lot of effort to adhere to the treatment regimen, life-style rules and behavioural changes. Furthermore, they have trouble finding the best or most suitable way to deal with the diabetes. Their succeeding can be called learning by doing. People go for regular follow-up visits to learn more about diabetes. They also relapse to old lifestyles or behavioural patterns from time to time, but they make serious attempts to deal with the illness. 
'Then I used oral medication. I was very time-conscious about eating. I tried a few things. I learned a few things. After some time, I found a pattern that was comfortable for me.'

At the same time, people have problems acknowledging that they are chronically ill. They feel that life has deceived them. They struggle with the fact that they have lost their health. Some people feel threatened, frightened, insecure and/or frustrated. Furthermore, they are also concerned about long-term complications of the disease and whether they are able to control the illness. Diabetes is a chronic health condition that is irreversible and it makes people feel powerless.

II feel uncomfortable. I have become a chronic patient. I will be ill for the rest of my life. I will never be healthy again. I am afraid of all the longterm complications. I am also afraid because I am labelled as diabetes patient.'

Participants struggle in different degrees. While some experience a lot of struggles others hardly experience struggles with the diabetes. The intensity of the struggle depends on how 'heavy or easy a burden' people perceive the diabetes. Mostly, participants perceive struggling in the context of their whole life, like in relation to other chronic diseases. Sometimes, people do not report any struggling.

'Diabetes, no problems. I take medication. I liked to eat a lot of fruits and now I am more careful. I eat sugar-free sweets. Diabetes diet is no problem. I also suffer from heart failure, high blood pressure and gout. I have to take care of a lot of other things. These are other sicknesses and I perceive complying with these other diets and care requirements as much more problematic than the diabetes.'

\subsubsection{Evaluating}

In the third phase, people with diabetes evaluate the effects of the treatment regimen and life-style changes. They compare the health status they had before they were diagnosed, or before they followed a particular regimen, to their current health status. They weigh their personal efforts against the outcomes. They are aware of the positive impact of the treatment regimen and life-style changes on their health status and quality of life. They experience the positive outcomes as a reward for all the personal efforts that are required to regulate the diabetes properly. 
I was exhausted for years and, in the time before I was diagnosed, I was very irritated and I felt uneasy. But now these symptoms have gone. I am no longer exhausted. I am more relaxed, not so stressed and aggressive anymore. This is wonderful. I hardly recognize myself now. I have never been like this. I was so stressed that I couldn't deal with normal everyday things. That situation has gone. I started exercising, biking. And I've got more energy. My energy has come back. I can do a lot more than before I was diagnosed. Now I feel that I have more fun doing things... Since I have been using insulin, things have been turning out fine.'

Some people search for feedback about their experiences from DSN, while others discuss and reflect on diabetes-related issues with family caregivers. They need the appreciation and encouragement of others to confirm the progress they have made. It gives them a sense of achievement that is an incentive to carry on.

'When I visit my nurse, we talk about diabetes a lot. She always gives me some advice, like 'exercise regularly'. Half a year ago, I started doing sports. She is so enthusiastic about it. I am really trying keep it up. Her way of talking is so encouraging. I talk to her like: I feel like this or I started doing that. And my nurse replies with something like: 'That's perfect. You should just keep on doing that. Way to go!' This kind of support really keeps me going.'

\subsubsection{Mastering}

In this phase, people master the diabetes and its care requirements. Mastering means that people have a certain expertise and thereby know how to handle the situation. Mastering has two components, first people acknowledge the fact that they suffer from an irreversible chronic condition. They integrate life-style and behavioural changes and the necessary treatment into their daily lives. Diabetes becomes a part of themselves and they regard themselves as normal (like others). They are aware of certain limitations imposed by diabetes.

I have accepted the fact that I have diabetes. Let me explain. I am ill. When I have a pain in my stomach, I take medication. I have diabetes and I need injections. Diabetes is not a disease that kills you. If you are careful, you can become a normal person again. This is how I see it.'

Second, people with diabetes feel responsible for looking after their illness. They are engaged in the care for the diabetes. Some participants might want to share 
care tasks with others. Accordingly they create a supportive environment and they are aware about the division and boundaries of these tasks. Others might want to take all care tasks on themselves. People with diabetes define their responsibilities within the individual diabetes care process and personal context.

'It's my task to take care or not to take care at all. If I go somewhere and I eat a piece of cake, then I know that my sugar level will increase. Yes and then I take the responsibility for what I do.'

\subsection{Discussion}

In this study, we investigate the process that underlies identification as a dimension of autonomy as experienced by people with type 2 diabetes. Identification is a process. Some studies describe several distinctive phases though which people move. Researchers assume that people advance through sequential phases to reach a certain condition $[11,15,20]$. In our study identifying with the diabetes is conceptualized as a process that includes moving through phases but identifying with the diabetes is a non-linear, cyclical and continuous process because people have to deal with changing conditions. This is congruent with several empirical reports [9, 12-14]. Paterson et al. [12] describe the transition experience not as a straight trajectory but as a 'never complete' process consisting of plateaus, accelerations prompted by new and unfamiliar challenges in living with diabetes and times of retreat. Identifying with diabetes is a process of personal comprehending, struggling, evaluating and mastering. People with diabetes create an environment that supports and sustains this process. People involved in this process participate actively to re-pattern their lives or as Patterson [13] puts it, the perception of personal reality, not reality itself, is the essence of how individuals interpret and respond to their illness.

The first phase, comprehending, is similar to awareness as described by Medich et al. [9]. Their concept of awareness reflects conscious awakening to the nature of the health event and is characterized by a search for meaning. People are awakened to 'what is?' and are consciously confronted with 'what does it mean to me?' In our study, comprehending centers on past experiences, explaining the change in the treatment plan and health condition and outbreak of the diabetes and future perspectives. This is congruent with image of the disease, meaning of diagnosis and future prospects as described by Hoernsten et al. [21] who studied personal understandings of illness among people with type 2 diabetes. 
The second phase, struggling, is related to the experience of vulnerability as a human response to a health crisis $[9,15]$. We describe two kinds of struggles. The first kind comprises the struggle with the necessary care activities and the second one includes emotional distress. The first kind deals with the struggle of living according to the treatment plan and initiating the necessary life-style and behaviour changes. This implies vulnerability. People are struggling because they have trouble finding a suitable way to handle the diabetes, so that they have to learn by trial and error. They are tempted to abandon new behaviour. In this period of vulnerability they put great effort into preventing relapses into old behavioural patterns. Various empirical findings provide evidence of the existence of this vulnerability $[9,14,15]$. The second kind of struggle in our study is related to emotional vulnerability: the loss of control, feelings of dread, insecurity, frustration and then the fear of health complications. Other findings confirm emotional vulnerability $[9,11,14,15]$. Interestingly, people with diabetes in our sample did not mention fear of death [11], awareness of a damaged body, or corroded selfesteem and self-worth [14].

In our study, evaluating means reviewing the treatment regimen, life-style changes, health status and quality of life. This aspect is mentioned in most of the literature we reviewed and it seems to be a central theme. It is described as clarifying values [9], a turning point [11], differentiation of self and body [12], a reflexive process [14] and satisfaction with life-style changes [15]. People with diabetes also consider the positive outcomes of their personal efforts to manage diabetes properly. A positive evaluation encourages them to carry on $[9,14,15]$. Surprisingly, the literature does not mention the fact that, especially in this phase, people with diabetes need others (family members and nurses) to supply appreciation and support.

In our research, mastery has two features: living normally as others do, despite the diabetes and its limitations and being responsible for the care. Living normally with diabetes is similar to integrating new behaviour into daily routine [9, $11,15]$, desire to live a normal healthy life [10], interweaving the diabetes and the personal self $[11,15]$, reconstructing identity [14] and finding a balance $[14,15]$. Being responsible for the care has several connotations in the literature: becoming a partner [9], assuming control [10], taking care of oneself [11], directing care [12], making choices and gaining empowerment and control [14] and trust one's purposefulness and trust in fortitude [16]. Almost all of the reviewed literature makes use of terms which are alike to our interpretation of mastery. These terms explain concepts such as transition, (lived) experience of diabetes, transformation or self-management. Surprisingly, researchers have not placed and discussed their findings in the context of patient autonomy so far. 
Our findings do not confirm the 'having diabetes' phase as described by Hernandez et al. [11]. This phase is characterized by four sub-phases: denying having diabetes, minimizing or downplaying the impact of diabetes on one's life, 'normalizing' by means of ignoring and neglecting diabetes and turning to spirituality. We did not find any of these elements in our study. Perhaps this was because our study sample consisted of participants who were being treated by DSN. We did not interview people with diabetes outside this care setting who might have had different experiences with the disease.

Certain themes occur across the empirical studies we reviewed, but they are located in different phases of identification. An example of this is acquiring knowledge about diabetes and building new behaviour. We found this theme in the struggling phase. Medich [9] describes this topic in the awareness phase as well as in the responding phase. Hernandez et al. [11] refer to this subject in the turning point phase and similarly, Kralik [14] describes it in the transforming phase. Hoernsten et al. [16] mention this topic in the first phase of psychosocial maturity as trust in one's understanding. Wittemore et al. [15] describe this theme at the beginning in the phase of establishing a pattern.

Research with people suffering from chronic disease like cardiac rehabilitation [9] and arthritis [14] implies that it is likely that people with chronic diseases go through a similar process of identification as people with type 2 diabetes do. However, we assume that every chronic illness has certain illness-specific aspects, which need to be taken into consideration.

A limitation of this study is that the interviews took place within a restricted geographical area. Diversity in sampling ensured data that covered a range of behaviour in different situations. An interview requires certain physical and cognitive strengths. People with severe diabetes-related health problems were not included. A further limitation is that this study was restricted to interviews. No observations were made to collect additional data. We tried to compensate for this by asking participants further questions or by asking for examples to illustrate a statement.

\subsection{Implications for practice}

Understanding autonomy as identification and the underlying process will move nurses toward a more patient-oriented approach. The focus is on what, in the area of care intervention, people with diabetes consider will fit into their lives so that they can personally identify with. Although people with diabetes move 
through the process in a personal way, nurses can support patient autonomy in every stage individually. In the first phase (comprehending), nurses can support the autonomy of the patient by helping to explain the occurrence of diabetes in a way that fits the patient's explanatory model. In the struggling phase, nurses can foster patient autonomy by temporarily simplifying the treatment regimen, encouraging and recognizing small steps of progress, providing situation-specific diabetes knowledge and assisting people to acquire new skills. In the evaluation phase, nurses can facilitate autonomy by helping the patient reflect on personal boundaries or behavioural pitfalls, but also on accomplishments, successes and their rewards. In the mastering phase, nurses can promote patient autonomy by coaching their patients in maintaining the new life-style patterns and creating a supportive relationship where care responsibilities are shared.

\subsection{Conclusion}

Autonomy for a person with diabetes is competency in shaping his/her life. Competency here implies a construct of individual autonomy that joins various dimensions of autonomy. An important dimension is identification. This article focuses on the process that shapes this dimension. The process, as described by people with diabetes, is a process of identifying with diabetes and its care requirement. The phases of identification are comprehending, struggling, evaluating and mastering but identifying with the illness is a non-linear, cyclical and continues process because people with diabetes have to deal with changing conditions. Nurses can promote autonomy as identification with suitable interventions that foster identification and by creating a supportive partnership. Interventions can be tailored to each phase and to the individual patient so that they are meaningful to the patient. Since people with diabetes realize their autonomy in many different ways, further research is recommended to investigate the processes that shape the remaining dimensions of autonomy. 


\section{References}

1. Amos, A.F., D.J. Mc Carthy and P. Zimmet, The rising global burden of diabetes and its complications: estimates and projections to the year 2010. Diabetic Medicine, 1997. 14: p. S7-S85.

2. Mooy, J., P. Groothuis, H. De Vries, H.A. Valkenburg, L.M. Bouter, P. Kostense, and R.J. Heine, Prevalence and determinants of glucose intolerance in a Dutch caucasian population. Diabetes Care, 1995. 18: p. 1270-1273.

3. Van den Arend, I.M., G.E.H.M. Rutten, G.J.P. Schrijvers and R.P. Stolk, Experts' opinions on the profile of optimal care for patients with diabetes mellitus type 2 in The Netherlands. The Netherlands Journal of Medicine, 2001. 58: p. 225-231.

4. Temmink, D., A. Francke, J.B.F. Hutten, J. Van der Zee and H. Huijer Abu-Saad, Innovations in the nursing care of the chronically ill: a literature review from an international perspective. Journal of Advanced Nursing, 2000. 31: p. 1449-1458.

5. Spreeuwenberg, C. and P. Pop, Transmurale zorg, in Handboek tansmurale zorg., C. Spreeuwenberg, et al., Editors. 2000, Elsevier Gezondheidszorg: Maarssen. p. 17-36.

6. Frederix, M., Gespecialiseerde verpleegkundigen nemen taken van specialist over. Tijdschrift voor Verpleegkundigen, 1998. 108(13): p. 416-419.

7. Vrijhoef, H.J.M., C. Spreeuwenberg, I.M.J.G. Eijkelberg, B.H.R. Wolffenbuttel and G.G. Van Merode, Adoption of disease management model for diabetes in the region of Maastricht. British Medical Journal, 2001. 323: p. 983-985.

8. Moser, A., H. Van der Bruggen and G.A.M. Widdershoven, Competency in shaping one's life: Autonomy of people with type 2 diabetes mellitus in a nurse-led, share-care setting; a qualitative study. International Journal of Nursing Studies, 2006. 43: p. 417-427.

9. Medich, C.J., E. Stuart and S.K. Chase, Healing through integration: Promoting wellness in cardiac rehabilitation. Journal of Cardiovascular Nursing, 1997. 11(3): p. 66-79.

10. Paterson, B., S. Thorne and M. Dewis, Adapting to and managing diabetes. Image: Journal of Nursing Scholarship, 1998. 30(1): p. 57-62.

11. Hernandez, C.A., I. Antone and I. Cornelius, A grounded theory study of the experience of type 2 diabetes mellitus in First Nation adults in Canada. Journal of Transcultural Nursing, 1999. 10(3): $p$. 220-228.

12. Paterson, B., S. Thorne, J. Crawford and M. Tarko, Living with diabetes as a transformational experience. Qualitative Health Research, 1999. 9(6): p. 786-802.

13. Paterson, B., The shifting perspectives model of chronic illness. Journal of Nursing Scholarship, 2001. 33(1): p. 21-26.

14. Kralik, D., The quest for ordinariness: transition experienced by midlife women living with chronic illness. Journal of Advanced Nursing, 2002. 39(2): p. 146-154.

15. Wittemore, R., S.K. Chase, C.L. Mandle and C. Sister Roy, Lifestyle change in type 2 diabetes: $A$ process model. Nursing Research, 2002. 51(1): p. 18-25.

16. Hoernsten, A., A. Norberg and B. Lundman, Psychosocial maturity among people with diabetes mellitus. Journal of Clinical Nursing, 2002. 11: p. 777-784.

17. Agich, G., Dependence and autonomy in old age. 2003, Cambridge: Cambridge University Press.

18. Strauss, A. and J. Corbin, Basics of qualitative research: grounded theory procedures and techniques. 1990, Newbury Park: Sage.

19. Guba, E.G. and Y.S. Lincoln, Naturalistic Inquiry. 1985, Newbury Park: Sage.

20. Price, M.J., An experiential model of learning diabetes self-management. Qualitative Health Research, 1993. 3(1): p. 29-54.

21. Hoernsten, A., H. Sandstroem and B. Lundman, Personal understanding of illness among people with type 2 diabetes. Journal of Advanced Nursing, 2004. 47(2): p. 174-182. 



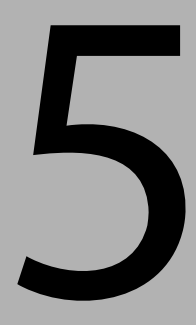

\section{Self-management and the DSN's and family's role}

Preventive
Experiencing
Learning
Being
cautious
Putting into
practice

Daily

Adhering

Adapting

Acting

routinely

Off-course

Becoming

aware

Reasoning

Deciding

Acting

Evaluating

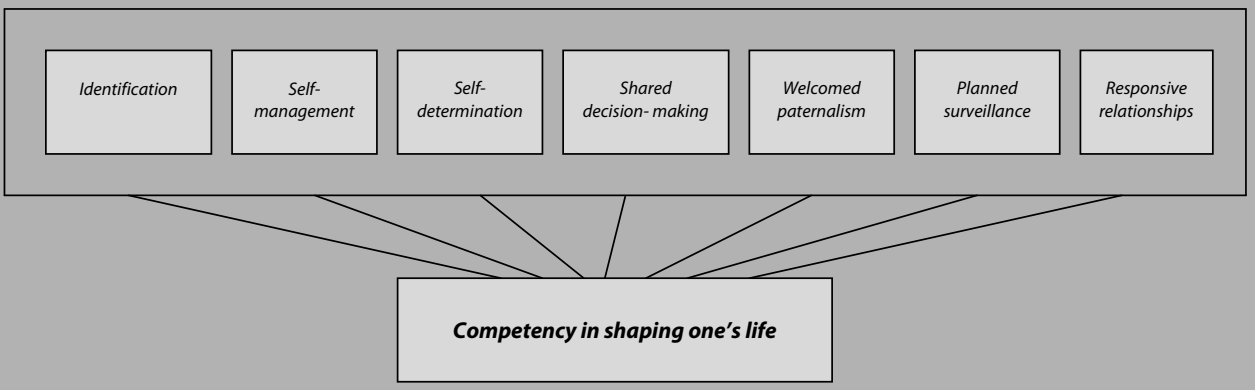




\section{Abstract}

Diabetes mellitus is a major public health problem. Little is known about how people with type 2 diabetes experience self-management in a nurse-led, shared care programme. The purpose is to report an empirically grounded conceptualization of self-management in the context of autonomy of people with type 2 diabetes. This study has a qualitative descriptive and exploratory design with an inductive approach. Data were collected by means of in-depth interviews. The sample consisted of older adults with type 2 diabetes mellitus in a nurse-led, shared care setting. The data analysis was completed by applying the constant comparative analysis as recommended in grounded theory. People with type 2 diabetes use three kinds of self-management processes: daily, off-course, and preventive. The steps for daily self-management are adhering, adapting, and acting routinely. The steps for off-course self-management are becoming aware, reasoning, deciding, acting, and evaluating. The steps for preventive selfmanagement are experiencing, learning, being cautious, and putting into practice. These processes are interwoven and recurring. Self-management consists of a complex and dynamic set of processes and it is deeply embedded in one's unique life situation. Support from diabetes specialist nurses and family caregivers is a necessity of self-managing diabetes.

This chapter is based on the publication:

Moser, A., H. Van der Bruggen, G.A.M. Widdershoven, and C. Spreeuwenberg, Self-management of type 2 diabetes mellitus: a qualitative investigation from the perspective of participants in a nurse-led, shared care programme in the Netherlands. BMC Public Health 2008. 8: 91. 


\subsection{Introduction}

Diabetes mellitus constitutes a serious public health problem. The prevalence of diabetes mellitus is increasing [1]. The total number of people with diabetes is expected to increase from 171 million in 2000 to 366 million in 2030 [2]. The most significant demographic change of diabetes prevalence world-wide appears to be the increase in the proportion of people older than 65 years [2]. In the Netherlands, type 2 diabetes accounts for about $90 \%$ of all diabetes cases [3].

Western countries should establish a healthcare system that meets the needs of the population [4]. Shared care is an approach to provide needs-based care for chronically ill people [5]. In the Netherlands, several types of shared care models have been implemented [6] in order to treat people with diabetes. In the Maastricht shared care model, diabetes patients have been allocated to three types of care pathways: (a) patients with complicated health problems that may require radical medical decisions are referred to a medical specialist; (b) general practitioners provide basic care for the less complex cases and home health-care nurses provide the essential daily diabetes care; and (c) the diabetes specialist nurse (DSN) has an intermediate position between the medical specialist and the general practitioner. DSN work independently with their patients and are responsible for the care of the ones whose health status is stable but complex [7]. These patients require medium-intensity care [8]. DSN function in both hospitals and primary care settings. This nurse-led, shared care programme consists of a diabetes outpatient department at Maastricht University Hospital and specialty clinics in general practices. DSN follow the agreed guidelines and protocols [7]. The tasks of the DSN are to provide direct patient care, to organize and coordinate care (including medical care) for individual patients, and to provide advice and health education to patients and other care providers [8]. The result is that this particular nurse-led, shared care setting is characterized by a mix of specific medical care and advanced nursing practice [9].

One of the goals of nurse-led, shared care is to encourage people with diabetes to be active participants in their own care [5, 8]. A literature review of the patient's perception of autonomy showed that autonomy has empirically been studied in the hospital, the nursing home, and home health care, but not in this particular setting [10]. Specifically, people with type 2 diabetes are required to manage many aspects of diabetes themselves on a life-long basis. The responsibility for day-to-day disease management shifts from health-care professionals to the individual [11]. Self-management places a large burden on patients [12]. It is a complex task involving diet, skin care, medication and insulin administration, exercise and rest, self-monitoring, and consulting health-care professionals. This requires 
researchers to take the self-management of chronically ill people into consideration as a general experience in their lives [13].

Our study is part of an ongoing research project regarding the autonomy of people with type 2 diabetes in a nurse-led, shared care setting $[9,10,14]$. The longterm purpose of this project is first, to identify what issues need particular attention to foster patient autonomy in diabetes care provided by DSN and second, to formulate recommendations to promote patient autonomy on the individual as well as policy level. The design of the ongoing research project is qualitative explorative which focuses on patient autonomy as perceived by older adults with type 2 diabetes mellitus. In a previous article we report how people with type 2 diabetes who are being cared for by a DSN in a nurse-led, shared care unit view autonomy [9]. The core category 'competency in shaping one's life' describes how people with diabetes exercise their autonomy. Competency is the individual repertoire of skills that includes recognizing the possibilities and having the abilities, capacities, and expertise that allow people to shape their own lives. This implies that people with diabetes initiate and complete various daily actions, which are, in fact, dimensions of autonomy. To shape one's life means that a person actively strives towards a form of autonomy that is exactly right for only this particular person. Autonomy is based on characteristics that are unique to this person, and it is flexible with regard to changing health conditions and life situations. Shaping one's life is a construct of joining various dimensions of autonomy. Thus, the combination of the dimensions of autonomy is not fixed, but rather a mix of what seems most appropriate at a given time. We found seven dimensions of autonomy: identification, self-management, welcomed paternalism, self-determination, shared decision-making, planned surveillance, and responsive relationships. Each of the seven dimensions gives a different outline of competency for shaping one's life. In this article we focus on the dimension self-management.

During the interviews and analysis, we became aware of the dynamic character of the seven dimensions of autonomy. Therefore, we investigated the processes that underlie these dimensions. Most of the dimensions are shaped by more than one process, and the analysis provided a vast amount of data. To do justice to our findings, we chose to classify them for presentation. According to Sandelowski [15], qualitative findings can be grouped along temporal, thematic, event, or subject lines. We have chosen to make a thematic cut since self-management is very important to people with diabetes. In this study we define self-management as encompassing activities pertaining to taking care of one's health and diabetes. Self-management includes skills for activities of daily living (regular foot care) and the instrumental activities of daily living necessary for the treatment regimen (preparing diet meals, contacting the nurse). Self-management also refers to deci- 
sion-making. Skills for effective self-management activities and deciding on selfmanagement issues are intertwined [9].

\subsection{Literature review}

In relation to nursing, Orem [16] describes three phases of self-care: the investigative, judgmental, and decision-making phases. Price [17] reports a diabetes selfmanagement model for adults with type 1 diabetes that has two phases. Phase one, which consists of getting regulated, has four stages: trying it out, figuring it out, trial and error, and basic routine. Phase two consists of being regulated, with two substages: basic routine and applies basic routine to new diabetic situations. Ellison and Rayman [18] describe the experience of self-management of women with type 2 diabetes, who are expert self-managers. They move through three phases: management-as-rules, management-as-work, and management-as-living. Paterson and Thorne [19] describe the development of self-management expertise of people with type 1 diabetes. The four phases are passive compliance, naive experimentation, rebellion, and active control. Paterson and Thorne [20] report how people with type 1 diabetes who are experts make everyday self-care decisions regarding unanticipated blood glucose levels. The five components in both familiar and unfamiliar situations are assessment of risk, comparative analysis, diagnosis, choice of action, and evaluation. Thorne et al. [21] did a secondary data analysis of how persons with expertise in self-managing type 1 and type 2 diabetes, HIV/AIDS, and multiple sclerosis learn everyday self-management decisionmaking. The authors identify three phases: assuming control, fine-tuning, and evaluating.

Research has focused mainly on people with type 1 diabetes and women with type 2 diabetes who are expert self-managers. It is less well understood how the "average" older adult person with type 2 diabetes manages diabetes. Additionally, the literature generally focuses on the development of self-management expertise, while we start from the notion of patient autonomy. Therefore, we want to answer the research question: what are the processes through which older adults self-manage their diabetes in the context of autonomy? The purpose is to report an empirically grounded conceptualization of self-management in the context of autonomy of people with type 2 diabetes. This research is primarily not about the sufficiency of self-management in terms of outcomes such as wellregulated glycaemia control instead our attention centres on the personal understanding of the self-management of people with diabetes. Nevertheless, medical issues such as good blood results are part of the patient's experience of selfmanagement. 


\subsection{Method}

The design of this study is qualitative descriptive and exploratory, with an inductive approach as described in grounded theory [22]. According to Strauss and Corbin [22], the grounded theory approach is used because little is known about autonomy and self-management of people with type 2 diabetes in a nurse-led, shared care setting. Grounded theory provides a way to go beyond experience to move it from description of what is happening to understanding the process by which it is happening [23].

\subsubsection{Participants}

We carried out the study with type 2 diabetes patients who were enrolled at the Maastricht Shared care Unit VII. Fifteen people with type 2 diabetes participated in this study. The 6 women and 9 men were aged 55 to 77 years. They had been diagnosed with type 2 diabetes 1 to 16 years earlier. Eleven participants had general secondary or intermediate vocational education, and 4 had university education or higher vocational education. Eight participants were insulin dependent, and the remaining 7 were not. On average, the duration of the treatment by DSN was 2.4 years and the participants had visited the DSN 8.7 times. We invited patients who had been enrolled for at least 1 year at the nurse-led, shared care clinics in the Maastricht region to participate in the study. All respondents were Dutch. People with confirmed and stable type 2 diabetes but with a complex health status, were included. Patients who lived independently in the community and were able to complete an interview of about 1.5 hours were included too. Type 2 diabetes patients with cognitive impairment and severe geriatric symptoms (diagnosed by a physician), newly diagnosed patients, and those for whom the interview was too great a burden were excluded. Elderly type 1 diabetic patients and type 2 diabetic patients who lived in an assisted-housing environment such as nursing homes or homes for the elderly were also excluded.

The researcher, in cooperation with DSN and the project manager from the nurseled, shared care unit, selected the participants with the aid of theoretical sampling [22]. The sample of this study stems from a common parent sample which is the basis of the long-term project mentioned earlier. The analyzed population is the same as in previous publications $[9,14]$.

\subsubsection{Data collection}

Fifteen in-depth interviews took place from March to September 2003. All participants were interviewed at home. The interview guide consisted of open-ended questions, for example, what diabetes care activities do you carry out? what do you do when you have a problem caused by the diabetes? Interviews were tape- 
recorded and transcribed verbatim. Field notes were taken during and after each interview. One researcher (AM) conducted all interviews.

\subsubsection{Data analysis}

We analysed the data by applying constant comparative analysis as recommended in grounded theory [22]. In this approach, theory arises inductively from the interview data and deductively through constant comparison. Inductive coding was used to examine the phenomenon under study. We provided initial open coding for each interview and the field notes. We divided the data into small pieces and grouped these codes in larger subcategories and categories. We compared and contrasted the subcategories and categories and formulated concepts. Theoretical coding was used to develop models that clarify the relationships among concepts. We put the concepts back together to find patterns and processes and derived theoretical constructs by clarifying the relationships among the concepts. After analysis of 12 interviews, conceptual saturation occurred. The remaining 3 interviews were used to confirm and verify the analysis and findings. During the whole analysis, from open coding to writing down the findings, we had a continuous dialogue with the data. Memos were taken and analysed in each step of the analysis and helped to formulate the findings.

\subsubsection{Ethical considerations}

After receiving detailed information about the research, the participants gave written informed consent prior to the interviews. The respondents were assured that interview data would be dealt with confidentially. Anonymity was secured by code-numbering the interviews. The ethics commission of Maastricht University Hospital and Maastricht University gave ethical approval.

\subsubsection{Trustworthiness}

We assure credibility [24] by using multiple methods of data collection such as indepth interviews and field notes (methodological triangulation). Several investigators were part of the project groups, and two researchers were involved in the analysis and interpretation of data (investigator triangulation). Different sources of the same information, such as numerous interviews, were used to validate the findings (data triangulation). Several distinctive questions were asked regarding topics related to autonomy and self-management; participants were encouraged to support their statements with examples, the interviewer asked follow-up questions, and the researchers studied the data from raw interview material until the theory emerged to provide the scope of the phenomenon under study (prolonged engagement). The researchers concentrated on the aspects of the interviews and field notes that were most relevant to the issue under study and focused on them in detail; we read data, analyzed them, theorized with them, and revised the concepts accordingly until the findings provided depth (persistent 
observation). Throughout the inquiry, the project group held meetings to review and explore scientific and organizational aspects of the project (peer debriefing). We sought cases and events that disconfirmed evolving categories until the theory accounted for all cases (negative case analysis). We guarantee transferability [24] by providing descriptive data of the study context (thick description) on request to enable readers to evaluate whether the findings are transferable to other care contexts. Dependability and confirmability [24] are assured by an academic auditor. The auditor checked whether the analysis was in line with accepted standards and examined the analysis process and records for accuracy.

\subsection{Findings}

One of the seven ways people with type 2 diabetes pursue their autonomy as 'competency in shaping one's life' is self-management. People with diabetes exercise self-management by a set of particular activities. We consider these specific series of practices as self-management processes. These processes provide understanding how self-management in relation to autonomy actually happens and is achieved. The analysis of participant's descriptions of their self-management practices as related to autonomy resulted in three processes: daily, off-course, and preventive self-management.

Most participants reported all three kinds of self-management. Some practised all of them while others reported (a) particular self-management process(es) at a given time. Additionally, some participants said that they took process steps in a linear order, while others reported that they occasionally repeated some steps. Some said that the processes were recurrent and cyclical. Some might not take all steps, and others might take their steps in a slightly different sequence. In this study, the participants described short-term (off-course) and long-term (daily and preventive) self-management processes. They also mentioned that a short-term self-management strategy might turn into a long-term one. People evaluate the effect of the short-term decision made and the action taken. The decision to turn a short-term self-management strategy to a long-term one depends upon how well the off-course event was dealt with. We report analytical steps, but in practice these steps occur simultaneously and in an interactive process.

\subsubsection{Daily self-management}

Daily self-management is related to daily diabetes activities such as administering insulin, exercising, and resting. It includes activities that belong to the treatment regimen and activities for staying healthy in general. Daily self-management consists of three steps: adhering, adapting, and performing routinely. 


\subsubsection{Adhering}

People with diabetes adhere with the treatment regimen as prescribed by healthcare professionals. They stick to the rules and carry out self-management activities as required by the treatment plan, e.g., they take their medication exactly on time.

'At the very beginning, I did as I was told. I started taking my medication and eating precisely on time, doing exercises and losing weight, going to have my blood and blood pressure checked every 3 months.'

Some participants said that they adhered rigorously to 'new' rules when they had to deal with a new treatment. They had been suffering from diabetes for a longer period and already had some experience with diabetes self-management. This kind of adherence is temporary until people with diabetes become more confident with the new treatment.

'The units of insulin, yes, I really need supervision and monitoring. I do not change one unit without consulting my nurse. I am still somehow inexperienced at using insulin. I know my body very well, but I do not know its reaction (to insulin) yet. (...) At the beginning, I asked a lot of questions. Now I have gained more confidence, and I ask fewer questions.'

\subsubsection{Adapting}

People with diabetes adapt to the prescribed treatment regimen. They make small adaptations, like changing their food patterns. Then they alter the treatment to fit their lifestyles better, or because they perceive their measures as good enough, e.g., acceptance of a fairly low blood sugar level. Adapting the treatment is often related to self-management issues that people are familiar with. They deal with self-management strategies more flexibly.

'My average blood sugar level has been decreasing in the last few months. At my last visit it was low. I am on oral medication and I stuck to a rigid diet. I handle my diet more flexibly now. Nowadays I use more noodles and rice in my daily cooking.'

\subsubsection{Acting routinely}

Diabetes care activities become a habit. People with diabetes have routines that are embedded in their personal lives. They are confident in these activities. 
'I do the same thing every day. It has become a habit. In the morning, I take my medication, I take care that I eat a mid-morning snack, then I cook. I rest a little. Later in the afternoon, I go for a walk or take some other exercise. I take a piece of fruit with me. I have dinner. I do a selfmonitoring sugar profile once every 2 weeks.'

\subsubsection{Off-course self-management}

Off-course events include certain health problems caused by diabetes that may occur - sometimes repeatedly, e.g., unanticipated blood sugar levels. When their blood sugar concentrations are below or above a certain value, people take action in response. Off-course self-management includes five steps: becoming aware, reasoning, deciding, acting, and evaluating.

\subsubsection{Becoming aware}

People recognize certain patterns that are unusual. They become aware of irregularities by listening to their bodies, by learning from previous experience, and by monitoring their glucose parameters. Awareness can be improved with a diabetes education course and by consulting the DSN.

'I feel it when my sugar level is not what it should be. I feel dizzy and sometimes I become irritated. It happens when I work hard; for example, when I clean the house.'

\subsubsection{Reasoning}

People try to reason why irregularities occur. They explore their self-management activities critically to find an explanation for their unusual blood sugar levels. People with diabetes also consider other bodily symptoms and glucose parameters to support or refute possible causes.

'I checked my glucose levels yesterday. The glucose profile for the day was quite high. I had a very busy weekend, and a lot of friends visited us. I also ate different food. I really had peaks. I think it happened because of the busy weekend.'

\subsubsection{Deciding}

People with diabetes make decisions to solve certain off-course events. They decide how to deal with the health problem at hand.

Some time ago I had hypos in the evenings. I decided to decrease the amount of the fast-acting insulin.' 


\subsubsection{Acting}

People with type 2 diabetes take action on the relevant decision. They actively undertake specific actions to resolve the off-course event, e.g., by taking some extra fast-acting carbohydrates.

'When I notice that my sugar level is too low, I eat some chocolate.'

\subsubsection{Evaluating}

After carrying out a certain self-management activity, people observe the reactions of their bodies and their blood sugar parameters. They critically evaluate the effect of their decisions and actions.

'Some time ago, I had hypos (hypoglycemia) 3 days in a row. Then I decreased the amount of insulin that I injected in the morning. And it worked out well. I have not had hypos for quite some time.'

\subsubsection{Preventive self-management}

Preventive self-management means that people do certain things to prevent health problems. Diabetes-related health problems encompass short-term complications, such as hypoglycaemia, and secondary long-term complications, such as blindness. Preventive self-management is composed of four steps: experiencing, learning, being cautious, and putting into practice.

\subsubsection{Experiencing}

People may undergo a health experience such as a severe hypoglycaemia. This experience is perceived as very unpleasant, frightening, or threatening.

'I have had some hypos during my vacation. I was not eating the right things. I did not eat carbohydrates because I wanted to loose weight. At the same time, I walked a lot and then I had several hypos. It was very unpleasant.'

People are sometimes faced with negative health events in the family. In one case, a family member had diabetes and suffered from severe health problems, some of which were short-term and some long-term.

'I am afraid of getting a really bad hypo. My mother had a very severe hypo. She was unconscious, and I thought that she was dead. I am being very careful not to get one, but I'm still afraid. I am being very careful to prevent anything like that.' 


\subsubsection{Learning}

People learn about short-term and long-term complications caused by diabetes. They gain practical knowledge from experience with them. The DSN provide a lot of technical and generic learning. People also get information by reading diabetes literature and taking part in diabetes education programs.

'The nurse explained to me that I can get a lot of health problems if I do not take care of my diabetes. I can get problems with my feet, kidneys, and eyes. It is important to know all these things.'

\subsubsection{Being cautious}

People with type 2 diabetes are cautious in situations that could cause short-term and long-term health problems. They also listen to their bodies to recognize certain symptoms early.

'The nurse explained the symptoms of hyper-and hypoglycaemia to me. She also gave me some literature about it. I am much more cautious about these things now and I observe and listen more carefully to my body.'

Furthermore, people with diabetes monitor their blood sugar levels regularly. They are cautious because such irregularities might cause long-term problems.

'A few days ago, my sugar levels for the day were very unstable. I need to keep them within a certain range because of all the health problems that might develop over the years.'

\subsubsection{Putting into practice}

People with diabetes put particular strategies into practice to prevent a shortterm health complication such as hypocalcaemia.

'If I go cycling, I always have an apple in my bag to get enough carbohydrates.'

People are aware of the long-term health problems of diabetes. They implement courses of actions to prevent these complications.

'I try to slow down the process of long-term complications. I cycle a lot. It helps keep my sugar levels low and stable. I cycle, I take long walks, and I keep myself busy.' 


\subsubsection{The involvement of DSN and family caregivers}

\subsubsection{DSN}

DSN are important to diabetes self-management. They teach, guide, and advise people with diabetes about self-management issues. DSN confirm, modify, monitor, and change self-management strategies. They help to develop selfmanagement schemes and skills.

'Now I know that I will see her regularly. If something is not right, she explains to me what went wrong and what I need to change. She monitors my health status. She advises me. If I need to know something, I give her a call.'

The DSN are available as a safety net to assist people when they have run out of self-management strategies or find themselves in unfamiliar situations.

'Some time ago, I had a hypo during the night. I did not know how to interpret this. It makes me feel insecure. I called my nurse.'

The role of the DSN depends on the complexity of the self-management. If the complexity decreases or the diabetes management becomes stable, the role of DSN may become less significant. In some cases, as with radical changes in the treatment plan or episodes of severe illness, the role of DSN may expand temporarily.

'I think that, if I have serious health problems, her (the nurse's) role will get bigger. She needs to take over the lead. This is not necessary right now because my condition is stable. I handle things myself.'

\subsubsection{Family caregivers}

Diabetes self-management becomes part of the family life. People with diabetes embed the diabetes in the family context in different ways. All participants in this study state that family caregivers support them in their diabetes selfmanagement. The involvement differs from person to person. Some participants call on their relatives in an emergency.

'He (the participant's husband) knows how to inject insulin. We learned it together. He also pricked my finger with a needle. I do everything myself now, and I try to solve all my own problems, but he takes care of me too. He only comments on my diabetes things every now and then, but he needs to know everything. This is important to me. If I am uncon- 
scious and need to be admitted to the hospital, he must be able to provide the necessary information.'

Some family caregivers help the person with some self-management activities, for example, by preparing meals.

'My wife takes care of the cooking. I took a course about diet, and my wife knows how to cook for someone with diabetes. She takes care of my meals and my eating pattern. I manage everything else myself.'

Some participants see the family caregiver as a partner or companion with whom they share all self-management. In these cases, family caregivers have a significant part in every single self-management step.

'She' (the participant's wife) 'is my assistant. She cooks, she thinks with me, she takes care of the medication. I also do all these things, but she keeps me company in managing the whole diabetes thing, which is essential to me.'

\subsection{Discussion}

The purpose of this article is to report of an empirically grounded conceptualization of self-management in the context of autonomy of people with type 2 diabetes. Diabetes self-management is a lifelong matter and is clearly directed towards care. This study shows that self-management, as described by people with diabetes themselves, goes far beyond compliance and 'good blood control'. It takes shape within the context of a unique life in which one establishes one's personal self-management strategies. Not all the participants attained or maintained the same level of self-management [17]. For some, self-management relates to daily activities based on a firm structure. Others have developed sophisticated selfmanagement skills that allow situational modifications. Furthermore, most participants said that they did not manage diabetes equally well every day. This is congruent with other research $[18,19,21]$. As Ellison and Rayman [18] put it, " $100 \%$ some days and $40 \%$ other days".

The processes of self-management require a mix of cognitive (e.g. reasoning), practical (e.g. acting), and social (e.g. communicating) skills. In line with our findings, empirical researchers report an interplay of cognitive and practical skills in their descriptions of self-management processes [17-21]. In this study, the importance of social skills comes to the fore because people request social support in 
self-management. The data suggest that social support from DSN and family caregivers is essential and fosters self-management. Research mainly reports supportive relationships with nurses [17-21], but rarely mentions the relationships with family caregivers and their role in self-management. The participants in our study did not refer to support from peers [20,21], but some offered their services voluntarily to diabetes support groups.

In previous research, the participants were recruited by means of a diabetes newsletter [17], a diabetes teaching and research centre [18], self-nomination or nomination by an internist $[19,20]$, and nomination by primary care specialists [21]. Apparently, the participants were not treated by nurses. In this study, DSN are the main caregivers. Their tasks include both medical and nursing procedures. Our findings confirm characteristics that seem common across studies but highlight aspects that are specific to nursing, such as preventive diabetes care. Preventive self-management has not yet been conceptualized in the literature. In public health nursing, it is critical to avoid both short-term and long-term complications. Perhaps we have been led to turn our attention to preventive selfmanagement because of the long-term and care nature of nurse-led, shared care and our participants are older adults. Many of them suffer from more than one chronic condition, and diabetes-related complications might be linked to functional losses and increased risk of care dependency. They associate preventive self-management with sustaining freedom and prolonging independence. Most of our participants had been confronted with the complications of family members or had developed some of their own. Such experience influenced their own self-management. Attempting to avoid severe complications seems to be the motivator of preventive self-management.

Self-management is heavily influenced by professional recommendations. Understanding the processes that underlie self-management will enable nurses to provide diabetes counselling, which goes beyond generic technical education, symptom management, compliance, and metabolic control. Nurses should focus on providing people with diabetes with the necessary cognitive, social, and practical skills needed for autonomously exercising of self-management. Continuous social support is essential for self-management. DSN are in a position to provide longterm counselling for people with diabetes and, in order to do so, they should build collaborative and accommodating relationships with their patients, and if appropriate, with family caregivers. Especially in the care for older adults DSN should focus on preventive self-management. In some cases, DSN need to provide support to people with diabetes and to family members which are (sometimes closely) involved in the care for the person with diabetes. In these cases DSN should include family caregivers in their counselling. However, DSN should 
keep autonomous self-management as desired by the person with diabetes as the focal point of their counselling.

People with diabetes frequently mention that their family members assist them with diabetes-specific self-management activities. In our study, people with diabetes experience the participation of close ones as positive, thus enhancing autonomous self-management. Family members should support the person with diabetes by being attentive to the self-management wishes and needs of their close ones. The involvement of family caregivers has a different meaning to each individual person with diabetes and there are various ways family members can participate in diabetes self-management. Family caregivers should take part in the consultancies with the DSN if the person with diabetes wishes so. In addition, family members too need DSN to find answers to their caring questions to contribute effectively to the diabetes self-management of their kin. We encourage family members to assist their kin with diabetes to a degree that they view themselves as self-managers and are able to maintain an equilibrium between selfmanagement autonomy and reliance on close ones.

A limitation of this study is that the interviews took place within a restricted geographical area. Diversity in sampling ensured data that covered a range of behaviour in different situations. An interview requires certain physical and cognitive strengths; therefore, people with severe health problems were not interviewed. Another limitation is the fact that nurses who work at the nurse-led, shared care unit selected the participants. At the time of the study, all participants were treated by DSN. We could not interview people who were enrolled at the nurseled, shared care unit but did not comply with the follow-up regime. The findings might not be applicable to the so-called non-compliers. These people might associate non-compliance with a need for autonomy or see it as a way of asserting independence. The results are comparable to those programmes similar to the one described here. First, the scope and tasks of nurses should be comparable to those of advanced practice nurses at the general practitioner's or health visitors. Secondly, the context in which care is given should have common features such as the ones in follow-up monitoring care settings. Third, the patient population should be similar to our sample of people with diabetes without acute and serious health problems.

\subsection{Conclusion}

Autonomy for people with diabetes requires competency in shaping one's life. Competency in shaping one's life means that individual autonomy is achieved by 
matching up various dimensions of autonomy. Self-management is an important dimension in realizing autonomy and consists of daily, off-course, and preventive self-management. These processes are interwoven and recurring. Complex processes shape the three kinds of self-management because it is much more than learning and complying with a treatment regimen. Self-management is deeply embedded in one's unique life situation. Support from DSN and family caregivers are a prerequisite for people to self-manage the diabetes.

\section{Acknowledgement}

The authors thank all the people with type 2 diabetes who were willing to spend time for the interviews and share their experiences. The study was funded by the School for Public Health and Primary Care, Maastricht University. 


\section{References}

1. Amos, A.F., D.J. Mc Carthy and P. Zimmet, The rising global burden of diabetes and its complications: estimates and projections to the year 2010. Diabetic Medicine, 1997. 14: p. S7-S85.

2. Wild, S., G. Roglic, A. Green, R. Sicree and H. King, Global prevalence of diabetes. Diabetes Care, 2004. 27: p. 1047-1053.

3. Nationaal Kompas Volksgezondheid. Diabetes mellitus: Omvang van het probleem. 2007 31. mei 2007 [cited 11 juni 2007; Available from: http://www.rivm.nl/vtv/object_document/o1259n17502.html.

4. Eijkelberg, I.M.J.G., C. Spreeuwenberg, B. Wolffenbuttel, L.J.G.P. Van Wilderen and M. MurVeeman, Nurse-led shared care diabetes projects: lessons from the nurses' viewpoint. Health Policy, 2003. 66: p. 11-27.

5. Spreeuwenberg, C. and P. Pop, Transmurale zorg, in Handboek tansmurale zorg., C. Spreeuwenberg, et al., Editors. 2000, Elsevier Gezondheidszorg: Maarssen. p. 17-36.

6. Temmink, D., A. Francke, J.B.F. Hutten, J. Van der Zee and H. Huijer Abu-Saad, Innovations in the nursing care of the chronically ill: a literature review from an international perspective. Journal of Advanced Nursing, 2000. 31: p. 1449-1458.

7. Frederix, M., Gespecialiseerde verpleegkundigen nemen taken van specialist over. Tijdschrift voor Verpleegkundigen, 1998. 108(13): p. 416-419.

8. Vrijhoef, H.J.M., C. Spreeuwenberg, I.M.J.G. Eijkelberg, B.H.R. Wolffenbuttel and G.G. Van Merode, Adoption of disease management model for diabetes in the region of Maastricht. British Medical Journal, 2001. 323: p. 983-985.

9. Moser, A., H. Van der Bruggen and G.A.M. Widdershoven, Competency in shaping one's life: Autonomy of people with type 2 diabetes mellitus in a nurse-led, share-care setting; a qualitative study. International Journal of Nursing Studies, 2006. 43: p. 417-427.

10. Moser, A., R. Houtepen and G.A.M. Widdershoven, Patient autonomy in nurse-led shared care: $a$ review of theoretical and empirical literature. Journal of Advanced Nursing, 2007. 57(4): p. 357365.

11. Barlow, J., C. Wright, J. Sheasby, A. Turner and J. Hainsworth, Self-management approaches for people with chronic conditions: a review. Patient Education and Counseling, 2002. 48: p. 177-187.

12. Reed, J.A., J.M. Lawrence, S. Hollinghurst and E.R. Higgs, Diabetes self-management: how are we doing? Practical Diabetes International, 2003. 20(9): p. 318-322.

13. Mars, G.M.J., I.M. Proot, P.P.M. Janssen, J.T.M. Van Eijk and G.I.J.M. Kempen, How do people with COPD or diabetes type 2 experience autonomy? An exploratory study. Disability and Rehabilitation, 2007. 29(6): p. 485-493.

14. Moser, A., H. Van der Bruggen, G.A.M. Widdershoven and C. Spreeuwenberg, Autonomy through identification: a qualitative study of the process of identification used by people with type 2 diabetes. Journal of Clinical Nursing, 2008. 17(17 (7b)): p. 209-216.

15. Sandelowski, M., Divide and conquer: avoiding duplication in reporting of qualitative research (Editorial). Research in Nursing \& Health, 2006. 29: p. 371-373.

16. Orem, D.E., Nursing: concepts and practice. 2001, St. Louis: Mosby.

17. Price, M.J., An experiential model of learning diabetes self-management. Qualitative Health Research, 1993. 3(1): p. 29-54.

18. Ellison, G.C. and K.M. Rayman, Exemplars' experience of self-managing type 2 diabetes. Diabetes Educator, 1998. 24(3): p. 325-330.

19. Paterson, B. and S. Thorne, Developmental evolution of expertise in diabetes self-management. Clinical Nursing Research, 2000. 9(4): p. 402-419.

20. Paterson, B. and S. Thorne, Expert decision making in relation to unanticipated blood glucose levels. Research in Nursing \& Health, 2000. 23: p. 147-157. 
21. Thorne, S., B. Paterson and C. Russel, The structure of everyday self-care decision making in chronic illness. Qualitative Health Research, 2003. 13(10): p. 1337-1352.

22. Strauss, A. and J. Corbin, Basics of qualitative research: grounded theory procedures and techniques. 1990, Newbury Park: Sage.

23. Artinian, B.M., Grounded theory research: its value for nursing. Nursing Science Quarterly, 1998. $11(1)$ : p. 5-6.

24. Guba, E.G. and Y.S. Lincoln, Naturalistic Inquiry. 1985, Newbury Park: Sage. 



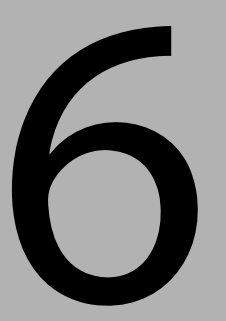

\section{Self-determination, shared decision-making, welcomed}

\section{paternalism and moral capacities}

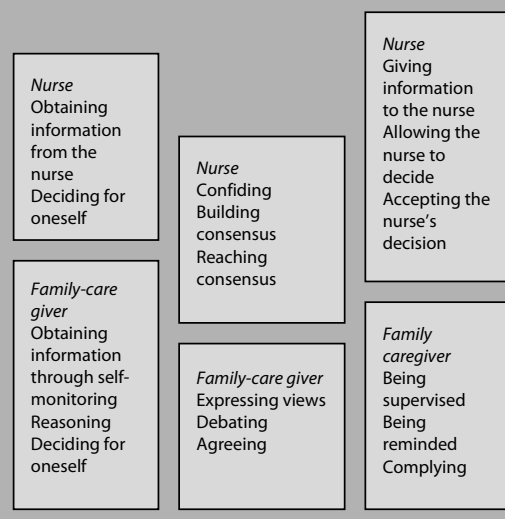

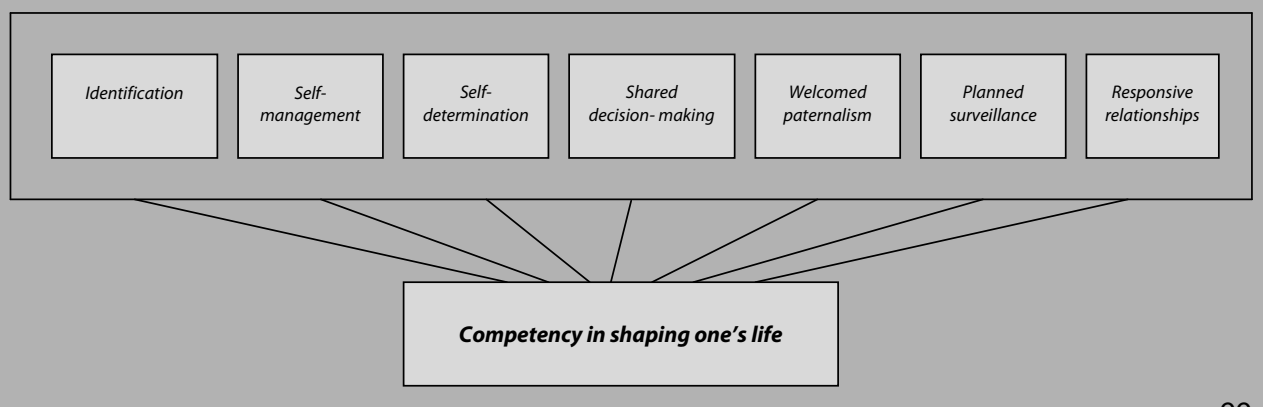




\section{Abstract}

This chapter examines how people with diabetes type 2 perceive autonomous decision-making and which moral capacities they consider important in the diabetes nurses' support of autonomous decision-making. The purpose is twofold: to analyse patient perspectives on decision-making processes relevant to patient autonomy and based on these perspectives, to identify moral capacities nurses need to promote patient autonomy. Fifteen older adults with type 2 diabetes were interviewed in a nurse-led unit. First, data were analyzed using the grounded theory method. Second, descriptions of the decision-making processes were analyzed using a hermeneutic text interpretation interfering moral capacities nurses need to support patient autonomy from the patients' perspective. Participants described a variety of decision-making processes in the nurse and family-care giver context regarding self-determination, shared decision-making and welcomed paternalism. In the nurse-patient context self-determination consists of obtaining information from the nurse and deciding for oneself and in the family-patient context it contains of obtaining information through selfmonitoring, reasoning and deciding for oneself. In the nurse-patient context shared decision-making contains confiding, building consensus and reaching consensus and in the family-patient context it consists of expressing views, deliberating and agreeing. In the nurse-patient context welcomed paternalism includes giving information to the nurse, allowing the nurses to decide, and accepting the nurse's decision and in the family-patient context it consists of being supervised, being reminded and complying. In reality these processes occur together in a dynamic process and the nurse-patient and the family-patient contexts are interwoven. From the hermeneutic text interpretation we inferred firstand second order moral capacities. First-order moral capacities are: commitment, sensitivity and flexibility. Second-order moral capacities are curiosity and comprehensiveness (self-determination), tactfulness, frankness and mediation (shared decision-making), and familiarity and inclusiveness (welcomed paternalism). We recommend nurses to engage in on-going, interactive reflective practice to further develop their moral capacities to support patient autonomy.

This Chapter is based on the publication:

Moser, A., R. Houtepen, H. Van der Bruggen, C. Spreeuwenberg, and G.A.M. Widdershoven, Autonomous decision-making and moral capacities. Nursing Ethics, 2009. 16(2): p. 203-218. 


\subsection{Introduction}

Patient autonomy is a leading principle in medical [1] and nursing ethics [2]. Feinberg [3] distinguishes four different kinds of autonomy: autonomy as capacity, autonomy as actual condition, autonomy as character ideal, and autonomy as right to sovereign authority. In healthcare, autonomy is mostly conceptualized as the right to sovereign authority or self-determination [1]. Several authors question this conceptualization of autonomy and a common theme in their criticism is that it is too individualistic, because autonomy can best be realized in relationship with others [4, 5]. Scholars [6-9] describe various models of the doctor-patient and family-patient relationship with different degrees of autonomous decisionmaking. In nursing, Peplau [10] states that interpersonal relations take one of three forms: participation or interdependence with the nurse, independence or isolation from the nurse, and helplessness or dependence upon the nurse. Millard et al. [11] examined the extent of patient involvement in decision-making, which can be classified as an "involving-non-involving continuum". Schoot et al. [12] explored the patient-nurse interaction with respect to client-centred care from the patient's perspective. They found six patterns of actual interaction: toeing the line, reluctance, consent, dialogue, consuming, and fighting. Reust [13] identified three roles that families play in medical decision-making: supporting the patient during the process of decision-making, being affected by the decision, and advocating for the patient's interests, rights and autonomy. Bailey and Kahn [14] explored spousal helping behaviour as described by the diabetic. Diabetics exhibited four response patterns: grudging acceptance of help, grateful acceptance of help, respectful rejection of help, and punitive rejection of help. The literature shows that autonomous decision-making within the nurse-patient and familypatient context is a complicated matter. The perspectives on autonomous decision-making in the literature are often theoretical [15] and it is common to describe the basic ethical principles on a theoretical level rather than in relation to the process as it happens in the actual nursing context [16]. Empirical literature concentrates on the extent of involvement. Little is known of the actual process of autonomous decision-making of patients. We want to look at the practical performance of nurses by examining the capacities patients see as necessary to support their autonomous decision-making.

From an educational perspective, there are three domains of competence [17]: knowledge, skills, and attitudes. Nursing textbooks consider nursing competency to encompass technical knowledge, practical skills, and knowledge of procedure, as well as moral character and professional etiquette [18]. Tronto [4] conceptualizes four moral qualities necessary to provide good care: attentiveness, responsibility, competence and responsiveness. Empirically, competency frameworks 
have been developed from an educational and professional perspective [18, 19]. Schoot et al. [20] studied nurses' competencies from the patients' perspective. These were: attentiveness, responsiveness, being a critical partner in care, and being a developer of patient competencies to participate in care. In this chapter, we decided to label these diverse but overlapping skills, qualities and competencies as "moral capacities". The literature provides much information from an educational, ethical, and professional perspective. However, currently, we have limited knowledge of what capacities nurses need to support patient autonomy from the patients' perspective.

The purpose of this chapter is twofold: to analyse patient perspectives on decision-making processes relevant to patient autonomy and, based on these perspectives, to identify the moral capacities nurses need to support patient autonomy.

\subsection{Research project and setting}

This study is part of an ongoing research project regarding the autonomy in older adults with type 2 diabetes in a nurse-led setting [15, 21-23]. The long-term purpose of this project is to identify what issues need particular attention to support patient autonomy in diabetes care provided by diabetes specialist nurses (DSN) and to formulate recommendations to promote patient autonomy on the individual and policy level. We investigate autonomy in the daily life of older adults with type 2 diabetes mellitus and focus on it in its broadest sense, including its relevance in the relationships between diabetic patients, DSN and family members.

In the Maastricht nurse-led model, DSN treat people with type 2 diabetes who require medium intensity care [24] but live at home. DSN provide care independently to patients with a stable health condition but who suffer from complex diabetes and age-related co-morbidity [25]. DSN are responsible for direct care such as taking the nursing and medical history, reading and interpreting diabetes diaries and laboratory results, organising and coordinating care for the individual patient such as referral to other care providers, and providing information and advice [26]. Patients receive care that is a combination of medical treatment and advanced nursing care. They see the DSN regularly and have a check-up once a year at their general practitioner's or with their endocrinologist. Patients may contact the DSN by phone during business hours. 


\subsection{Theoretical orientation}

The theoretical departure point is "competency in shaping one's life" [21], which describes how older adults with diabetes view their autonomy. Competency includes recognizing possibilities and having the abilities, capacities, and expertise that enable people with diabetes to shape their own lives. To shape one's life with diabetes means that they actively strive for the right degree of autonomy based on their unique character, and are flexible with regard to changing health conditions and life situations. Competency implies that people with diabetes initiate and complete various actions daily. These courses of actions are conceptualised as dimensions of autonomy. We found seven dimensions of autonomy: identification, self-management, welcomed paternalism, self-determination, shared decision-making, planned surveillance, and responsive relationship. The diverse dimensions of autonomy are related to one another in various ways. The combination of the dimensions of autonomy is not fixed, but rather a mix of what seems most appropriate at a given time. Each of the seven dimensions highlights one aspect of autonomy and specific processes supporting it.

In this chapter, we broaden our analysis. We focus on the dimensions selfdetermination, shared decision-making and welcomed paternalism as they relate to the professional-patient and family-patient relationships. We selected selfdetermination as the traditional "hard core" perception of autonomy, welcomed paternalism as an unlikely and possibly, suspect kind of autonomy, and shared decision-making as a middle ground between the two seemingly opposing dimensions of autonomy. In particular, we focus on the interactive aspect of decision-making.

\subsection{Method}

\subsubsection{Grounded theory}

All 15 participants in this study were Dutch and lived in or around the city of Maastricht. These older adults had a confirmed diagnosis of type 2 diabetes at least one year before the study began, a stable but complex health condition, were living independently at home, had been enrolled for at least 1 year at the nurse-led shared-care unit and capable of completing an interview of about 1.5 hours without cognitive impairment or severe geriatric symptoms (diagnosed by a physician).

The interview guide consisted of open-ended questions directed towards aspects of autonomy related to daily life in its broadest sense. We asked "How would you 
describe the care you receive for your diabetes?" or "How would you describe your visit to the nurse?" The participants were encouraged to provide examples to support their statements and researchers asked follow-up questions. When discussing the visit to the DSN, follow-up questions were, depending on the interview context: "What did you talk about?" or "Who took the initiative to raise this topic?" The interviews were tape-recorded and transcribed verbatim. Field notes were made, concerning observations and impressions during the interview and informal talk after each interview.

The participants gave written informed consent prior to the interviews. They were assured that interview data would be dealt with confidentially and anonymously. The Ethics Commission of the University Hospital Maastricht and Maastricht University gave approval.

Using grounded theory, we broke the data into smaller parts. Every line was coded using open codes that were often descriptions used by the participants. We made as many codes as possible to ensure broad coverage. Next, we compared and contrasted the incidences and open codes and grouped them into categories, making sure that categories included similar incidents and codes which yielded increasingly complex and inclusive categories. The phenomenon represented by each category was given a conceptual name. Subsequently, we employed axial coding, putting the data back together in new ways by making connections between the categories and sub-categories. Next, we used selective coding to select the core category and related it to the other categories. We continued to watch for evidence in the data to develop the categories further. Finally, we integrated the data to form a substantive theory. Theoretical sampling [27] involved asking specific questions about the emerging codes and categories in subsequent interviews. First, we asked general questions, and later, more focused ones. Memos were written about codes and categories and their interrelationships. After analysis of 12 interviews, saturation was considered to have occurred. The remaining three interviews were used to ensure that no new categories emerged. The third author, who was not familiar with the literature, but a specialist in grounded theory, analysed five interviews independently from the first author. This resulted in good agreement. When there were differences in coding and interpretation the authors went back to the original data to reflect on these by discussing until agreement was reached. The analysis resulted in the development of a substantive theory of autonomy consisting of seven categories, which we describe as dimensions of autonomy, and several sub-categories including the decision-making processes. 


\subsubsection{Hermeneutic text interpretation}

Knowing the scope and depth of the existing data, we were able to consider additional research questions which were not explicitly asked during the grounded theory interviews and analysis. We asked the following research question: what moral capacities are required from nurses to support autonomous efforts of their patients? For that reason we decided to perform a secondary analysis on the existing data set. This procedure has been described as "analytical expansion"[28]. Hermeneutic text interpretation is a suitable method to perform a secondary data analysis [29, 30]. It permitted us to formulate a normative question [31], which enabled us to integrate empirical data and ethical reflection [31]. Following on from the grounded theory analysis, the hermeneutic text interpretation focused on making normative aspects explicit in terms of moral capacities of DSN in this particular practice.

In a hermeneutic text interpretation the text is seen as a meaningful whole and understanding is reached through dialogue. In this context, dialogue is not limited to a conversation between two people, it is also possible to have a dialogue between the reader and the text. The dialogue between the researcher and the text should occur with the hermeneutic imperative of movement between the whole and parts of the text, and back to the whole. We used the method of gaining understanding [32], a prerequisite of which is the identification of one's preunderstanding of the topic. To make our pre-understandings apparent the authors' team had conversations before and during the text analysis. Our preunderstandings were based on a moral view on nursing and a relational view on autonomy. The hermeneutic text interpretation occurs in several steps. These steps are not mutually exclusive and may happen simultaneously. First, the transcripts of the patients' interviews about decision-making processes were read several times. Next, the first two authors, independently, formed from the text as a whole, a global interpretation of the normative implications for nurses' behaviour. This led to a focus on moral capacities. Subsequently, the text was studied sentence by sentence for similarities as well as differences in the moral capacities DSN were perceived to need to support patient autonomy. We identified moral capacities relating to self-determination, shared decision-making and welcomed paternalism. We also found capacities which were common across these three dimensions. Next, we related the moral capacities within the dimensions of autonomy in each text and then across the dimensions of autonomy in the same text. After that, we compared the moral capacities across all text. In the final step, we related the moral capacities to the competency in shaping one's life as a whole. This increased our understanding of the whole and the parts, and we were able to distinguish first- and second-order moral capacities. 


\title{
6.5 Findings
}

\subsubsection{Decision-making processes}

The findings describe what the diabetic patients perceived to be important for safeguarding their autonomy in decision-making processes. The decision-making processes of self-determination, shared decision-making and welcomed paternalism were examined. We make a distinction between decision-making in the nurse-patient context and in the family-patient environment. First we will define the concept of autonomy and then we will describe the decision-making processes within the nurse-patient and the family-patient contexts.

\subsubsection{Self-determination}

Self-determination stresses making decisions and choices regarding one's own treatment, care, and behaviour, independently and without intrusion from others [21]. Self-determination in the nurse-patient context consists of obtaining information from the nurse and deciding for oneself, and in the family-patient context of obtaining information through self-monitoring, reasoning and deciding for oneself.

\subsection{Nurse-patient context}

Obtaining information from the nurse. Patients need relevant nursing, medical and diabetes care information. They obtain this from DSN. If the diabetic patients as well as DSN want to obtain further information, they ask each other specific treatment-related questions.

\begin{abstract}
'If there is a need to change something in my treatment plan the nurse explains this to me quite clearly: If you go on like this you will encounter this and this problem. If you do that that then that will happen. I will give you an example. My average glucose indicator is slowly increasing. She told me that oral medication is no longer sufficient. If the parameters are constantly high I will have health problems with my eyes, kidneys, and in the worst case, chronic wounds. If I start using insulin the HbA1c will decrease and it will have a positive impact on my body.'
\end{abstract}

Deciding for oneself. Patients decide on the therapy and choose the treatment option which they think is best. In some cases patients do not agree with the proposed options. They decide autonomously and act against the advice of the DSN. 
'She (nurse) tells me what she thinks about the parameters, what she knows and what she thinks what should happen. Then I make the decision.'

\subsection{Family-patient context}

Obtaining information through self-monitoring. Patients obtain information and knowledge of their diabetes by monitoring their blood parameters and physical symptoms. Monitoring also includes observing, watching and listening to body clues.

'I observed that my condition was becoming worse. I am out of breath quite quickly. (...) Last year when I was on vacation (...) I climbed up the mountains and had to rest a lot.'

Reasoning. Patients weigh various arguments and behavioural options against each other. Their reasoning also involves personal preferences and care requirements. They also consider the consequences of their decision.

'Sometimes I visit friends. They offer me a glass of wine. It is nice to drink wine with friends but I know that wine is not good for my diabetes. It increases my sugar level too much.'

Deciding for oneself. Patients decide how to deal with the situation. They do not involve family members. They take control over their own decisions and feel responsible for the diabetes care plan.

'I do everything (diabetes care) myself without any assistance. It's not my husband's business. (...) I decide by myself.'

\subsubsection{Shared decision-making}

Shared decision-making means deciding together with others about care and treatment issues. Those involved share information about personal views and preferences with one another. They take steps to participate in the decisionmaking process and agree on the decision made [21]. Shared decision-making in the nurse-patient context consists of confiding, building consensus and reaching consensus; in the family-patient context it involves expressing views, deliberating and agreeing.

\subsection{Nurse-patient context}

Confiding. Patients are encouraged to confide in DSN about their health problem to shed light on their experiences, perceptions, feelings and expectations with 
regard to the diabetes and their overall health. DSN react by giving information about, for example, treatment options, potential risks and benefits depending on the issues raised by the patient. Both the DSN and the person with diabetes actively share information and the conversation is a dialogue.

'I tell the nurse how I feel and how I have felt since the last visit. We speak not only about the results of my blood parameters and physical examination, but also about everyday things I experience. We speak about my emotional feelings, too. I think that emotional distress or wellbeing has some influence on my diabetes. For me it is important that the nurse knows about these things too because she can interpret and explain the findings more accurately. She takes her time and her attention to my concerns makes me feel comfortable.'

Building consensus. The patient and the DSN actively participate in the discussion on care and treatment preferences, opinions, and views. The patient probes the information presented. Consensus building can be quite time consuming and might last for more than one visit. If views differ, a negotiation is likely to occur.

'The HbA1c parameter was around 10.9. Oral medication did not work anymore and my nurse told me that the best option is to use insulin therapy. I was upset. My reaction was: Must I do this? and, Are there no other tablets? She explained to me that insulin is better for my health, that I will feel better, and that my condition will improve. She gave me some time to think it over (...) But injecting insulin did not decrease the HbA1c. I was quite upset again. We started discussing it all over again. She explained to me why this parameter was still not decreasing and she proposed to stop oral medication step by step and to increase the dose of insulin accordingly. I did not want to inject more insulin but the nurse explained to me what was going to happen if we changed my treatment plan again and why the combination of insulin and oral medication did not work out.'

Reaching consensus. Patients and DSN reach consensus about a care decision that satisfies both. The goal is to reach a decision that is best for the person with diabetes. If necessary, both patients and DSN take on responsibilities to carry out care activities or treatment.

'We speak about what is the best for my problem. In fact, my nurse says what she thinks I might want to do. Then we speak about it. Sometimes we have discussions. If I am convinced that her advice is good for me I 
consent. I need to think it through before we reach consensus. It makes no sense if I get prescribed medication and I do not take it.'

\subsection{Family-patient context}

Expressing views. Patients and the family-care giver express their opinions, preferences, fears, hopes, and beliefs about a diabetes care issue. Spouses, too, express personal thoughts and feelings that are part of an intimate relationship. They may be influenced by diabetes or have an impact on the diabetes care within the family context.

'Some time ago I had some problems with my kidneys. It took more than a year for us to know what was going on. My husband and I experienced a lot of tension. After some time we spoke about it. I told him about my feelings and opinions and he spoke about his point of view.'

Debating. Diabetics and the family-care giver debate about care issues. They question their preferences, fears, hopes, beliefs, dislikes, perceptions and views. Both participate and are open to each other's contributions.

'My husband is a bit too caring every now and then. He says that he worries a lot about my diabetes and health condition and what will happen to me later. Sometimes this makes me uncomfortable. I tell him: Don't speak about it all the time. You can help and remind me but not every moment of the day. We were in a restaurant and when the soup was served he commanded: Inject insulin! This is not necessary. I do try hard not to forget to take it. I say: it is better if you give me a little hint. It is true that when there is a special event I sometimes forget about the diabetes and then it is nice if he takes care.'

Agreeing. Family-care givers and the patient agree on the care decision and how to implement it. In most cases, both the patient and the family member work together to reach and implement an agreement. However, this does not necessarily mean that the agreement and the implementation will have the desired effect and patients and family members might, again, engage in expressing their viewpoints.

'Due to my diabetes I cannot help my husband with housekeeping. I cannot do anything anymore. My husband cannot do all the housekeeping by himself because of his age. We were looking for solutions. Although I do not like strangers in my house we finally agreed to make 
use of the housekeeping service of our local home healthcare organization.'

\subsubsection{Welcomed paternalism}

We speak of welcomed paternalism when people with diabetes defer to someone with expertise to make an informed decision on their behalf or simply when they want others to decide for them in some cases [21]. These people freely transfer or delegate some of their decision-making to another person. They express their wish for others to tell them what to do, or express their satisfaction with such a procedure. Welcomed paternalism in the nurse-patient context consists of giving information to the nurse, allowing the nurse to decide, and accepting the nurse's decision. In the family-patient context this consists of being supervised, being reminded and complying.

\subsection{Nurse-patient context}

Giving information to the nurse. Patients give requested information on an ongoing basis to DSN so that they can assess care issues. DSN ask questions related to patients' experiences since the last visit such as hypoglycaemia, etc. They also collect data such as physical examinations and biomarkers results. Patients participate mainly by answering the DSNs' questions and presenting their diabetes dairy.

'I enter the room and then the nurse asks: How are you? She explains the results of the blood indicators to me. She makes comments on them like: cholesterol was ok. Then she checks on my sugar profiles which I write down in my diabetes diary. She tells me if she is satisfied. Then she checks my weight and blood pressure.'

Allowing the nurse to decide. DSN decide for the patient. They offer the solution to care or treatment problems. DSN choose a therapy which they think will best deal with patients' health problems.

'In January I used 42 units of insulin in the morning. I have had some hypos. She told me to inject only 38 units. She also decided not to decrease the dose of insulin in the evenings.'

Accepting the nurse's decision. Patients accept the nurses' treatment decisions and implements the therapy options that the nurses favour. They incorporate the proposed care interventions into their diabetes care regimen, accordingly. In some cases, DSN further support the implementation of their decisions by carrying out the appropriate diabetes treatment. 
'Last time she told me that I had to inject insulin into my thighs. She examined my belly and explained that the skin has grown too thick and does not absorb insulin anymore. The glucose day profiles have also increased. She wanted to see how I inject insulin but she was not satisfied. She demonstrated how to do it in the right way. Since then I have to inject insulin into my thighs.'

\subsection{Family-patient context}

Being supervised. Family-care givers supervise behaviour or actions people with diabetes performed. This does not mean that they constantly observe their relatives. Generally, close relatives know the weaknesses of their diabetic family members and in which situations they have problems adhering to the regimen. Family-care givers pay special attention to their behaviour in such situations. They also watch the health of their relatives.

'I like to eat. Especially in the evening when I watch TV I need to eat something. I prefer cheese to sweets. My wife keeps an eye on me.'

Being reminded. The family-care giver reminds the patient to follow their treatment plan accordingly. Some people do not experience this as negative. They appreciate it if family members remind them to act in accordance with care requirements.

'My wife reminds me to take my medication or she tells me to go for a walk if the weather is nice. She also reminds me to watch my diet. Every now and then she reminds me not to eat too much meat. She knows that my cholesterol is a bit too high.'

Complying. People with diabetes comply with what the family-care giver tells them to do. Family members also take on roles that help their relatives to conform with their treatment and life-style requirements.

'In the morning before breakfast he (husband) says: Don't forget to measure your blood sugar level. Only after I have measured my blood sugar do we start having breakfast.'

Patients perceive a complex set of decision-making processes underlying the dimensions of self-determination, shared decision-making and welcomed paternalism. They describe different processes in the nurse-patient and in the familypatient relationship. We identified distinct decision-making steps for analytical purposes, although in reality these steps occur together in a dynamic process. For 
example, the decision-making approach of a patient may change depending on the particular setting. During the nurse-patient consultation, patients may shift their decision-making approach from the welcomed paternalism towards the shared model approach with their family-care givers. Likewise, a DSN might start the consultation with an informed approach and might switch to welcomed paternalism if the patient does not want to make the decision. Some processes may not be completed within a single interaction, especially when negotiation takes place. The nurse-patient and the family-patient contexts are interwoven: some patients will share some or all decision-making steps with family members. They might seek advice from family-caregivers to make the most appropriate decision.

\subsubsection{DSNs' required moral capacities}

Here we present the hermeneutic text interpretation of the patients' interviews about the aforementioned decision-making processes with regard to the moral capacities that are required for DSN to support patient autonomy. We distinguish between first-order and second-order capacities.

\subsubsection{First-order moral capacities}

\subsection{Commitment}

DSN should be able to establish and maintain a good rapport with patients and to act in a dedicated way. Diabetes care is on-going and, as a result, often embedded in care settings in which the nurse-patient relationship is long-term. DSN have to keep track of the patient even when less care is required. Commitment in self-determination suggests that DSN are committed to freedom of choice. They do not intervene in the decisions made by patients. Commitment in shared decision-making is demonstrated when DSN participate and are involved in the decision-making process. It is a mutual endeavour between DSN and patients and, in some cases, significant others. Commitment in welcomed paternalism means that DSN are instrumental in making decision that needs to be made. DSN relate to patients in different ways. Commitment may encompass giving freedom, participating, as well as close engagement.

\subsection{Sensitivity}

DSN need to be able to assess patients' needs and wants and determine which aspect of autonomy is at stake in a specific situation. DSN should respond to the individuals' courses of action. Needs and wishes will differ among patients and at different times within the same relationship. Sensitivity in self-determination requires that DSN give patients all necessary medical and nursing information that is lacking. Sensitivity in shared decision-making includes that DSN should engage in a dialogue with the patient and/or family members. DSN are willing to 
discuss which therapy would be best and are able to follow the flow of such a conversation. Sensitivity in welcomed paternalism means that DSN supply patients with appropriate decisions. DSN invite patients to consent to and follow the proposed therapy. In all three dimensions, DSN are sensitive to the different means that patients require to pursue autonomy. Sensitivity covers providing facts, dialogue or a "ready" decision.

\subsection{Flexibility}

DSN act within the context of a particular situation. They have to be able to adapt their approach to support autonomy to different circumstances. They should be flexible in each nurse-patient encounter and need to fine-tune the aspect of autonomy which is at stake to fit any given situation. This gives an indication what kind of commitment and sensibility is required. Flexibility is of special importance because the nurse-patient interaction is dynamic since the decisionmaking process can change within a single interaction or perhaps during the next nurse-patient interaction. Patients' wish to involve family-care givers may also change, for example, when their health situation deteriorates. Hence, flexibility cannot be seen apart from commitment and sensibility.

\subsubsection{Second-order moral capacities}

\subsection{Self-determination}

Curiosity. DSN have to pursue professional knowledge continuously so that they can give patients adequate information. Professional knowledge entails nursing, medical and scientific information, for example, DSN keep guidelines up to date. Comprehensiveness. DSN should provide patients with sound and complete information. This must be relevant and include the benefits and risks of nursing and medical therapies. This allows patients to make their own informed decisions.

\subsection{Shared decision-making}

Tactfulness. DSN should be able to talk about diabetes-related issues or perform necessary actions without embarrassing patients. They encourage reflection on treatment and care. In this way, patients' and DSNs' values gradually become evident. DSN should allow time with each patient to satisfy their needs (informational and emotional) and to come to a decision. This could extend beyond one consultation.

Frankness. DSN should be approachable and willing to enter into a dialogue with their patients. Frankness includes active listening, open interaction and candid conversation. 
Mediation. Mediation relates to the family context. DSN need to be aware of roles within the patients' family networks to be able to work with these family members regarding care decisions.

\subsection{Welcomed paternalism}

Guidance. DSN need to be able to direct the whole process from information gathering and giving information to making the final decision. This requires DSN to take the lead, for example, by informing the patient to increase the number of units of insulin.

Familiarity. DSN should be acquainted with the care and life circumstances of their patients. This will better equip them to get to know their patients well and identify their wishes and needs in relation to treatment and autonomy preferences.

Inclusiveness. This capacity is closely related to the family context. DSN should be able to take the patients' care, social and environmental conditions into account when making decisions. This includes the possibilities of the family to support the diabetic in daily care.

DSN need both first- and second-order moral capacities to support patient autonomy. First-order capacities are relevant to the patients' autonomy, "competency in shaping one's life," irrespective of the dimension of autonomy. Secondorder capacities relate to specific dimensions of autonomy. In practice, these capacities are interlinked and they occur together. For example, if a person's autonomy preference is self-determination, DSN should be sensitive to this and support those autonomy efforts by exhibiting the appropriate capacity. Likewise, if patients change their autonomy preferences from shared decision-making to self-determination, DSN need to be aware about that shift and be flexible to adapt their second-order moral capacities, accordingly. Second-order capacities can be relevant for more than one dimension. For example, although welcomed paternalism requires DSN to be guiding, familiar and inclusive, they also need to be curious. The patients regarded autonomous decision-making as embedded in a web of multiple relations between themselves, DSN and family members. The roles played by family-caregivers are equally relevant, although not necessarily apparent to DSN. Interests of family members are affected by treatment decisions made for their loved ones and these family members' concerns influence decisions regarding the patients' care. 


\subsection{Discussion}

Our findings were derived from patients' experiences of actual nursing practice and they fit into more general frameworks of decision-making and moral capacities. Our interpretation of welcomed paternalism as an expression of patient autonomy differs from the ethical theoretical view in which paternalism is conceptualized as the opposite of autonomy [1, 7]. Welcomed paternalism involves the delegation of decision-making and actions, for example, patients consider reminders from the spouse prompting them to initiate care that is important [14].

Although most ethicists tend to focus on these concepts as separate entities, Charles and colleagues [8] imply that there might be some interplay. They mention that various in-between approaches could exist. It is also noteworthy that Peplau [10] claims that the three forms of the nurse-patient relationship develop either singly or in combination, starting with one pattern and moving through the other two as a relationship develops. In our study, the decision-making processes were found to be flexible and interrelated. Nurses should, therefore, avoid a "one-for-all" approach to patient autonomy.

The various dimensions of autonomy require different decision-making processes. This implies different relationships between the people involved and different moral capacities on the part of nurses, depending on the context. We believe that it is too often suggested that autonomy requires one particular set of attitudes and actions from the nurses. To date, this leads to a homogeneous, but generic description of moral capacities. To enable patient autonomy and to do justice to its different dimensions for different patients at different times, the prime requirement is a two-level approach to moral capacities. DSN need a basic set of first-order capacities with which to assess the dimensions of autonomy in decision-making to be able to act upon them. First-order capacities enable DSN to have a long-term relationship with patients, without assuming that one specific dimension of autonomy or one kind of decision-making will apply on one individual in all circumstances or at all times. DSN need to shift between first-order and second-order capacities, which is possible only if DSN possess first-order capacities.

We consider the practical implications of decision-making and moral capacities to be more important than the conceptual and theoretical propositions [31, 33]. Given the moral primacy of practical work we advocate, that further conceptual work should be based on nurses' experiences in diverse clinical settings. The differentiation between decision-making processes and the first- and second-order 
moral capacities, that we found may serve as tools for such deliberations. It will, however, require further specification in the light of particular clinical settings.

Nurses play leading roles in the delivery of chronic care. DSN have been included to conventional diabetes care teams in several countries [34, 35]. A literature review of the nursing activities [34] showed that the generaliability of the findings is limited by the poor description of the nurse interventions. We believe that our findings are transferable to other nurse-led settings through the comprehensive description of the Maastricht nurse-led care context. This allows readers to compare their own care context with ours and to make transferability judgments [36].

\subsection{Conclusion}

People with diabetes describe several decision-making processes in the nursepatient and in de family-patient interaction concerning self-determination, shared decision-making and welcomed paternalism. Each process outlines differently how people with diabetes attempt to achieve their autonomy. From patients' perspective, DSN need several first- and second-order moral capacities to support their autonomous decision-making effectively, given its range and complexity. Thus, DSN can improve autonomous decision-making of patients by cultivating their moral capacities and by reflecting on their performance. Further research is required to study the nurses' evaluation and deliberation process in order to learn as much as possible about moral capacities and to maximize their cultivation.

\subsection{Recommendations}

Specialist nurses function in an intermediate position because traditional boundaries between nursing and medical care are becoming increasingly blurred. Unfamiliar and "new" ethical issues call for the kind of subtle and flexible capacities we have discussed. Although our research setting is specific and moral capacities were developed bottom-up, we believe that our findings are relevant and applicable to the nursing profession at large. From an educational viewpoint, nurses must learn to understand which capacity is relevant for a particular situation. Our research reflects a specific practice-based approach to developing capacities in nurses, moral or otherwise. We believe that nurses mature by learning first- and second-order moral capacities and their interplay in their daily work. This can be achieved through reflection and deliberation. Much can be learned about these and how to support the autonomous decision-making of patients by 
collectively studying the nurses' narratives on good nursing care. All situations have an ethical aspect [37] and our overview may serve as a tool for deliberation. We recommend institutional interactive reflective practice for nurses to support patient autonomy. This can be realized through sensitive and critical discussion of nurses' narratives by way of moral case deliberation [38] or ethics meetings [39]. Thus, both nursing education and deliberation ought to incorporate collective reflection on actual nursing practice situations, particularly if we want to do justice to the subtleties and contextuality of supporting patient autonomy. 


\section{References}

1. Beauchamp, T.L. and J.F. Childress, Principles of biomedical ethics. 5 th ed. 2001, New York: Oxford University Press.

2. Fry, S.T. and M.-J. Johnstone, Ethics in nursing practice: a guide to ethical decision making. $2 \mathrm{nd}$ ed. 2002, Geneva: Blackwell Science Ltd.

3. Feinberg, J., Harm to the self: the moral limits of the criminal law. 1986, New York: Oxford University Press.

4. Tronto, J.C., Moral boundaries: a political argument of an ethic of care. 1993, New York: Routledge.

5. Verkerk, M., The care perspective and autonomy. Medicine, Health Care and Philosophy, 2001. 4: p. 289-294.

6. Charles, C., A. Gafni and T. Whelan, Shared decision-making in the medical encounter: what does it mean? (or it takes at least two to tango). Social Science and Medicine, 1997. 44(5): p. 681-692.

7. Emanuel, E.J. and L.L. Emanuel, Four models of the physician-patient relationship. Journal of the American Medical Association, 1992. 267(16): p. 2221-2226.

8. Charles, C., A. Gafni and T. Whelan, Decision-making in the physician-patient encounter: revisiting the shared treatment decision-making model. Patient Education Counseling, 1999. 49: p. 651-661.

9. Kuczewski, M.G., Reconceiving the family: the process of consent in medical decisionmaking. Hastings Center Report, 1996. March-April: p. 30-37.

10. Peplau, H., Interpersonal relations in nursing. 1988, Hampshire and London: Macmillan Education Ltd.

11. Millard, L., C. Hallett and K.A. Luker, Nurse-patient interaction and decision-making in care: patient involvement in community nursing. Journal of Advanced Nursing, 2006. 55(2): p. 142-150.

12. Schoot, T., I. Proot, R.H.J. Ter Meulen and L. De Witt, Actual interaction and client centeredness in home care. Clinical Nursing Research, 2005. 14(4): p. 370-393.

13. Reust, C. and S. Mattingly, Family involvement in medical decision making. Family Medicine, 1996. 28: p. 39-45.

14. Bailey, B. and A. Kahn, Apportioning illness management authority: how diabetes individuals evaluate and respond to spousal help. Qualitative Health Research, 1993. 3(1): p. 55-73.

15. Moser, A., R. Houtepen and G.A.M. Widdershoven, Patient autonomy in nurse-led shared care: $a$ review of theoretical and empirical literature. Journal of Advanced Nursing, 2007. 57(4): p. 357365.

16. Leino-Kilpi, H., Vaelimaeki, M., M. Arndt, T. Dassen, M. Gasull, C. Lemonidou, A. Scott, G. Bansemir, E. Cabrera, H. Papaevangelou, and J. McParland, Patient's autonomy, privacy and informed consent. 2000, Amsterdam: IOS Press.

17. Amin, Z. and K.H. Eng, Basics in medical education. 2003, Shanghai: World Scientific Publishing.

18. Bradshaw, A., Competence and British nursing: a view from history. Journal of Clinical Nursing, 2000. 9: p. 321-329.

19. Davis, R., E. Turner, D. Hicks and M. Tipson, Developing and integrated career and competency framework for diabetes nursing. Journal of Clinical Nursing, 2007. 17( 2): p. 168-174.

20. Schoot, T., I. Proot, R.H.J. Ter Meulen and L. De Witte, Recognition of client values as a basis for tailored care: the view of Dutch expert patients and family caregivers. Scandinavian Journal of Caring Sciences, 2005. 19: p. 169-176.

21. Moser, A., H. Van der Bruggen and G.A.M. Widdershoven, Competency in shaping one's life: Autonomy of people with type 2 diabetes mellitus in a nurse-led, share-care setting; a qualitative study. International Journal of Nursing Studies, 2006. 43: p. 417-427.

22. Moser, A., H. Van der Bruggen, G.A.M. Widdershoven and C. Spreeuwenberg, Self-management of type 2 diabetes mellitus: a qualitative investigation from the perspective of participants in a nurseled, shared-care programme in the Netherlands. BMC Public Health 2008. 8: p. 91. 
23. Moser, A., H. Van der Bruggen, G.A.M. Widdershoven and C. Spreeuwenberg, Autonomy through identification: a qualitative study of the process of identification used by people with type 2 diabetes. Journal of Clinical Nursing, 2008. 17(17 (7b)): p. 209-216.

24. Vrijhoef, H.J.M., C. Spreeuwenberg, I.M.J.G. Eijkelberg, B.H.R. Wolffenbuttel and G.G. Van Merode, Adoption of disease management model for diabetes in the region of Maastricht. British Medical Journal, 2001. 323: p. 983-985.

25. Maastrichtse transmurale diabetesorganisatie, Protocol: het MATADOR project. 1999, Maastricht: University Hospital Maastricht.

26. Wolffenbuttel, B., Het Matador-project (Maastrichtse transmurale diabetesorganisatie), in Transmurale zorgvormen van diabetes mellitus: een verkenning van de situatie anno 2000, H. Bilo, et al., Editors. 2000, Isala Klinieken: Zwolle.

27. Strauss, A. and J. Corbin, Basics of qualitative research: grounded theory procedures and techniques. 1990, Newbury Park: Sage.

28. Paterson, B., S. Thorne and M. Dewis, Adapting to and managing diabetes. Image: Journal of Nursing Scholarship, 1998. 30(1): p. 57-62.

29. Thorne, S., Secondary analysis in qualitative research: issues and implications, in Critical issues in qualitative research methods, J.M. Morse, Editor. 1994, Sage: Thousand Oaks. p. 263-279.

30. Wilson, H.S. and S.A. Hutchinson, Triangulation of qualitative methods: Heideggerian hermeneutics and grounded theory. Qualitative Health Research, 1991. 1(2): p. 263-276.

31. Van der Scheer, L. and G.A.M. Widdershoven, Integrated empirical ethics: loss of normativity? Medicine, Health Care and Philosophy, 2004. 7(1): p. 71-79.

32. Fleming, V., U. Gaidys and Y. Robb, Hermeneutic research in nursing: developing a Gadamerianbased research method. Nursing Inquiry, 2003. 10(2): p. 113-120.

33. Molewijk, B., A.M. Stiggelbout, W. Otten, H.M. Dupuis and J. Kievit, Empirical data and moral theory. A plea for integrated empirical ethics. Medicine, Health Care and Philosophy, 2004. 7: p. 5569.

34. Carey, N. and M. Courtenay, A review of the activity and effects of nurse-led care in diabetes. Journal of Clinical Nursing, 2007. 16(11c): p. 296-304.

35. Vrijhoef, H.J.M., J.P.M. Diederiks and C. Spreeuwenberg, Effects on quality of care for patients with NIDDM or COPD when the specialist nurse has a central role: a literature review. Patient Education and Counseling, 2000. 41: p. 243-250.

36. Guba, E.G. and Y.S. Lincoln, Naturalistic Inquiry. 1985, Newbury Park: Sage.

37. Walker, M.U., Moral understandings: a feminist study in ethics. 2nd ed. 2007, Oxford: Oxford University Press.

38. Abma, T.A. and G.A.M. Widdershoven, Moral deliberation in psychiatric nursing practice. Nursing Ethics, 2006. 13(5): p. 546-557.

39. Dierckx de Casterle, B., T. Meulenbergs, L. Van de Vijver, A. Tanghe and C. Gastmans, Ethics meetings in support of good nursing care: some practice-based thoughts. Nursing Ethics, 2002. 9(6): p. 612-622. 



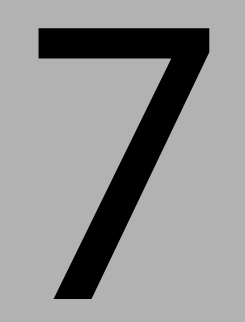

\section{Planned surveillance and motivational factors}

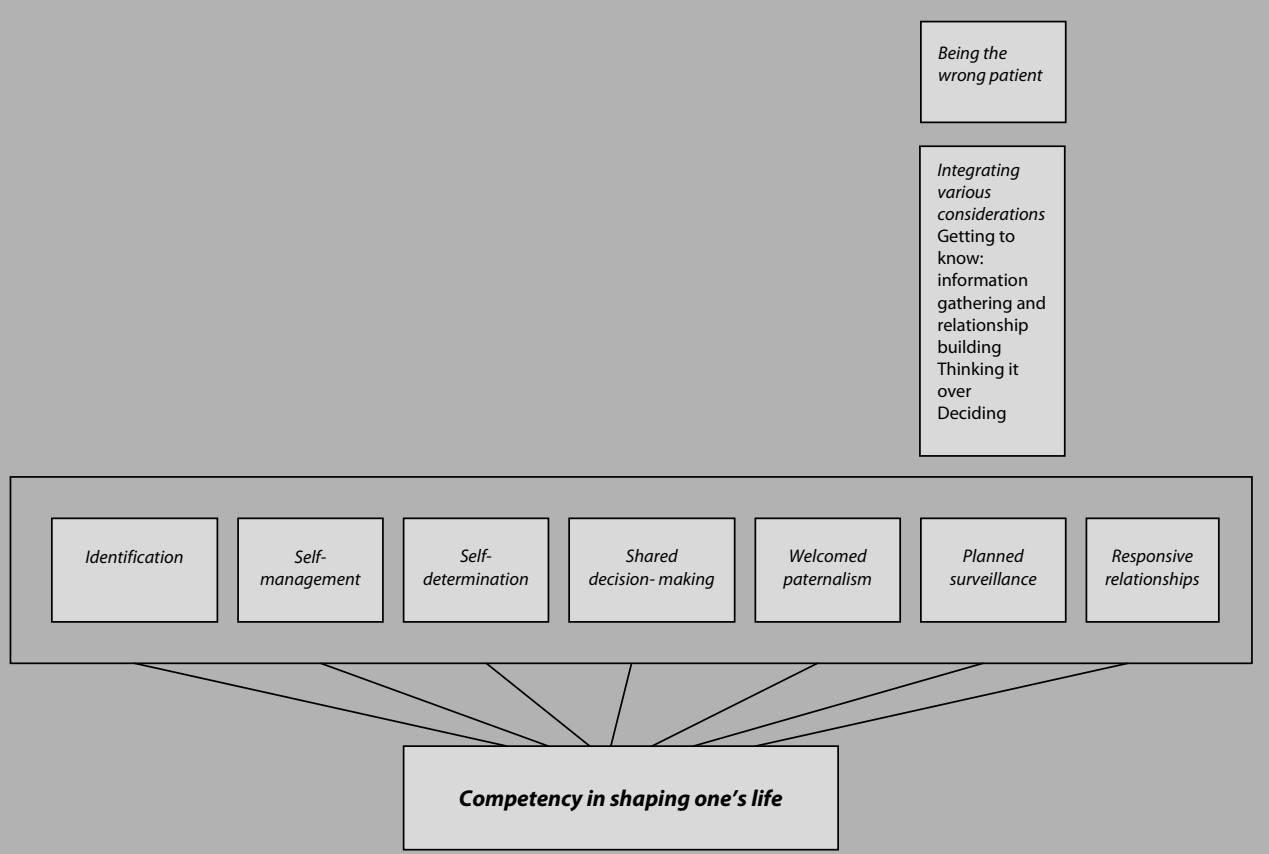




\section{Abstract}

Literature review, theoretical sampling and constant comparison are hallmarks of grounded theory. Yet little attention has been paid to the use of literature as data and as input for grounded theory analysis. In this article, the place of literature in grounded theory is discussed. We use the concept of planned surveillance from a study on the autonomy of older adults with type 2 diabetes mellitus, who are treated in nurse-led clinics, to illustrate how the data drawn from literature was theoretically sampled and used to develop the concept further. The concept of planned surveillance consists of two sub-categories: being the wrong patient and integrating various concerns. Participants name five motivational factors to remain under planned surveillance: continuity of supervision, sustenance of care responsibility, safety, information supply and necessity. The use of literature as data in the constant comparative analysis, as used in grounded theory, enhances and densifies theoretical concepts. 


\subsection{Introduction}

Grounded theory is a research method used in social sciences and nursing science to generate theory about a phenomenon from emerging data in the field [1, 2]. It does not start with testing a hypothesis. Rather, "a grounded theory is one that is inductively derived from the study of the phenomenon it presents. That is, it is discovered, developed, and provisionally verified through systematic data collection and analysis of data pertaining to that phenomenon [...] One does not begin with a theory, then prove it. Rather, one begins with an area of study and what is relevant to that area is allowed to emerge" (p 23) [3]. There are several elements that are essential for grounded theory studies: literature review, theoretical sampling and constant comparison.

The place of the literature review in grounded theory is an issue of considerable debate in the research community [4]. The original founders, Glaser and Strauss, differ in their views. Glaser [5] states that professional literature must not be consulted until the researcher has been in the field and codes and categories have emerged. Grounded theorists can and should keep themselves uncontaminated by existing theories [2]. In contrast, Strauss and Corbin [3] recommend reviewing the technical literature early in the research process because it stimulates theoretical sensitivity, provides a secondary source of data, stimulates questions, directs theoretical sampling and provides supplementary validity. McGhee and colleagues [4] discuss the place of the literature review in grounded theory before and after developing the categories based on their own research experiences. They conclude that the choice whether or not to perform a literature review is complex and depends on several considerations: the researcher's ontological perspective, previous background knowledge and knowledge of the topic area, the researcher's existing level of research experience, the need to meet ethics committee requirements and the timing of the decision to use grounded theory.

Some argue that in grounded theory all is data [4, 6-8]. The literature is a source of data which is theoretically sampled along with other emergent data $[4,6,7]$. According to Glaser [9], theoretical sampling occurs when "the analyst jointly collects, codes and analyzes his data and decides what data to collect next and where to find them in order to develop his theory as it emerges" ( $p$ 36). As mentioned before, he does not apply this to literature. Strauss and Corbin [3] relate theoretical sampling to the coding phases. Open coding requires open sampling, axial coding requires relational or variational sampling to validate relationships and selective coding requires discriminative sampling to verify the emergent theory and to further develop categories that have not been saturated. According to Strauss and Corbin [3], literature is theoretically sampled in the same way as 
interview or observational data are. A review of theoretical sampling in published grounded theory studies shows that researchers often use this to choose new participants, to modify interview guides, or to add data sources as a study progresses, but few describe how theoretical sampling is implemented in response to emergent findings [10].

The literature review serves as valuable source of data for analysis and comparison [2]. As the name suggests, constant comparative analysis involves constantly comparing codes, categories and concepts for similarities and differences [3]. It is a complex process, far from linear. The researcher is moving back and forth from open, axial and selective coding, to theoretical considerations, to memoing, and then back to the substantive theory [7]. The literature is data which can serve to expand and densify a theoretical construct $[6,7]$, because the constant comparative method does not end with completion of the interview and observational data analysis [2]. It is data which is compared for similarities and differences along with the emergent data and emerging substantive theory [6, 7]. Additional data from the literature further saturate or refine a substantive theory and the enhanced theory may be different from the initial one [7]. Wuest [6] describes this kind of analysis as a constant comparative process of emergent fit. "As long as the principle of constant comparison is respected and the codes evolve to fit all data, knowledge from extant theory will not dominate, and the emerging theory will be grounded in the data" ( $p$ 247) [7].

In the current methodological discussion, the place of literature in grounded theory is controversial. Researchers frequently select the literature according to theoretical sampling, but they rarely describe their motivation, procedures or how the theoretical sampling of literature expands and densifies the emergent theory. There is little information for researchers about how to integrate the process of reviewing the literature, the theoretical sampling of it and constant comparative analysis with the emergent concept or substantive theory. Little is published on how literature can be used as data for input in the grounded theory analysis. The goal of this article is to describe how the literature was used to enhance a concept (within a substantive theory) in response to the emergent concept. In this article, we consider the literature as a third source of data which supplements our interview and observational data. Presumably conceptual indicators found in the literature should correspond with the interview and observational data in such a way that a substantive theory is still grounded in the participant's real world. 


\subsection{The study}

This study is part of an ongoing study regarding the autonomy of older adults with type 2 diabetes in a nurse-led setting [11-15]. The long-term purpose of this project is to identify what issues need particular attention to support patient autonomy in diabetes care provided by diabetes specialist nurses (DSN) and to formulate recommendations to promote patient autonomy on the individual and policy level. We investigate autonomy and its dimensions in the daily life of older adults with type 2 diabetes.

Previous research in this project shows that older adults with type 2 diabetes view their autonomy as "competency in shaping one's life" [11]. This includes recognizing possibilities and having the abilities, capacities, and expertise to enable people with diabetes to shape their own lives. In this context, the person with diabetes actively strives for the right autonomy based on his or her unique character, and is flexible with regard to changing health conditions and life situations. Various actions are initiated and completed daily, accordingly. These courses of actions are conceptualised as dimensions of autonomy. We found seven dimensions of autonomy: identification, self-management, welcomed paternalism, selfdetermination, shared decision-making, planned surveillance and responsive relationships. The diverse dimensions of autonomy are related to one another in various ways. The combination of the dimensions of autonomy is not fixed, but is rather a mix of what seems most appropriate at a given time. Each of the seven dimensions highlights one aspect of autonomy and specific processes supporting it. Here, we focus on the dimension planned surveillance to illustrate how literature was used in the analysis process to enhance this dimension (category).

The willingness of people with type 2 diabetes to agree to planned surveillance is the result of the fact that people want the reassurance of being watched over by DSN. Therefore, they stick to a regular follow-up plan. They know that planned surveillance offers a degree of control over diabetes. It is also used to prevent or detect secondary long-term complications at an early stage. Nurses monitor blood indicators, blood circulation and the patients' neurological condition, and assess the positive or negative effects of the patients' health-related behaviour on an on-going basis. Surveillance data not only determine the actions to be taken, such as improved conformity and modifications in the treatment regimen. They also show whether these actions are effective [11]. In addition, we pay attention to motivational factors which can affect the continuity of planned surveillance. Moreover, these conditional aspects [3] can influence the individual, social and professional relationships and organizations themselves. 


\subsection{The use of the literature as data}

We used three sources of data to develop the concept of planned surveillance and its underlying processes. The first and second sources of data were interview and observational data obtained from 15 older adults with type 2 diabetes mellitus [11]. The third data source was published literature obtained for the purpose of concept development.

Fifteen interviews were conducted and observational data were analyzed using the constant comparative method [3]. Prior to these, we had performed an initial, but not exhaustive, literature overview. After conceptual saturation of the interview and observational data occurred, we turned to the literature, again, to validate our findings against existing ideas. We theoretically sampled the literature in the light of the emerging concept. Our initial literature review focused on patient autonomy, in general. In the subsequent review we looked for literature on the processes that shape autonomy, here with regard to the dimension planned surveillance.

Our analysis revealed that the processes underlying planned surveillance are: exchanging information, reasoning and deciding. We used planned surveillance as the initial search term. However, our search in the literature yielded no results.

Since planned surveillance, by definition, involves on-going health care and entry into the healthcare system, we looked for literature on patient autonomy in relation to a variety of care settings: admission to nurse-led clinics, nursing homes, and residential care for the aged. We also considered the degree of patient involvement to be conceptually relevant. We are aware that the move to a nursing home is a stressful life event and differs from nurse-led clinics. However, when circumstances no longer enable independent living and admission to nursing services is indicated patient autonomy is at stake. We found literature related to the decisionmaking on entering a nursing home from the patient's and the family-caregiver's perspective, making care arrangement choices based on the patients' view and theoretical papers on entry decision-making. From this literature it became clear that the family members are significant others in this process. Based on these findings we reviewed our emergent concept in relation to the role of family which we had included in our analysis initially. We extracted conceptual indicators from the literature and compared them with the interview and observational data for similarities and differences. Given our desire to include these additional properties in the emergent concept, we enhanced the process step reasoning. We relabelled reasoning to "thinking it over" to indicate that it was not a process that people with diabetes do on their own but in an interactive manner with family members. We realized that family members played an important role in the other two process steps as well and added these properties. 
The literature on nursing service entry made us also aware of the position of physicians as "powerful others" with regard to the decision for nursing home placement. This was a hunch for us to check the hypotheses that health professionals have a major position in entry decision-making. We looked at the interview and observational data for information regarding the position DSN in the process related to planned surveillance. In addition, to providing information about the nurse-led programme, DSN also gather information about the patients' situation. Having a closer look at their participation we found out that exchanging information was broader than only providing and receiving information about healthcare. The encounter was found to be much more interactive than previously thought. It also included the beginning of the process of establishing the nurse-patient relationship. The process step, exchanging information was expanded to include all that was relevant, not just limited to programme information. We refined that process step as "getting to know each other: information gathering and relationship building. Then we turned our attention to the position of medical professionals. From the data we found that the role of general practitioners and medical specialists was quite different from that of the DSN. They decided on the patient's transfer within the shared-care programme, according to the patient's health condition and agreed upon procedures. We conceptualized this finding as "being the wrong patient" to receive diabetes care by certain medical professionals. Therefore, we added this sub-category. As we considered the newly added subcategory as different from the three existing process steps - getting to know each other: information gathering and relationship building, thinking it over and deciding - we constructed another sub-category "integrating various considerations" which conceptually covered these three process steps.

The emergence of the sub-category being the wrong patient includes that people with diabetes are transferred to the nurse-led clinic by medical professional based on the complexity of care needed and a changing health condition. These two factors dictate changes in the needed care. People with diabetes are not "suitable patients" to receive care by these medical professionals. This led us to search for literature that examined the transfer of older people between different settings in the healthcare system. Next, we looked at the literature concerning patient participation in transfer and discharge planning and the position of medical professionals in that process. The conceptual indicators we extracted from that literature were, again, compared for similarities and differences in the interview and observational data. Upon re-examining our analysis of the literature, and interview and observational data we found no new conceptual variation pertaining to the processes underlying planned surveillance. At this point we considered the concept of planned surveillance to be saturated (15 interviews, observational data and 37 publications). 


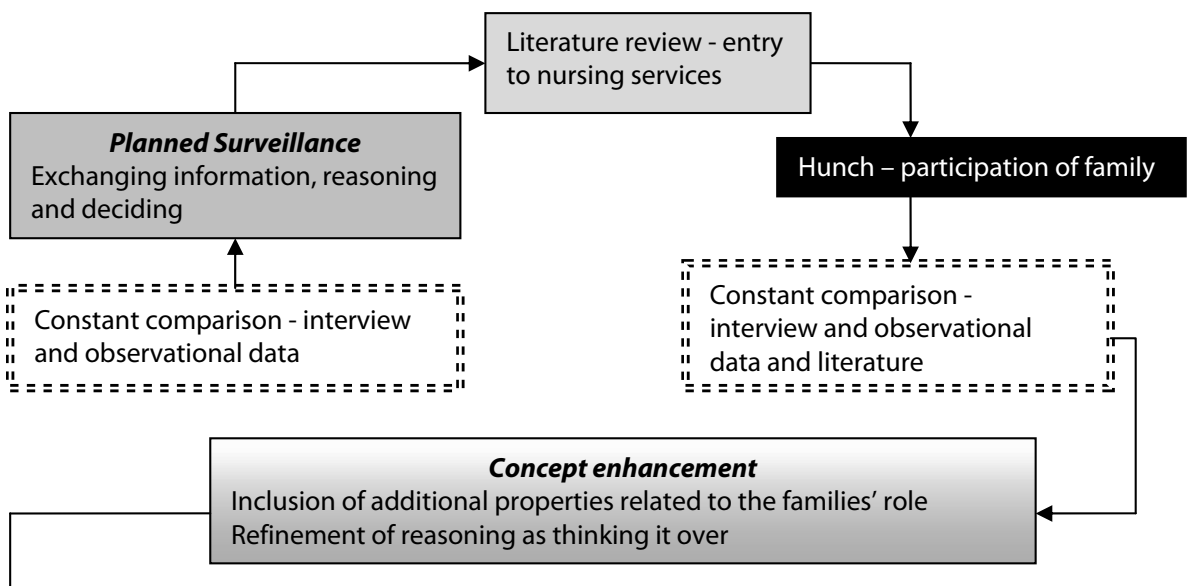

Hunch - position of health professionals

Literature review - role of medical professionals and nurses in entry decisions

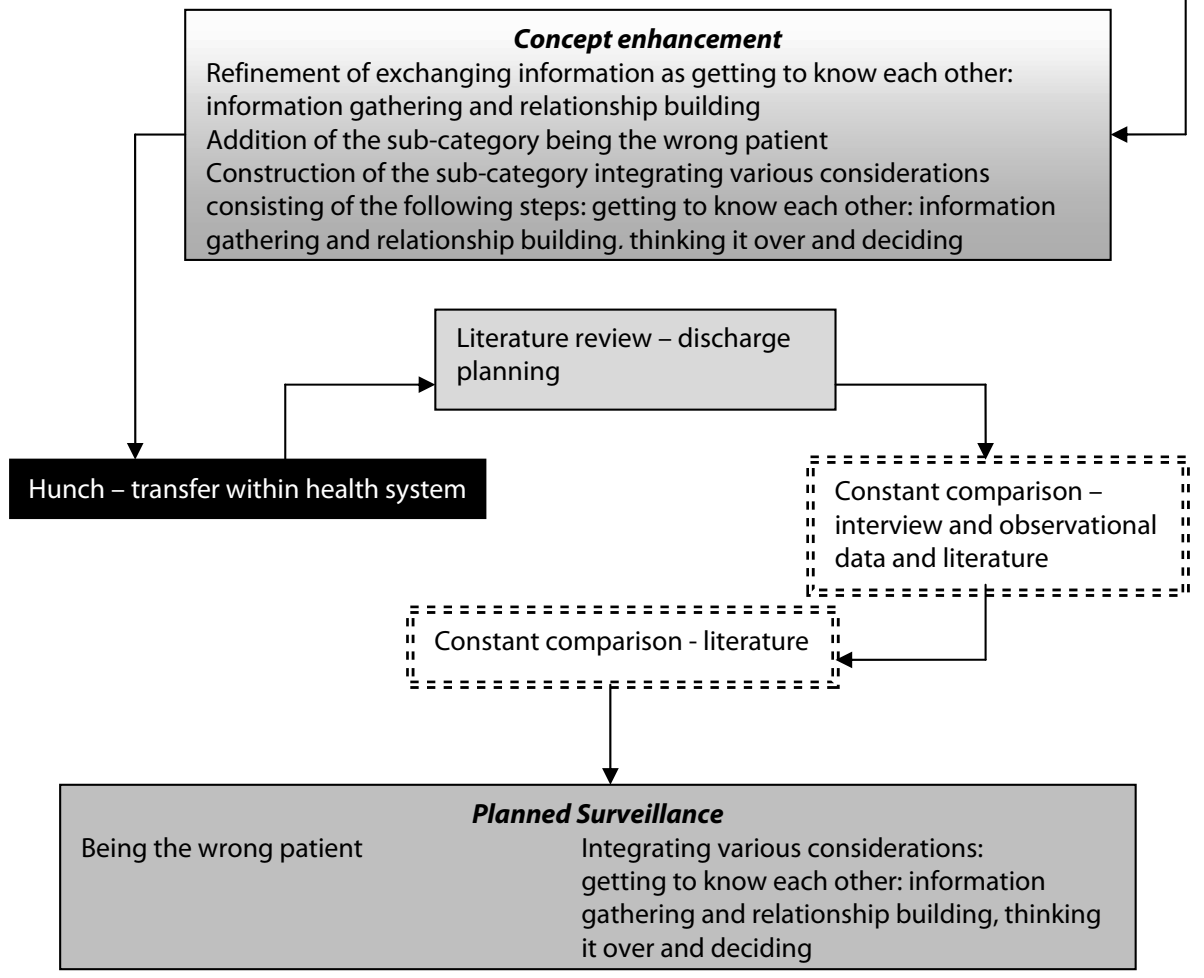

Figure 7.1 Analysis process 
In the literature we found various conceptual indicators that confirmed, changed or added sub-categories and properties to our emergent concept. For example, in an article [16] on the transfer from retirement village to residential care we found the conceptual indicator - need for more or different care or support service. This conceptual indicator was transferred in our study context to - the patient's health condition changed to a degree that DSN provided the most appropriate care. Not all conceptual indicators found, were used, such as availability of place (found in the same article). We excluded conceptual indicators from the constant comparative analysis which were deemed theoretically irrelevant. We did, however, apply the same process of analysis to the motivational factors to remain under planned surveillance.

Throughout the constant comparative analysis of interview and observational data and the literature, we wrote memos about the theoretical analysis of the emergent concept, its refinements and our theoretical sampling of the literature. These memos were a valuable source of data for our final report and also a valuable record of the somewhat "messy", non-linear process of analysis. Figure 7.1 provides a schematic outline of the analysis process.

\subsection{Trustworthiness}

In this grounded theory analysis, we assure credibility [17] by involving multiple methods of data collection, such as interview and observational data and theoretical and empirical literature (methodological triangulation). Several investigators were part of the study group and two or more investigators were involved in the data analysis and interpretation. Of the latter, one investigator analysed the data and a second one reviewed the analysis process and emergent concepts and process patterns; theoretical hunches were discussed in depth (investigator triangulation). In addition, during the period of data collection and analysis investigators held regular meetings (peer debriefing). In these meetings, general matters, such as concept development, were discussed. Different sources of information, the interview and observational data and the literature, were used to verify the emerging concept, category, sub-categories, process patterns and vice verse (data triangulation). We invested sufficient time to collect the data and to gain an in-depth understanding of the concept planned surveillance (prolonged engagement). We studied and observed the data from raw interviews and field notes and the literature until the concept emerged. We identified those aspects and conceptual indicators that were most relevant to the emergent concept of planned surveillance (persistent observation). Developing the codes, categories and sub-categories, selecting conceptual indicators from the literature and for- 
mulating hunches helped us to examine the characteristics of the data. We intensively studied the data, analysed them, theorized with them and revised the concept, accordingly. We coded recoded and relabelled codes and sub-categories. The researcher kept a reflective journal that documents personal experiences and reflections and the progress in the grounded theory analysis. Finally, we provide sufficient descriptive data (thick description) of our process of concept development so that readers can evaluate if the analysis process is transferable to their own research context.

\subsection{Findings}

People with diabetes name two processes that underlie planned surveillance: being the wrong patient and integrating various considerations. The process pattern underlying integrating various considerations is: getting to know: information gathering and relationship building, thinking it over and deciding. Participants name five motivational aspects to remain under planned surveillance: continuity in supervision, sustenance of care responsibility, safety, information supply, and necessity. These aspects are not isolated from each other. People with diabetes often mention several reasons for their willingness to continue longterm monitoring of their diabetes.

\subsubsection{Being the wrong patient}

Being the wrong patient means that people with diabetes perceived they are not considered being appropriate patients to be treated by medical professionals within the shared care setting. As congruent with previous findings [16, 18-23], the decision to enter a particular health service is made by someone other than the person with diabetes. Key players who assess the patient's healthcare requirement, and thus the healthcare setting, are either the general practitioner or the medical specialist. They participate in the shared care programme and know the organisation of the nurse-led clinics very well. A health-related event, $[16,19$, $20,24]$ may necessitate more or different care or support services [16], and do, therefore, influence the choice of medical options. The shift of a patient's treatment from medical professionals to treatment and monitoring by a DSN is, thus, precipitated by a health event. The physician transfers people with diabetes to the nurse-led clinics when the health condition and care requirements become more complex, for example, the treatment changes from taking oral medication to using insulin therapy. Medical specialists, such as internists or endocrinologists, are the primary case managers within the shared care model for patients who suffer from acute and serious diabetes-related health problems. The specialists transfers patients to the DSN when the health situation stabilized and becomes 
less complex. People with diabetes realize that the resulting transfer to a nurseled clinic is legitimate, but they do not welcome the shift away from the family physician or medical specialist, especially when they have a good relationship with them.

'The endocrinologist chose to transfer me back to the diabetes nurse. He said: Your diabetes is well regulated, good under control, and you can consult me at any time. It is well under control so it is better for you to be under surveillance of the diabetes nurse. This was not nice for me. I did not feel well because I had a good relationship with my endocrinologist. It was not nice for me but somehow I do understand. It was a logical step.'

\subsubsection{Integrating various considerations}

Some participants reach a well-considered and personal decision to enter a nurse-led clinic. People anticipate the admission to a nursing service and play an active role [20]. People with diabetes consider their personal views and medical facts. Often, they have additional conversations, discussions and interactions with family members and DSN.

\subsubsection{Getting to know: information gathering and relationship building}

Consistent with the literature the DSN's first contact is directed at giving patients programme information [20] and getting acquainted with each other [25]. The DSN explain the shared care model and the role and tasks of the nurse-led clinics to the prospective patient. Information includes the content of the programme, on-going follow-up visits, permanent monitoring of the health condition, and accessibility of healthcare providers. DSN also assess the participant's health condition and medical treatment. Asking questions [26] and seeking answers [27] is important in this phase to people with diabetes. They investigate the quality of nurse-led clinics in terms of the availability of the DSN. This is consistent with previous findings [19]. Participants also speak about their treatment plan, health condition and self-management strategies. People with diabetes consider the first contact as the starting point of their long-term relationship with the DSN. Several people with diabetes feel supported when a close family member accompanies them.

'I went there with my husband. She (DSN) told us how everything functioned, the regular visits, the regular blood checks and so on. We also spoke about my health status and why I got the call.' 


\subsubsection{Thinking it over}

After the meeting with the DSN patients take their time and think critically about the advantages and disadvantages of the nurse-led clinic. This is a period of rational thought, forward planning and exploration of feelings about this transition [20]. They gain a clear picture about proper expectations and the benefits to their health and life situation. They involve close family-members, take their point of view into consideration [16, 28, 29] and discuss alternatives [24].

I like the idea of being under surveillance. Then I know immediately if something goes wrong. My spouse liked the programme, too, and the idea that my nurse or her colleagues are accessible during the day. I can get hold of them if I need an advice or if I think something strange is happening.'

\subsubsection{Deciding}

Generally the people with diabetes in this study do not make the decision to go to the nurse-led clinic during the first meeting. They contact the DSN at a later point of time to inform them of their decision. Family members also encourage people to enter the nursing service [18-20] and they play a critical role by reinforcing and validating the patient's decision.

'I went home and I thought about the information the nurse gave me. I spoke with my husband about the programme. He also thinks that it is a good programme. So several days later, I phoned her to tell her that I had decided to become her patient.'

\subsubsection{Patients' motivation to remain under planned surveillance}

\subsubsection{Continuity in supervision}

The continuity of nursing care is an important issue to patients [19,27]. Patients appreciate the on-going supervision [19] by a DSN. The three-month cycles of check-ups are viewed favourably and are highly valued by literally all participants. For some people it is important to receive continuous feedback concerning the health condition, treatment and care. Others view continuous surveillance as a sort of warning system to detect a "danger signal" at an early stage. For them it is essential to identify negative behaviour and adverse health effects immediately. Some participants consider the timely and continuous adjustment of treatment as a motivation to submit to planned surveillance. Others pay attention to the competence and quality of service delivery by the DSN and staff. They consider the professionals' attitudes toward interactions with patients $[16,19]$ as impor- 
tant. People with diabetes appreciate the supervision of DSN for their broadfocused approach and reliable way DSN provided their service.

\subsubsection{Sustenance of care responsibility}

For some people with diabetes planned surveillance is a significant motivator to assume responsibility for the care of their diabetes. They consider the continuous character of the nurse-led clinics, especially the relatively short three-month cycles, as a kind of "structural" support to care for and manage the diabetes properly. Some people with diabetes are helped to exercise more self-control and stick to their healthcare regimen/requirements. They would not take care of the diabetes at all without regular consultations with the DSN. Continuous surveillance of diabetes measures, like glucose profiles, make patients accountable for their own diabetes care activities to DSN, which, too, serves as a supportive function.

\subsubsection{Safety}

As in previous research $[18,29]$, safety is found to be an important issue. Planned surveillance offers safety because the DSN are readily accessible on request during business hours. Patients value the quick availability of care [16] when needed. Some emphasize that this support from the DSN provides them with emotional safety and comfort, as well.

\subsubsection{Information supply}

Patients consider information supply to be vital [16, 18, 30,31]. Participants have confidence in the quality of information they receive. The trustworthiness and objectivity of the analysis of medical data and facts are reassuring to the patient as medical treatment can be adjusted, accordingly. In particular, the feedback of specific diabetes-related measures such as results of $\mathrm{HbA1c}$ is of uppermost importance to these people.

\subsection{Necessity}

The participants in this study view submission to nursing services as unavoidable, which is in line with the literature $[16,18-21,24,28,29,32,33]$. People with diabetes consider planned surveillance under a DSN as a must for their lives as diabetics. Some perceive that they do not have an alternative because of the chronic nature of the diabetes.

\subsection{Methodological implications}

Researchers should clearly communicate how they used the literature in their grounded theory studies and at what point in the data collection and analysis 
process it was used. When using literature as data they should integrate the literature in the findings as they present their theory. Researchers should verify that the theoretical hunches and conceptual indicators they find in the literature fit with the interview and observational data. This will ensure that they provide a "grounded" theory. Comparing interview and observational data and literature for differences and similarities ensures a proper constant comparative analysis, which is at the heart of ground theory. We theoretically sampled the literature and conceptual indicators after the data collection with participants was finished. We did not sample participants and literature parallel in the different coding phases. This raises the methodological question whether theories and concepts would be different if one uses the literature as data after the interview and observational data were collected as opposed to if the literature was sampled and analyzed simultaneously during the collection of interview and observational data. Would the literature be sampled differently and, therefore, yield different theoretical results? And if yes, what is the impact of the literature on concept and theory development during the different phases of coding?

\subsection{Practical implications}

A change in the health status, care requirements or treatment regimen may necessitate a change of healthcare provider. The DSN can provide patients with information when a transfer is necessary at the point of entry to nurse-led care. They should ensure that patients are involved in the process and avoid inadequate notification and discuss the option of transfer at an early stage. DSN should take initiatives at the policy level to make sure that patients are at the centre of the entry and transfer process. They should invite patients to participate in making guidelines and advocate that patient involvement is an explicit recommendation in agreed upon procedures. Finally, knowing the motivation of patients to remain under planned surveillance will help DSN to focus their service provision on aspects of care that will meet the patients' diabetes care needs most adequately.

\subsection{Conclusion}

In this article we described how the literature was used to develop the concept of planned surveillance further in response to the emergent concept. We illustrated how literature as data was used in the grounded theory analysis and how the literature was theoretically sampled based on the emergent concept during the constant comparative analysis. The evolving concept has been deepened and 
expanded in response to the new information from the literature. The strength of a substantive theory is that it is modifiable [6]. We conclude that integrating interview and observational data and literature in the process of constant comparison enhances and densifies grounded theories. 


\section{References}

1. Guba, E.G. and Y.S. Lincoln, Naturalistic Inquiry. 1985, Newbury Park: Sage.

2. Charmaz, K., Constructing grounded theory. A practical guide through qualitative analysis. 2006, London: Sage.

3. Strauss, A. and J. Corbin, Basics of qualitative research: grounded theory procedures and techniques. 1990, Newbury Park: Sage.

4. McGhee, G., G.R. Marland and J. Atkinson, Grounded theory research: literature reviewing and reflexivity. Journal of Advanced Nursing, 2007. 60(3): p. 334-342.

5. Glaser, B.G., Emergence vs Forcing. Basics of Grounded Theory analysis. 1992, Mill Valley: Sociology Press.

6. Wuest, J., Negotiating with helping systems: An example of grounded theory evolving through emergent fit. Qualitative Health Research, 2000. 10(1): p. 51-70.

7. Wuest, J., Grounded theory: the method, in Nursing Research. a qualitative perspective, P.L. Munhall, Editor. 2007, Jones and Bartlett: Sudbury, MA. p. 239-172.

8. Richards, L. and J.M. Morse, Read me first for a user's guide to qualitative methods. 2nd ed. 2007, Thousand Oaks: Sage.

9. Glaser, B.G., Theoretical sensitivity. Advances in grounded theory. 1978, Mill Valley: Sociology Press.

10. Drauker, C.B., D.S. Martsolf, R. Ratchneewan and T.B. Rusk, Theoretical sampling and category development in grounded theory. Qualitative Health Research, 2007. 17(8): p. 1137-1148.

11. Moser, A., H. Van der Bruggen and G.A.M. Widdershoven, Competency in shaping one's life: Autonomy of people with type 2 diabetes mellitus in a nurse-led, share-care setting; a qualitative study. International Journal of Nursing Studies, 2006. 43: p. 417-427.

12. Moser, A., H. Van der Bruggen, G.A.M. Widdershoven and C. Spreeuwenberg, Autonomy through identification: a qualitative study of the process of identification used by people with type 2 diabetes. Journal of Clinical Nursing, 2008. 17(17 (7b)): p. 209-216.

13. Moser, A., R. Houtepen and G.A.M. Widdershoven, Patient autonomy in nurse-led shared care: $a$ review of theoretical and empirical literature. Journal of Advanced Nursing, 2007. 57(4): p. 357365.

14. Moser, A., H. Van der Bruggen, G.A.M. Widdershoven and C. Spreeuwenberg, Self-management of type 2 diabetes mellitus: a qualitative investigation from the perspective of participants in a nurseled, shared-care programme in the Netherlands. BMC Public Health 2008. 8: p. 91.

15. Moser, A., R. Houtepen, H. Van der Bruggen, C. Spreeuwenberg and G.A.M. Widdershoven, Autonomous decision making and moral capacities. Nursing Ethics, 2009. 16(2): p. 203-218.

16. Cheek, J., A. Ballantyne, L. Byers and J. Quan, From retirement village to residential aged care: what older people and their families say. Health and Social Care in the Community, 2006. 15(1): p. 8-17.

17. Lincoln, Y.S. and E.G. Guba, Naturalistic Inquiry. 1985, Newbury Park, CA: Sage Publications Inc.

18. Cheek, J., A. Ballantyne and G. Roder-Allen, Factors influencing the decision of older people living in independent units to enter the acute care system. International Journal of Older People Nursing in association with Journal of Clinical Nursing, 2005. 14, 3a: p. 24-33.

19. Johnson, R.A., V.B. Schwiebert and P.A. Rosenmann, Factors influencing nursing home placement decisions. Clinical Nursing Research, 1994. 3(3): p. 269-281.

20. Nolan, M., A.J. Walker, J. Nolan, S. Williams, C. Curran, and B.C. Kent, Entry to care: positive choice or fait accompli? Developing a more proactive nursing response to the needs of older people and their carers. Journal of Advanced Nursing, 1996. 24: p. 265-274.

21. Victor, C.R., E. Young, M. Hudson and P. Wallace, Whose responsibility is it anyway? Hospital admission and discharge of older people in an inner-London District Health Authority. Journal of Advanced Nursing, 1993. 18: p. 1297-1304.

22. Dill, A.E.P., The ethics of discharge planning for older adults: an ethnographic analysis. Social Science and Medicine, 1995. 41(9): p. 1289-1299. 
23. Jewell, S.E., Discovery of the discharge process: a study of patient discharge from a care unit for elderly patients. Journal of Advanced Nursing, 1993. 18: p. 1288-1296.

24. Davis, S. and M. Nolan, 'Making the best of things': relatives' experience of decisions about carehome entry. Ageing and Society, 2003. 23: p. 429-450.

25. Bull, M.J. and J. Roberts, Components of a proper hospital discharge for elders. Journal of Advanced Nursing, 2001. 35(4): p. 571-581.

26. Bull, M.J., Patients' and professionals' perceptions of quality in discharge planning. Journal of nursing Care Quality, 1994. 8(2): p. 47-61.

27. Bull, M.J., H.E. Hansen and C.R. Gross, A professional-patient partnership model of discharge planning with elders hospitalized with heart failure. Applied Nursing Research, 2000. 13(1): p. 19-28.

28. Jenkins, C.L., Care arrangement decision for frail older women: quantitative and qualitative perspectives. Journal of Women \& Aging, 2000. 12(3/4): p. 3-20.

29. Jenkins, C.L., Care arrangements choices for older widows: decision participants' perspectives. Journal of Women \& Aging, 2003. 15(2/3): p. 127-143.

30. Roberts, K., Exploring participation: older people on discharge form hospital. Journal of Advanced Nursing, 2002. 40(4): p. 413-420.

31. Gilmartin, J., Contemporary day surgery: patents' experience of discharge and recovery. Journal of Clinical Nursing, 2007. 16: p. 1109-1117.

32. Davis, S. and M. Nolan, 'Making the move': relatives' experience of the transition to a care home. Health and Social Care in the Community, 2004. 12(6): p. 517-526.

33. Lundh, U., J. Sandberg and M. Nolan, 'I don't have any other choice': spouses' experiences of placing a partner in a care home for older people in Sweden. Journal of Advanced Nursing, 2000. 32(5): p. 1178-1186. 



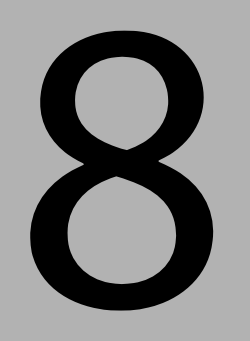

\section{Responsive relationships}

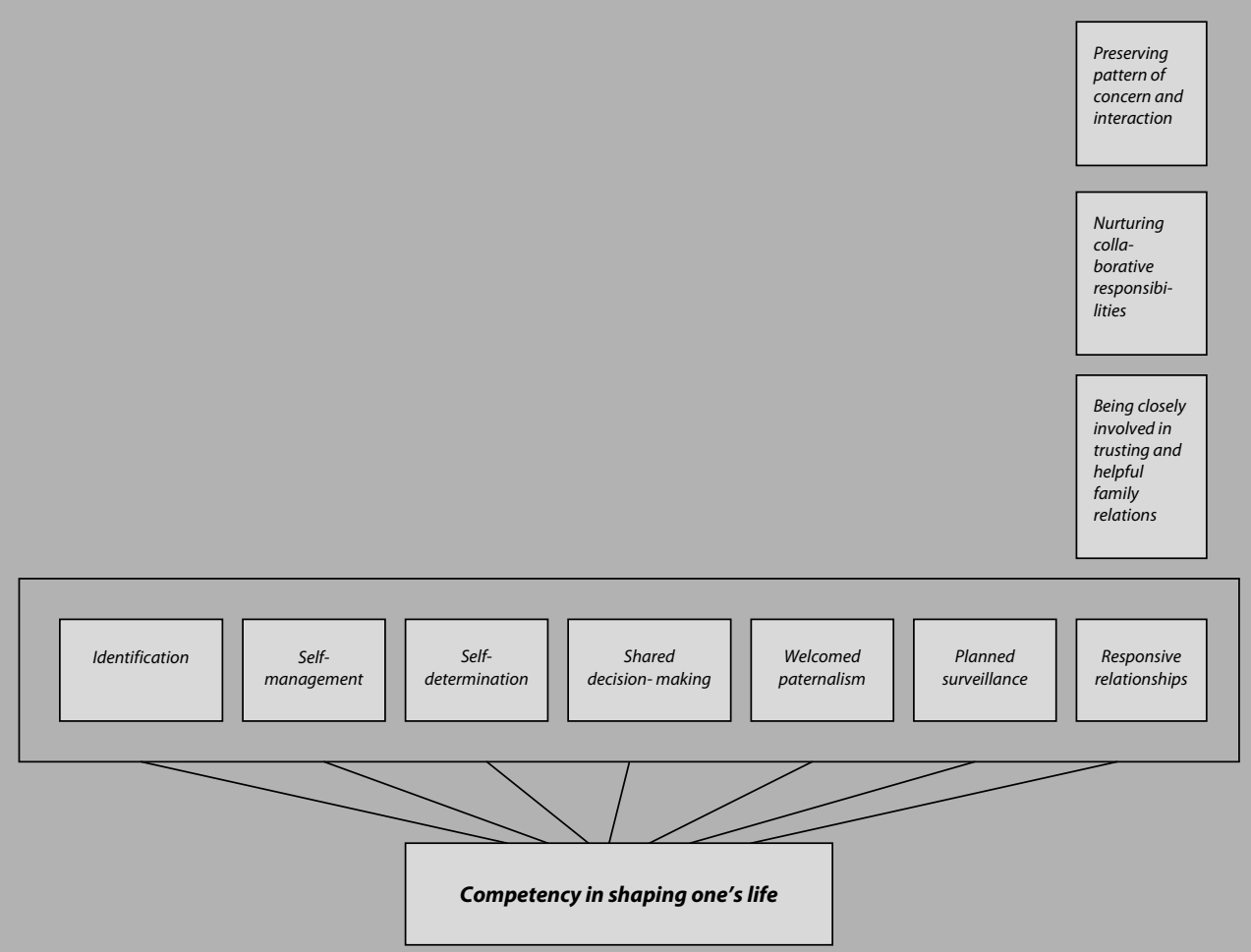




\section{Abstract}

The goal of this chapter is to augment the ethical discussion among nurses with the findings from our empirical research on autonomy of older adults with type 2 diabetes mellitus. We performed a literature review of care ethics and caring in nursing with regard to relational autonomy. We classified the literature in five strands of care: attitude-oriented, dialogue-oriented, activity-oriented, relationship-oriented and life-oriented. Fifteen older adults with type 2 diabetes mellitus were interviewed in a nurse-led diabetes clinic. These participants perceive three processes of their autonomy in their responsive relationships: preserving patterns of concern and interaction, nurturing collaboration responsibilities and being closely involved in supportive and helpful relations. People with diabetes realize autonomy in various responsive relationships in their unique life context. They can best realize their autonomy in relationships with others when several essential aspects of care and caring are present in their lives. Therefore, we advocate a comprehensive approach to care and caring. 


\subsection{Introduction}

Chronic illness such as diabetes may change peoples' lives dramatically. Living with diabetes means having to care for one's health in a situation of threatened autonomy. People with diabetes have to negotiate autonomy in their daily activities [1] and in their relationships with professionals and family [2]. They need collaborative relationships and support [3-6]. This chapter focuses on autonomy within responsive relationships between older adults with diabetes and diabetes specialist nurses (DSN), health professionals and family. The goal is to contribute to the theoretical and ethical discussion using findings from this empirical research on the autonomy of older adults with type 2 diabetes mellitus. First, we will introduce the findings of a larger grounded theory study, on which our interpretation of autonomy in responsive relationships is based. Then we will describe five strands of care and caring based on a literature overview. Next, we present our empirical findings in which we portray how older adults with type 2 diabetes realize their autonomy in responsive relationships with others. Finally, we discuss our findings in the light of the literature reviewed.

\subsection{The research project}

This study is part of a larger research project regarding the autonomy of older people with type 2 diabetes mellitus in a nurse-led clinic [7-10] The purpose is to identify what issues need particular attention to support patient autonomy in diabetes care, provided by DSN and to formulate recommendations to promote patient autonomy on the individual and policy level. A finding from earlier research is that older adults with type 2 diabetes perceive their autonomy as 'competency in shaping one's life'[7]. Competency is the individual repertoire of skills that includes recognizing possibilities and having the abilities, capacities, and expertise that enable people with diabetes to shape their own lives. Older adults with diabetes initiate and complete various actions daily, which are conceptualized as dimensions of autonomy. To shape one's life with diabetes means that a person with diabetes actively strives towards an autonomy that is right for this particular person in a particular situation; it is based on characteristics that are unique to the person, and it is flexible in changing health conditions and life situations. Shaping one's life is a construct combining several dimensions of autonomy. The synthesis of diverse dimensions arises in various ways. There are many factors influencing autonomy and the contexts in which shaping one's life occurs. These include: health conditions, treatment, knowledge, experience and skills, personal approach as well as familial patterns, type of relationship, life his- 
tory and social context. Thus, the combination of the dimensions of autonomy is not fixed, but rather a mix of what is most appropriate at a given situation.

In this article we focus on autonomy in responsive relationships [7] which evolves through social interactions and includes reacting to each other's thoughts, feelings, concerns, and habits. Certain behavioural rituals or patterns emerge from these interactions. Verbal and non-verbal cues flow freely between people with diabetes and their nurses, other professionals and their family caregivers which help guide decisions and activities, resulting in outcomes that suit the situation and relationships best. Decisions are made both explicitly and implicitly as the relationship unfolds. Responsibilities towards each other are presumed [7].

\subsection{Literature overview}

In recent years, there is a growing interest in the relational aspects of autonomy, usually associated with care ethics. Gilligan [11] was a pioneer of an ethic of care which centres on the moral understanding of responsibilities and relationships. Receptivity, relatedness and responsiveness [12] are at the core. In past decades this stance has taken on several forms. The departure point for our literature overview was to find publications that related to autonomy as realized in responsive relationships. We started with literature in the field of care ethics. Then, we extended our review to nursing with caring as the central focus. Next, we included literature beyond the field of ethics and caring that highlighted relational aspects. We classified the literature into five relational contexts in which caring takes place: attitude-oriented, dialogue-oriented, activity-oriented, relationshiporiented and life-oriented. Due to the overlap and interrelatedness of the theories we were careful to categorize this heterogeneous sample according to the major theoretical focus of the authors. For example, Gastmans [13] relates caring attitudes of nurses to life as a whole. We could have classified this theory as lifeoriented. However, since he primarily emphasizes the nurse's attitude we chose to place it in the attitude-oriented strand. In this way we identified the essential focus of the authors and at the same time highlighted the diversity of these theories.

An attitude-oriented care ethic views care as a personal quality or virtue. Verkerk [14] highlights attitudes such as commitment and attentiveness to the needs of the patients. Nurses should take an active and committed role following and directing patients when necessary. Hagerty and Patusky [15] describe four qualities that are essential to establish relatedness in relationships: sense of belonging, reciprocity, mutuality and synchrony. Gastmans [13] defines caring as a moral 
attitude, as a sensitive and supportive response of a nurse to the situation and circumstances of a vulnerable human being who is in need of help. He links the characteristics of a good nurse to the concepts of a good person and a good life. Responsible nurses develop a caring attitude throughout their life which is expressed in a unique way by each individual given their personality traits [13]. In comparison, Verkerk [14] and Hagerty and Patusky [15] mention attitudes only in relation to the profession of nursing. Nurses support patient autonomy by exhibiting and cultivating such traits and attitudes as commitment and reciprocity.

Whereas attitude-oriented theories focus on the nurses' individual characteristics, dialogue-oriented theories center on the communicative processes among those who belong to the patients' network. Some conceptualize dialogical autonomy in the care [16] and nursing [17, 18] context. Widdershoven [16] defines dialogical autonomy as participating in care, including decision-making, while Krouse and Roberts [18] define it as a final agreement in a decision made by agreement from the care-receiver and the nurse. In the family-patient relationship the autonomy of all family members should be respected by means of family dialogue [19] or family conferences [20]. This provides opportunities for all participants to articulate their perspectives, air disagreements, and empathically perceive others' viewpoints [19]. Donchin [19] points out that in the process of realizing autonomy the patients' wishes need to take precedence, while Kuczewski [20] claims that all family members who are involved in the patient's care should participate in the dialogue. Hardwig [21] argues that family members assist the patients in interpreting their values and translating them into treatment preferences. The key point is that autonomous patients actively take part in dialogue concerning healthcare decisions in the care, nursing and family contexts.

While dialogue-oriented theories focus on communication processes, an activityoriented strand emphasizes the activity of care itself in interactions with others. According to Struhkamp [22] care happens in the day-to-day work in institutional settings and in the interaction with professional and non-professional care-givers. For Mol [23], care means actorship. Professional actorship happens in the medical environment and patients take on actorship in daily life. Actorship is fluid and reciprocal since taking care of and being cared for alternate. The actors' roles are interdependent. Professionals cannot make an effective treatment plan if patients do not carry out the appropriate care activities. Acting means one provides care, tries out different treatments, tinkers, adjusts, with an uncertain outcome. In this sense, care as an activity is a continuous process. Struhkamp [22] claims that autonomy is realized through care activities to support the continuity of the biography and authentic life-style of patients at many locations, while Mol [23] concentrates on the consultation room. The main point to be drawn from these is 
that the process of patient autonomy takes shape by continuously carrying out certain care activities in an interactive manner in several contexts.

The relationship-oriented strand differs from the previous one because the relationship is not solely based on the activity of care but is characterized by being engaged with one another. At this point we focus on the nurse-patient relationship. Parker [24] describes a nurse-patient relationship as the co-construction of meaning between nurses and patients. As the journey unfolds, the nurse and patient are mutually receptive to change, and both are aware that the final destination remains open to negotiation. According to Tarlier [25] a caring nursepatient relationship encompasses three elements: respect, trust and mutuality. Mutuality is a negotiation process between the nurse and patient as the relationship develops. Tarlier [25] relates negotiation to the construction of the relationship, whilst Parker [24] considers negotiation to be the final outcome. Peplau [26] conceptualizes the nurse-patient relationship as a process to solve health problems: at one end are two people with separate goals and interests, and at the other end, two people working together to solve a health difficulty about which there is a common understanding. According to Watson [27] a transpersonal caring relationship begins when nurses enter into the phenomenal field of patients, are able to detect the patients' state of being, empathize, and respond to the condition in such a way that it evokes the patients' feelings and thoughts. Watson [27] puts the patient into a receiving role. This is in contrast to the other theorists who focus on negotiation and common understanding. The essence is that patients are involved in and give shape to their relationships with nurses. These relationships encompass attitudes, dialogue and activities.

The relationship-oriented strand focuses on the nurse-patient relationship whereas the life-oriented strand refers to the context in which people live. Tronto [28] defines care in its broadest sense, as activities that include everything we do to maintain, continue and repair our world. Care is an ongoing process in a certain context which includes the micro, meso and macro level as well as the private and public sphere. The caring process consists of four phases: caring about, taking care of, care-giving and care-receiving. From these four process phases, four ethical qualities arise which make care a moral practice: attentiveness, responsibility, competence and responsiveness. Thus, care is both a practice and a disposition. While Tronto focuses on care in the broadest sense, Friedemann and Köhlen [29] are more specific and relate it to the family context. The theory of family and environmental nursing [29] describes three levels of family: individual family members, the interpersonal level and the family system level. The last one includes structural and functional system components interacting with the broader environment which influence family systems. The goal of all interventions are 
family system change [30]. In family nursing, care is not delivered but actively shaped together with the family system. Nursing care starts with building relationships with the members of the family system and nursing goals are shared [30]. In this strand, the essence of realizing autonomy is that patients are part of the (nursing) care process. In sum, these strands provide various care perspectives on the process through which patients can realize autonomy in responsive relationships with others.

\subsection{Method}

To explore the process of autonomy in responsive relationships as described by older adults with type 2 diabetes mellitus we undertook an exploratory, qualitative study. We applied our theoretical orientation, symbolic interactionism [31], to study people's social interactions and the process of meaning-making with regard to autonomy in responsive relationships with others. We also used the grounded theory method [32] which is an inductive, from-the-ground-up approach, that uses everyday behaviours to generate a theory about a particular phenomenon [32]. Grounded theory provides a way to go beyond experience to move it from description of what is happening to understanding the process by which it is happening [33].

All 15 participants in this study were Dutch and lived in or around the city of Maastricht. These older adults had a confirmed diagnosis of type 2 diabetes and a stable but complex health condition. They were living independently at home, were enrolled for at least 1 year at the nurse-led shared-care unit, were capable of completing an interview of about 1.5 hours, and without cognitive impairment or severe geriatric symptoms (diagnosed by a physician). Newly diagnosed patients, Type 2 diabetes patients living in assisted-living housing arrangements or with cognitive impairment and severe geriatric symptoms (diagnosed by a physician), and elderly type 1 diabetic patients were excluded.

The DSN sent people with type 2 diabetes an information letter that included information about the research and asked consent for forwarding their personal data to the researcher. After sending this letter, the DSN contacted the patients to ask whether these data could, indeed, be given to the researcher. Then, the researcher approached these people to see if they were willing to participate and to make interview appointments. All those contacted by the researcher agreed to participate. The participants gave written informed consent prior to the interviews. The respondents were assured that interview data would be dealt with confidentially. Anonymity was secured by code-numbering the interviews. The 
Ethics Commission of University Hospital Maastricht and Maastricht University gave ethical approval.

Fifteen in-depth interviews took place and all participants were interviewed at home so that the environment was comfortable and familiar to them. The interview guide consisted of open-ended questions directed towards aspects of autonomy related to daily life in its broadest sense, like "How would you describe your visit to the nurse?" "How is your spouse involved in the care of your diabetes?" Participants were encouraged to provide examples to support their statements and researchers asked follow-up questions. For the married participants, questions regarding the spouse's involvement were: "What were his/her tasks?" or "Who took the initiative to deal with things in that way?" The interviews were tape-recorded and transcribed verbatim. Field notes were taken of observations and impressions during the interview and of the informal talk after each interview.

Using grounded theory, theory arises inductively from the interview data and deductively through a constant comparative method [32]. We broke the data into smaller parts. Every line was coded using open codes that were often descriptions used by the participants. We made as many codes as possible to ensure broad coverage. Next, we compared and contrasted the incidences and codes and grouped them into categories. We made sure that categories included similar incidents and codes, yielding increasingly complex and inclusive categories. The phenomenon represented by the category was given a conceptual name. Subsequently, we employed axial coding. We put the data back together in new ways by making connections between the categories and sub-categories. Next, we used selective coding to select the core category and related it to the other categories. Finally, we integrated the data to form a substantive theory. Theoretical sampling [32] involved asking specific questions about the emerging codes and categories in subsequent interviews. First, we asked general questions, and later, more focused ones. Memos were written throughout the analysis process. After analysis of 12 interviews, saturation occurred. The remaining 3 interviews were used to be sure that no new categories emerged. The analysis resulted in a substantive theory of patient autonomy.

\subsection{Findings}

People with type 2 diabetes mellitus identify three processes which support their autonomy in responsive relationships: preserving patterns of concern and interaction, nurturing collaborative responsibilities, and being closely involved in 
trusting and helpful family relations. The first two processes relate to the healthcare context and the ladder to the family environment.

\subsubsection{Preserving patterns of concern and interaction}

The nurse-patient relationship is a responsive relationship which develops over time. Both parties are engaged and give shape to this process. These older adults with diabetes feel the concern which DSN bring to their healthcare. A certain mode of interaction develops and responses to these interactions steer that relationship. Responses can be verbal as well as non-verbal, like eye contact or nodding to acknowledge a patient's experiences, or physical, such as the performance of care activities. The DSN and the person with diabetes agree, explicitly or implicitly, on care and treatment requirements, in terms of routines and habits, by communicating or interacting with each other. The nurse and the patient then know each other's responsibilities and requirements and act accordingly.

'The visit is always the same. We have found a rhythm. If things are fine it does not change. She asks: How are you? Have there been any noteworthy things since the last visit? Then we check the blood results and sugar profiles. Once a year she checks on my feet. She also asks: When will you see the ophthalmologist? Then I tell her when I have scheduled the appointment. Since I know that she asks about the ophthalmologist, I make regular appointments. She writes it down in my file. She is really concerned about the care of my diabetes. But I also do my best to make sure that things are as well as can be. We have become a good team.'

\subsubsection{Nurturing collaborative responsibilities}

People with diabetes also develop a responsive relationship with other health professionals who have a stake in their care. In the nurse-led clinics, various healthcare professionals from different disciplines and settings work together as a team based on a distinct set of responsibilities. In daily practice, care responsibilities are a coordinated series of (care) activities that are defined and agreed upon among the diabetes team members. The care process, thus, involves many health professionals that are part of the diabetes team. The number of members of the health team of individual patients is not static. Depending on the health of the patient, different professionals are involved at different times. If a person with diabetes needs additional care, such as dietary advice, for example, the dietician becomes a member of the diabetes team, sometimes permanently and sometimes temporarily. Patients and health professionals collaborate and take on care responsibilities as appropriate. This is possible in the nurse-led clinic because the various professionals value and appreciate each other's contributions to the team 
effort, each with their own professional and relational responsibilities with regard to the patient.

'My nurse discusses my health and treatment with my GP. Once, while I was at the GP I asked if they could check my blood pressure. Next, the doctor's assistant also checked my blood sugar level. That day my sugar level was high. The day after (name of diabetes specialist nurse) called and said: I got a phone call... I think it is very exceptional that the assistant of my GP contacted (name of diabetes specialist nurse) and that she got back to me. This is special. I appreciate that.'

\subsubsection{Being engaged in trustful and helpful family relations}

Responsive relationships with family members differ from those with professionals. In the family-patient relationship a responsive relationship has developed over many years. In such a relationship, the person with diabetes and the family member, usually the spouse, trust each other. Both are engaged with each others' concerns. The amount of involvement depends on the given situation and what family members consider appropriate within that relationship. In some cases spouses are not too involved while in other cases or circumstances spouses are very closely engaged. It varies accordingly and in any case, family members assume responsibilities.

'He (husband) is very close engaged. We have always been very close and we do everything together. He always helps me. In the morning I get up, I inject insulin, I prepare breakfast and then I take my medication. This is my part. During the day we do nice things together like visiting our grandchildren. In the evening he assumes responsibilities. He cooks and when he is ready he says: The meal is almost done. I inject insulin and then we have dinner.'

The family context is full of relational patterns in which the issue of autonomy is inherent. The extent to which responsibility is assumed by the patient and family member is the extent to which the person with diabetes is autonomous in that relationship. Often spouses deal with diabetes care issues as they deal with other care issues within the family context. This seems natural for spouses who have known each other for a long time and share a common past. In most cases diabetes care responsibilities and tasks are integrated seamlessly into these responsive family relationships and are embedded in the daily diabetes care routine, accordingly. 


\subsection{Discussion}

We investigated how older adults with type 2 diabetes mellitus perceive autonomy in responsive relationships with others. Autonomy is promoted and maintained in these supportive relationships. This process is dynamic and may vary from situation to situation and relationship to relationship.

Three kinds of responsive relationships are highlighted in this study: the person with diabetes with DSN, other professionals in the healthcare team and the family. Nurse theorists [25-27] primarily focus on the nurse-patient relationship since caring is seen as the essence of nursing as expressed in the nurse-patient relationship. They consider the broader patient context as relevant but do not specify it. This is surprising since some nurse scholars claim that nurses pursue "holistic" caring [27, 29, 30]. Exceptions are Friedemann and Köhler [29] who state that family nursing is an integral part of all fields of nursing. They also consider the broader environment, such as the community in which a family lives, to be important in family system nursing care. Philosophers have already acknowledged that relational autonomy happens in different contexts. Some [16, 22] relate it to the context of health care institutions and the patients' private environment. Gastmans [13] links caring attitudes of nurses to life as a whole and Tronto [28] relates caring to everything people do. People with diabetes have a unique life context and unique responsive relationships within which they realize their autonomy.

As our second segment shows, that patients exercise their autonomy in responsive relationships by nurturing collaborative responsibilities with the heath team. The organization of chronic care has become increasingly specialized and fragmented: a number of professionals work together to care for one chronically ill patient. Organizational arrangements are important to realize autonomy in relations with other [22, 28]. According to Mol [23], care has no defined boundaries, it is an open process that takes place in a care team with a variety of tasks. Patients are also participants in the care team. She underscores that it is important to clarify what task is done by whom. Verkerk [14] is more specific about the division of tasks: the nurse's responsibility is to be attentive to the needs of the patients and patients should be responsive to the care received. Tronto [28] provides the most comprehensive view of the division of tasks. She differentiates between four phases. In the first three phases, it is the professionals and informal care providers who take on responsibilities. The last phase focuses on care-receiving, the patient's response to the care received. Tronto [28] points out that these phases may occur at different levels of the health care system and that the care-giving process is only complete if all phases are well integrated into a whole. When this 
is the case, then people with diabetes receive autonomy in nurturing collaborative responsibilities.

As is clear from our third segment, patient autonomy in responsive relationships is not necessarily dialogue-oriented, although conversation and dialogue are part of it [16]. In the family context the extent to which autonomy is realized is influenced by the particular pattern of interaction. It is less overt in communication processes but more apparent in care activities that typify the specific relationship. In general, dialogical care ethics tends to give too little attention to the nature of the care work being given although Widdershoven [16] advocates a broader notion of dialogue. Family-care-giving is becoming increasingly important since more and more people with chronic conditions will rely on the help of family members. If nurses want to provide good care, they should take on the challenge to facilitate responsive relationships in families. Ideally, nurse scholars should move away from nurse-focused theories and towards patient-centered theories [34] in which family and the patient's life context become additional facets of the nurse-patient relationship. By definition, family relationships precede relationships with professional caregivers and are, thus, a natural context wherein the patient exercises autonomy.

There are four elements that older adults with diabetes consider as important resources: the distribution of responsibilities, relational patterns, character traits and care activities. The realization of autonomy relies on situational factors at any given time, for example, health situation or context. Furthermore, due to the dynamic nature of a patient's situation, the responsibilities of patients, professionals and family members may be redefined and change accordingly. Autonomy in responsive relationships brings into play those parts of care that do not centre on decisions but are vital to the patients' exercise of autonomy. Autonomy is broader than exercising authority in decision-making situations [22] and it is not necessarily an explicit agenda item. In contrast, our findings show that autonomy is embedded in relational pattern and is subtle, implicit, less conscious and less directive. In our study, older adults with diabetes also draw on caring traits and care activities. For example, we interpret preserving patterns of concern and interactions as a combination of character traits (preserving patterns of concern) and care activities (preserving patterns of interaction). Both are interconnected and necessary to realize autonomy. A trait is an attitude to sustain a relationship with an older adult with diabetes. A care activity is an action related to diabetes care. The action might be practical, such as performing the actual care intervention, but it also includes actions such as having conversations or listening. Depending on the context of the responsive relationship, a specific trait is at the foreground and that trait influences care activities that need to be carried out. 
Caring actions have an ethical value in light of the quality of the caring attitude [13]. Tronto [28] points out that care is a practice and a disposition and both must be present. Struhkamp [22] and Mol [23], consider caring primarily as a practice which, in our view, is too restricted to the notion of practical and technical competence. Nursing is, indeed, a practical, hands-on job [35] and caring can be enhanced if one also develops a caring attitude. However, we think that caring work cannot be done without a caring attitude.

Most theories cover some aspects that are important to patients with diabetes to exercise their autonomy in relationships with others. Our findings presented in this study point to the necessity of an inclusive theory, such as Tronto's, in order to do justice to the different social contexts in which autonomy is realized and in which people play an imperative part in the autonomy process. In addition, people with diabetes perceive that autonomy in responsive relationships can only be realized when a caring attitude accompanies a care activity. Finally, autonomy is promoted in a supportive and responsive environment. At the same time, responsibilities are assumed or shared.

\subsection{Conclusion}

In this study we investigated how older adults with type 2 diabetes realize responsive relationships as a dimension of autonomy. We found several processes, namely, preserving patterns of concern and interaction, nurturing collaborative responsibilities, and being engaged in trustful and helpful family relationships that influence the dynamic of that specific relationship. The issue of autonomy in responsive relationships is not confined to a specific health care practice but is an aspect of several relationships within the patient's life context.

According to our respondents, realizing autonomy in responsive relationships takes place when patient, nurses, professionals of the health care team and family members carry out care activities supported by a relational attitude of care. People with type 2 diabetes can best realize autonomy in responsive relationships when there is an integration of both relational caring traits and care activities.

Theories of care and caring in our overview focus on attitude, dialogue, activity, relationships and life as a whole. The majority of theories tends to centre on one aspect of care and caring which is considered to be essential to good care. However, patients with diabetes can best realize their autonomy in relationships with others when several essential aspects of care and caring are present in their lives. Therefore, we advocate a comprehensive approach to care and caring. 
It is important for nurses (and other professionals involved in diabetes care) to cultivate their relational caring attitudes and express them in their nursing to successfully support patient autonomy in their responsive relationships. Nurses sometimes work in an environment that is not conductive to the cultivation of deeper, caring relationships with their patients due to their heavy work load and time constraints. Ideally, nurses should take on the responsibility to request adequate resources and time. Efforts should not remain at the individual or team level but should be extended to the various policy levels. This is not easy to accomplish since it is at odds with the current policy of 'production in minutes'. 


\section{References}

1. Ingadottir, B. and S. Halldorsdottir, To discipline a "dog": the essential structure of mastering diabetes. Qualitative Health Research, 2008. 18(5): p. 606-619.

2. Williams, G.H. and P.H.N. Wood, Coming to terms with chronic illness: the negotiation of autonomy in rheumatoid arthritis. International Journal of Disability Studies, 1988. 10(3): p. 128-133.

3. Paterson, B., S. Thorne and M. Dewis, Adapting to and managing diabetes. Image: Journal of Nursing Scholarship, 1998. 30(1): p. 57-62.

4. Mamhidir, A.-G. and b. Lundman, Having control over type 2 diabetes means daring to be free. Journal of Diabetes Nursing, 2004. 8: p. 12-16.

5. Paterson, B.L. and J. Sloan, A phenomenological study of the decision-making experience of individuals with longstanding diabetes. Canadian Journal of Diabetes Care, 1994. 18(4): p. 10-19.

6. Nagelkerk, J., K. Reick and L. Meengs, Perceived barriers and effective strategies to diabetes selfmanagement. Journal of Advanced Nursing, 2006. 54(2): p. 151-158.

7. Moser, A., H. Van der Bruggen and G.A.M. Widdershoven, Competency in shaping one's life: Autonomy of people with type 2 diabetes mellitus in a nurse-led, share-care setting; a qualitative study. International Journal of Nursing Studies, 2006. 43: p. 417-427.

8. Moser, A., H. Van der Bruggen, G.A.M. Widdershoven and C. Spreeuwenberg, Autonomy through identification: a qualitative study of the process of identification used by people with type 2 diabetes. Journal of Clinical Nursing, 2008. 17(17 (7b)): p. 209-216.

9. Moser, A., H. Van der Bruggen, G.A.M. Widdershoven and C. Spreeuwenberg, Self-management of type 2 diabetes mellitus: a qualitative investigation from the perspective of participants in a nurseled, shared-care programme in the Netherlands. BMC Public Health 2008. 8: p. 91.

10. Moser, A., R. Houtepen, H. Van der Bruggen, C. Spreeuwenberg and G.A.M. Widdershoven, Autonomous decision making and moral capacities. Nursing Ethics, 2009. 16(2): p. 203-218.

11. Gilligan, C., In a different voice: psychological theory and women's development. 1982, Massachusetts: Harvard University Press.

12. Noddings, N., Caring - a feminine approach to ethics and moral education. 1984, Berkeley, CA: University of California Press.

13. Gastmans, C., Care as a moral attitude in nursing. Nursing Ethics, 1999. 6(3): p. 214-223.

14. Verkerk, M., The care perspective and autonomy. Medicine, Health Care and Philosophy, 2001. 4: p. 289-294.

15. Hagerty, B.M. and K.L. Patusky, Reconceptualizing the nurse-patient relationship. Journal of Nusing Scholarship, 2003. 35: p. 145-150.

16. Widdershoven, G.A.M., Care, cure and interpersonal understanding. Journal of Advanced Nursing, 1999. 29(5): p. 1163-1169.

17. Roberts, S.J., H.J. Krouse and P. Michaud, Negotiated and nonnegotiated nurse-patient interactions. Clinical Nursing Research, 1995. 4(1): p. 67-77.

18. Krouse, H.J. and S.J. Roberts, Nurse-patient interactive styles: power, control, and satisfaction. Western Journal of Nursing Research, 1989. 11(6): p. 717-725.

19. Donchin, A., Autonomy, interdependence, and assisted suicide: respecting boundaries/crossing lines. Bioethics, 2000. 14(3): p. 187-204.

20. Kuczewski, M.G., Reconceiving the family: the process of consent in medical decisionmaking. Hastings Center Report, 1996. March-April: p. 30-37.

21. Hardwig, J., What about the family? Hastings Center Report, 1990. Mar-Apr: p. 5-10.

22. Struhkamp, R.M., Patient autonomy: a view from the kitchen. Medicine, Health Care and Philosophy, 2005. 8: p. 105-114.

23. Mol, A., De logica van het zorgen: actieve patienten en de grenzen van het kiezen. 2006, Amsterdam: Van Gennep. 
24. Parker, R.S., Nurses' story: the search for a relational ethics of care. Advances in Nursing Science, 1990. 13(1): p. 31-40.

25. Tarlier, D.S., Beyond caring: the moral and ethical bases of responsive nurse-patient relationship. Nursing Philosophy, 2004. 5: p. 230-241.

26. Peplau, H., Interpersonal relations in nursing. 1988, Hampshire and London: Macmillan Education Ltd.

27. Watson, J., Nursing: human science and human care. A theory of nursing 1988, New York: National League for Nursing.

28. Tronto, J.C., Moral boundaries: a political argument of an ethic of care. 1993, New York: Routledge.

29. Friedemann, M.-L. and C. Köhlen, Familien- und umweltbezogene Pflege. 2003, Bern: Hans Huber Verlag.

30. Friedemann, M.-L., The concept of family nursing. Journal of Advanced Nursing, 1989. 14: p. 211216.

31. Blumer, H., Symbolic interactionism. 1969, New York: Englewood Cliffs.

32. Strauss, A. and J. Corbin, Basics of qualitative research: grounded theory procedures and techniques. 1990, Newbury Park: Sage.

33. Artinian, B.M., Grounded theory research: its value for nursing. Nursing Science Quarterly, 1998. 11(1): p. 5-6.

34. Morse, J.M., S.M. Solberg, W.L. Neander, J.L. Bottorff and J.L. Johnson, Concepts of caring and caring as a concept. Advances in Nursing Science, 1990. 13(1): p. 1-14.

35. Tschudin, V., Ethics in nursing: the caring relationship. 3rd ed. 2003, London: Butterworth Heinemann. 


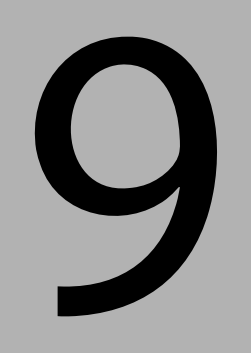

\section{General conclusion and discussion}




\subsection{Introduction}

The main aims of this study were, first, to develop a substantive theory of patient autonomy in diabetes care; second, to conceptualize the essence of complex interactional processes relation to patients' realization of autonomy, and third, to formulate recommendations for specialist nurses to support patient autonomy at an individual as well as a policy level.

In the late 1990s, diabetes specialist nurses (DSN) took on an independent role in the care for people with diabetes. In the Maastricht shared care model, nurse-led clinics have been implemented where DSN have taken over medical tasks from medical specialists and general practitioners [1]. One goal of this transformation was that these nurses are highly skilled in encouraging people with diabetes to participate actively in their own care $[2,3]$. Improving patient autonomy, in turn, is one of the goals of the Maastricht shared care model. This means that the responsibility for day-to-day care shifts from the professional to the individual [4]; it places a heavy burden on patients [5] because the core point is no longer adherence to the health professional.

A review of ethical and nursing theories and empirical literature (Chapter 2) on patient autonomy showed that it can be realized in different ways and bolstered by a variety of factors, including nurse and family support. The literature also showed that empirical research on patient autonomy has been carried out in home care, nursing homes and hospital care but rarely in nurse-led clinics. This gave rise to the following questions:

1. How do older adults with type 2 diabetes who are treated by DSN view their autonomy?

2. How do these older adults realize autonomy?

3. How can DSN support the autonomy of their patients?

A qualitative, descriptive and exploratory research project was designed. The theoretical orientation was symbolic interactionism [6], which was used to study people's social actions and interactions in an effort to understand the meaningmaking process concerning autonomy in nurse-led clinics as embedded in a shared care model. Fifteen older adults with type 2 diabetes mellitus participated in in-depth interviews to explore their perspectives and experiences of patient autonomy. The grounded theory method [7], based on social interactionism, was integral here. Grounded theory is an inductive, from-the-ground approach that examines everyday behaviours to generate theory about a particular phenomenon [7]. 


\subsection{Overview of the findings}

This section gives an overview of the findings, summarizing the main findings from the various chapters of this dissertation for each research question. Figure 9.1 also presents the main findings.

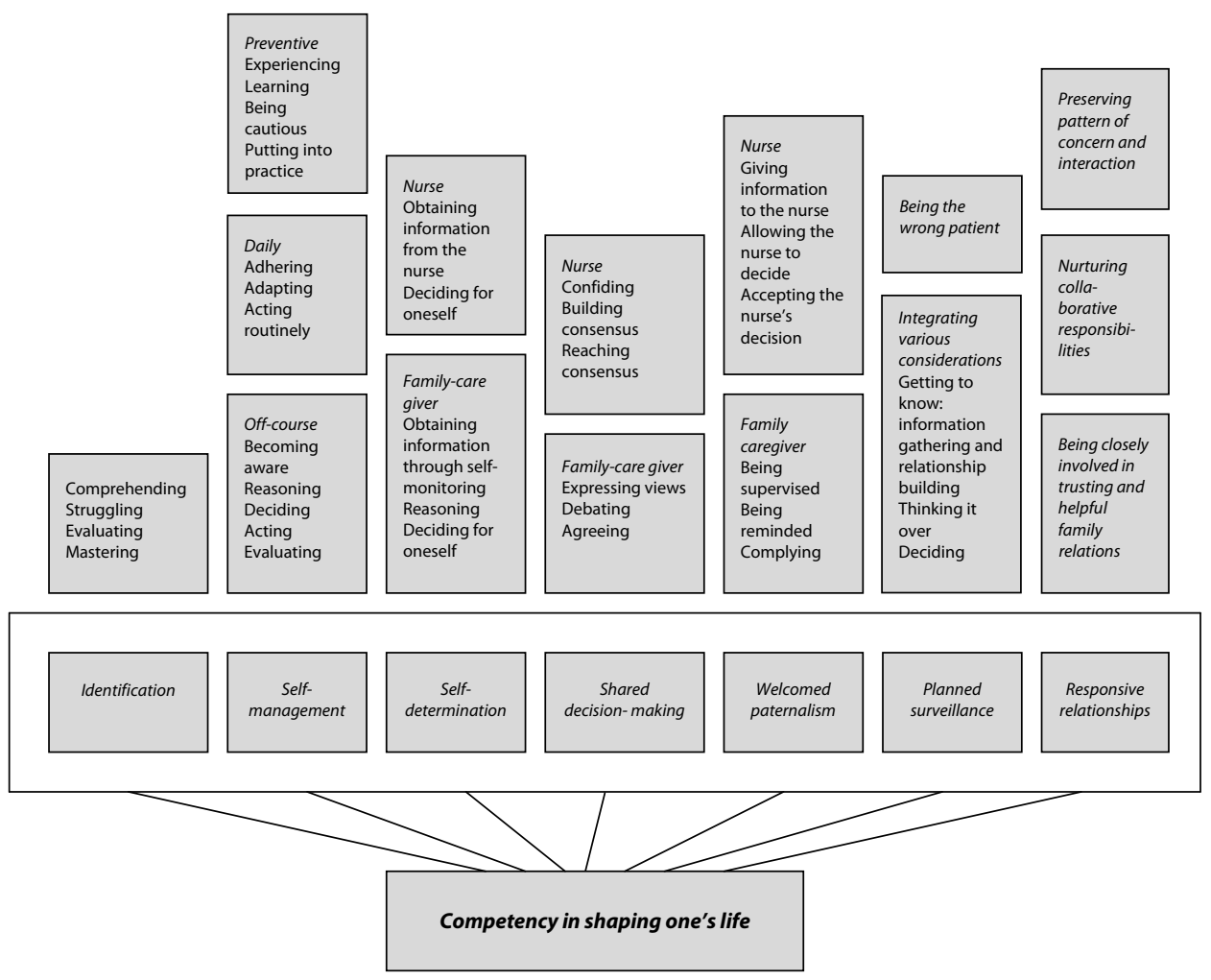

Figure 9.1 Dimensions of autonomy

\subsubsection{How do older adults with type 2 diabetes, whose main caregivers are DSN, view their autonomy?}

Based on the findings, patient autonomy as viewed by older adults with type 2 diabetes can be described as 'competency in shaping one's life' (Chapter 3). Competency is the individual repertoire of skills that includes recognizing the possibilities and having the abilities, capacities, and expertise that allow people with diabetes to shape their own lives. It implies that people with diabetes accurately initiate and complete various courses of action each day. These actions are 
conceptualized as dimensions of autonomy, with each dimension outlining differently how people with diabetes realize autonomy. The seven dimensions are identification, self-management, shared decision making, self-determination, welcomed paternalism, planned surveillance and responsive relationships. 'Shaping one's life' with diabetes means that the people with diabetes actively strive towards an autonomy that is right for them; it is based on their unique characteristics, and is flexible in times of changing health conditions and life situations. Shaping one's life, then, is a construct encompassing various dimensions of autonomy. The synthesis of the diverse dimensions arises in various ways, depending on health conditions, treatment, social context, familial patterns, knowledge, experience and skills, relationship type, life history, and personal approach. Thus, the combination of the dimensions of autonomy is not fixed, but rather a combination of what seems most appropriate at a given time.

\subsubsection{How do older adults with type 2 diabetes realize autonomy?}

Older adults with type 2 diabetes realize the seven dimensions of autonomy via sets of particular activities. We consider these particular activities to be processes that underlie the dimensions of autonomy and that provide understanding of how autonomy in each particular (sub-)dimension is actually achieved.

Identification as a dimension of autonomy implies that older adults with type 2 diabetes mellitus identify with their illness (Chapter 4). They are aware of their lifestyle's impact on their lives and health. They work actively to modify their behaviour and adapt to the limitations imposed on them by the illness. Thus, they engage in a lively process of development such that the diabetes fits into their lives. When they are successful, they feel their lives to be normal again. However, changes in the treatment plan or health condition may disrupt their lives; they might have to identify with a new therapy or a health and life situation. Identification is a therefore a cyclical and continuous process. It involves the phases comprehending, struggling, evaluating, and mastering.

Self-management encompasses activities pertaining to taking care of one's health (Chapter 5). It includes skills for daily living activities necessary for diabetes treatment, such as taking medication or ensuring regular foot care. It also refers to decision making, involving communication, knowledge, or cognition skills. The skills required for self-management activities and for deciding on selfmanagement issues are intertwined. Self-management as a whole is composed of three sub-dimensions: preventive, daily, and off-course self-management. First, preventive self-management means that people with type 2 diabetes carry out activities to prevent certain short-term and secondary long-term health problems. It is composed of four steps: experiencing, learning, being cautious, and putting 
into practice. Second, daily self-management relates to everyday diabetes care activities, such as administering insulin or exercising and resting, as well as activities to stay healthy in general. It consists of three steps: adhering, adapting, and performing routinely. Finally, off-course self-management means that certain health problems caused by type 2 diabetes occur repeatedly (e.g. unanticipated blood sugar levels) and people with diabetes need to take action to fight these health events. The phases for off-course self-management are becoming aware, reasoning, deciding, acting, and evaluating. Most participants report engaging in all three kinds of self-management; some report practising all at once while others use one or more particular self-management process(es) at given times. Some report that they take the process steps in a linear order, others take the steps in a slightly different sequence or occasionally repeat steps, and still more might not take certain steps at all. The processes, in any event, are recurrent and cyclical. A short-term self-management strategy might turn into a long-term one: people evaluate the effect of the short-term decision and the action taken, and base further decisions on how well the off-course event was dealt with. Overall, the support of DSN and family members is important to self-management as a dimension of autonomy. DSN teach, guide, and advise people, and confirm, modify, monitor, and change self-management strategies. They help to develop selfmanagement schemes and skills, and are available as a safety net. Older adults with diabetes embed their illness in the family context in different ways, ranging from giving information in case of emergency to being a companion.

Self-determination stresses making decisions and choosing one's own care, treatment, and health behaviour (Chapter 6 ). A prerequisite is that patients have sufficient knowledge about diabetes and its treatment and consequences. In the nurse-patient context it consists of obtaining information from the nurse and deciding for oneself; in the family-patient context it involves obtaining information through self-monitoring, reasoning and, again, deciding for oneself.

Shared decision-making implies deciding together with others about care and treatment issues (Chapter 6). All people involved take steps to participate in the decision making and ultimately agree on the decision made. In the nurse-patient context, shared decision making consists of confiding, building consensus, and reaching consensus, while in the family-patient context it refers to expressing views, deliberating, and agreeing.

Welcomed paternalism means that older adults with type 2 diabetes comply with what others tell them to do (Chapter 6); that is, they freely transfer or delegate some of their decision making to another person. In the nurse-patient context, this consists of giving information to the nurse, allowing the nurse to decide, and 
accepting the nurse's decision. In the family-patient context it involves being supervised, being reminded and complying.

Patients perceive a complex set of decision-making processes underlying the three previous dimensions (Chapter 6). They describe different processes in the nurse-patient and in the family-patient context. Above, we identified distinct decision-making steps for analytical purposes. However, in reality the steps occur together in a dynamic process. Some processes may not be completed within a single interaction, especially when negotiation is involved. The nurse-patient and the family-patient contexts are interwoven: some people share some or all decision-making steps with family members.

Planned surveillance means that people with type 2 diabetes want to be watched over by DSN (Chapter 7). Therefore, they stick to a regular follow-up plan because it offers a degree of control over their diabetes. Older adults with diabetes perceive two processes here: being the wrong patient, and integrating various considerations. The latter consists of the process steps getting to know: information gathering and relationship building, thinking it over and deciding (Chapter 7). In doing so, people with diabetes involve DSN and family members. The motivation to remain under planned surveillance exists in continuity of supervision, safety, information supply, sustenance of care responsibility, and necessity.

Finally, autonomy in responsive relationships evolves through social interactions and includes reacting to each other's thoughts, feelings, concerns, and habits (Chapter 8). Certain behavioural rituals or patterns emerge from these interactions, and autonomy, in turn, emerges both explicitly and implicitly as the relationship unfolds. Responsibilities towards each other are presupposed. Older adults with diabetes realize their autonomy in such relationships by preserving patterns of concern and interactions, nurturing collaborative responsibilities, and being closely involved in trusting and helpful family relations.

\subsubsection{The model}

Viewing autonomy as competency in shaping one's life reveals that there are many ways in which people with diabetes realize autonomy. Most theories of autonomy advocate a one-dimensional approach. This is insufficient, however, to portray the wealth of views and experiences of autonomy as described by chronically ill people. For this reason, some empirical studies do report several dimensions of autonomy [8-11]. A multi-dimensional theory captures the richness of the diverse meanings of autonomy as experienced by chronically ill people. 
Since competency in shaping one's life is multi-dimensional, the combinations of dimensions are not always the same. People are always subject to new influences and change [12]. Peplau [13] suggests that patients' responses to nurses can take one of three forms: participation or interdependence with the nurse, independence or isolation from the nurse, and helplessness or dependence upon the nurse. These forms appear either singly or in combination, starting with one pattern and moving through the other two as the relationship develops. According to Husted's [14] notion of autonomy as self-creation, people become what they are by successive choices and actions. They create valuable options that suit their individual, unique situation, and follow certain paths rather than others [14]. This is in line with our findings. Patient autonomy is a dynamic process and differs from person to person.

The seven dimensions of competency in shaping one's life involve a number of processes that suit each particular dimension. The processes are built on a series of particular activities that people with diabetes carry out. These activities and processes together show how the dimensions of autonomy in relation to competency in shaping one's life manifest themselves and are realized. The processes are not mutually exclusive: people with diabetes may simultaneously follow various courses of action that appear contradictory from a theoretical perspective such as the distinction between positive and negative freedom as described by Berlin [15]. Older adults with diabetes are dependent: insulin treatment means dependency in itself and adherence to other aspects of diabetes care necessitates further dependency [16]. Yet, dependency does not preclude autonomy. Competency in shaping one's life combines elements of negative and positive freedom: on the one hand, the dimension of self-determination matches the notion of negative freedom; on the other, the remaining dimensions fit with the theory of positive freedom where others actively take part in the patient's realization of autonomy. People are socially embedded and autonomy is realized within the context of social relationships [17]. Thus, autonomy as competency in shaping one's life with diabetes depends on the specific character of one's life situation and context because it is shaped in interactions with the social environment, including nurses and family members. It is always contextual.

Several factors play a role here. These include patient-related contextual factors such as health conditions, treatment, knowledge, experience and skills, life history, and personal approach. They also involve social factors: relationship types, familial patterns and social context. In nursing, context is mostly defined as the nurse-patient relationship. As an exception, Friedemann and Köhlen [18, 19] state that the family is a matter for every nurse. Autonomy is essentially about a person's life [12] and includes everything that people do to maintain, continue, and 
repair their world, which involves bodies, people's selves, and the environment [20]. Patient autonomy is thus not only related to the professional-patient context but embedded in the person's context, including all aspects of their life with and in spite of a chronic condition.

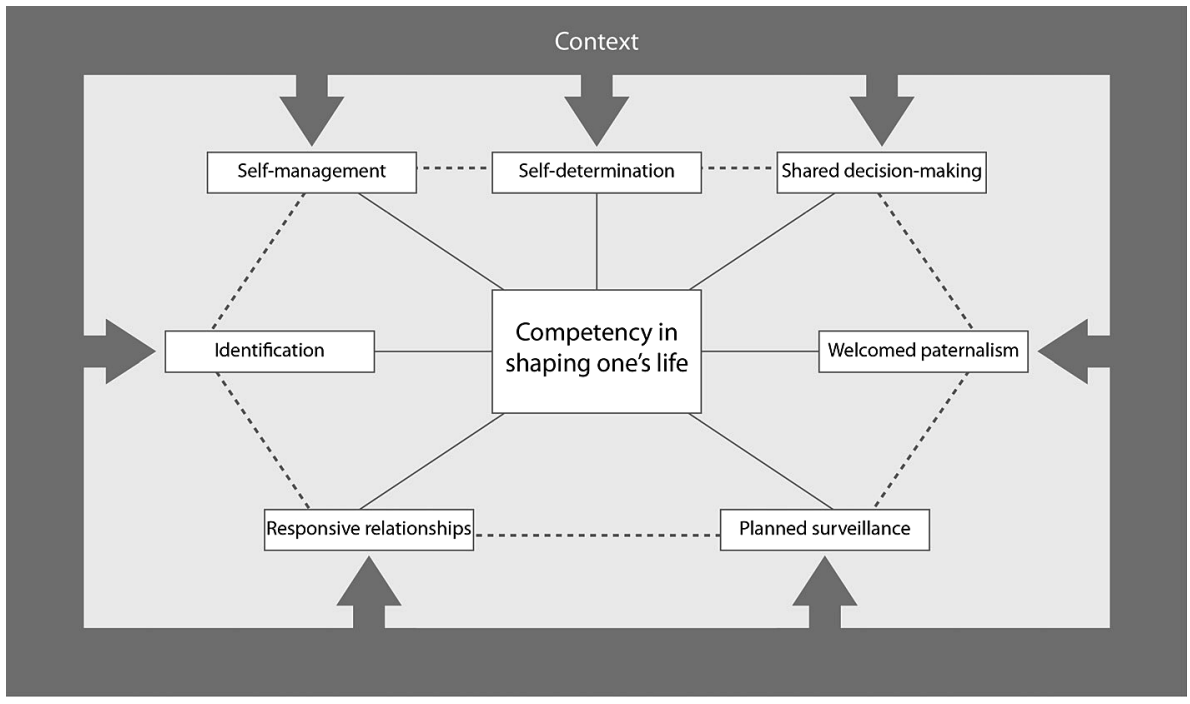

Figure 9.2 Model of patient autonomy

Competency in shaping one's life contributes to theory development in that it provides key ideas about the essence of patient autonomy as described by older adults with type 2 diabetes in nursing care. It supplies a structured description of autonomy in practice, based on patients' experiences and perceptions. It also fits with middle-range theories, which - being less abstract than grand theories [21] contain limited numbers of concepts and have limited scope [22]. Middle-range theories, comparable to substantive grounded theories [7], classify phenomena, and categorize the described commonalities into mutually exclusive, overlapping, hierarchical, or sequential dimensions [23]. The dimensions of competency in shaping one's life exist at the level of practice theories, at whose core is a desired goal and blueprints for action to achieve that goal [22]. For instance, to achieve autonomy in identification, nurses perform a particular set of interventions separately in every process phase (Chapter 4). The link between middle-range theory and practice theory is that competency in shaping one's life guides the prescriptions of the autonomy dimensions that focus on concrete situations. In this perspective, practice theories, as part of competency in shaping one's life, are of uppermost importance because they are concrete and applicable to actual nursing practice. In addition, they support the trustworthiness of competency in shaping one's life as embedded in patient care. 


\subsubsection{How can DSN support the autonomy of their patients?}

Our literature review shows that patients realize their autonomy in many ways (Chapter 2) and in doing so are facilitated by a number of factors, including support from nurses. Providing such support is complex because nurses cannot rely exclusively on one model of autonomy. In daily practice, they must be sensitive to differences and shifts in patients' needs and wishes relating to their autonomy. Supporting autonomy successfully thus requires knowledge of the patient in the context of their particular situation. For this reason, DSN need to ascertain what kind of autonomy their patients want to pursue in order to provide sufficient support.

Autonomy as competency in shaping one's life means that people exercise their autonomy in a way that is right for them. Naturally, this varies from person to person (Chapter 3). The DNS should be aware that the patient's exercising of autonomy is determined individually, understand the patient's perception of autonomy, and tailor their approach to the patient's particular needs and beliefs.

Competency in shaping one's life is not an attribute but a skill, and not everybody possesses the same degree of autonomy. DSN should support patient autonomy by facilitating and mobilizing opportunities to improve the skills of people with diabetes and thereby support their competency to shape their own lives. The social environment in which patients live is important to this competency. The DNS should pay attention to the familial background, and facilitate the involvement of family caregivers when appropriate. Also, as mentioned above, several other contextual factors influence how people realize autonomy. Because it is rooted in and shaped by the context, autonomy is intricate and complex. The DNS should therefore be alert and attentive to such contextual features.

Every DSN has a certain understanding of and mindset about what constitutes patient autonomy. This means the nurse's vision might conflict with the patient's perception of competency in shaping their lives. Therefore, they must be alert to the possibility that the patients' view may differ from theirs, and that they should put the patient's view central. This does not mean, however, that they must relinquish their own view completely; rather, they should bring up different perspectives and stimulate the patient to consider them. To this end, DSN need several moral capacities to support patient autonomy, including commitment, sensitivity and flexibility (Chapter 6). These are relevant to competency in shaping one's life irrespective of the dimension of autonomy. We thus consider them first-order moral capacities. 
Next, we want to outline how DSN can support autonomy in the various dimensions of competency in shaping one's life. In relation to identification, DSN should support patient autonomy by focusing on what, in the area of care intervention, people with diabetes consider as fitting into their lives and that they can personally identify with. Because patients move through the process in a personal way, nurses should support them at every stage individually (Chapter 4).

DSN should support self-management by providing diabetes counselling, which goes beyond generic technical education, symptom management, compliance, and metabolic control (Chapter 5). Rather, they should provide people with diabetes with the necessary cognitive, social, and practical skills. In the care for older adults, they should especially focus on preventive self-management. DSN also need to support family members who are (sometimes closely) involved in the care for the person with diabetes. However, they should ensure that the patient's selfmanagement remains the focal point of their counselling.

The moral capacities with which DSN should promote patient autonomy in selfdetermination are curiosity and comprehensiveness (Chapter 6). Curiosity entails that DSN continuously pursue professional knowledge to provide the patients with adequate information. Comprehensiveness means that they provide sound and complete information.

Tactfulness, frankness and mediation are moral capacities to support patient autonomy in shared decision-making (Chapter 6). Tactfulness means that DSN are able to talk about diabetes-related issues or perform necessary actions without embarrassing patients. They encourage reflection on treatment and care, and allow time with each patient to satisfy their informational and emotional needs. Frankness means that DSN are approachable and willing to enter into a dialogue with their patients. It includes active listening, open interaction, and candid conversation. Mediation, finally, relates to the family context. DSN are aware of roles within the diabetic's family network and are able to work with family members regarding care decisions.

The moral capacities required for DSN to support patient autonomy in welcomed paternalism are guidance, familiarity, and inclusiveness (Chapter 6). Guidance means that DSN are able to direct the whole process from information gathering and giving to final decision making. Familiarity implies that DSN are acquainted with the patient's care and life circumstances, which will better equip them to grasp their wishes and needs with regard to autonomy preferences. Finally, inclusiveness is closely related to the family context. DSN take the patient's care, social, 
and environmental conditions into account, including the family's possibilities to support the patient in daily care.

We consider the capacities related here to self-determination, shared decision making and welcomed paternalism second-order moral capacities. As previously mentioned, first-order moral capacities (commitment, sensitivity and flexibility) relate to promoting 'competency in shaping one's life'. From the patient's perspective, DSN need several first- and second-order moral capacities to support their autonomy processes, given their range and complexity. To support patient autonomy and do justice to different dimensions for different patients at different times, the prime requirement is that DSN need first-order capacities in order to assess the dimensions of autonomy and act upon them. These capacities enable DSN to have long-term relationships with patients without assuming that one specific dimension of autonomy or one kind of decision-making will apply in all circumstances or at all times. It is necessary that DSN shift between first- and second-order capacities, and clearly this is only possible if DSN indeed possess firstorder capacities.

DSN should support patient autonomy in planned surveillance by providing them with information when a transfer is necessary at the point of entry to nurse-led care (Chapter 7). In addition, a change in health status, care requirements or treatment regimen may necessitate a change of healthcare provider. DSN can ensure that patients are involved in the transfer process. They should avoid inadequate notification and discuss the option of transfer at an early stage. They should also take initiatives at the policy level to ensure adequate procedures and guidelines in which patients are central in the entry or transfer planning process. Moreover, they should not only invite patients to participate in creating these procedures and guidelines, but also ensure that patient participation is an explicit recommendation.

DSN can support autonomy in responsive relationships if they have adequate resources and time to build long-term relationships with their patients (Chapter 8). Their efforts should not remain at the individual and local levels but also include the various policy levels, such as institutional and national boards and commissions. Additionally, they should support responsive relationships by broadening their scope of nursing and facilitating responsive relationships within families. 


\subsection{Comparison of the model of competency in shaping one's life with ethical, nursing, and empirical literature}

Competency in shaping one's life combines elements of negative and positive freedom [15]. On the one hand, it matches models and theories that fit with negative freedom $[8,9,24-27]$ in the dimension of self-determination. On the other, it suits models and theories of positive freedom: identification is in line with Agich's [12] theory of actual autonomy, and self-management corresponds with self-care and dependent care $[11,25]$. The dimension of shared decision-making aligns with the deliberative model [26], dialogical ethics [28], the negotiated consent model [29], the model of balance between self-direction and obedience [30] and negotiated nurse-patient interaction [31]. Welcomed paternalism, too, fits into the paternalistic professional-patient model [26, 27], though its authors consider paternalism to be the opposite of autonomy. Rather, welcomed paternalism involves the delegation of decision making and actions, which has a positive meaning for people with diabetes. Next, the dimension of planned surveillance fits with Agich's [12] concept of actual autonomy: people are still autonomous if they can truly identify themselves with the people or things they are dependent on [12]. Finally, the dimension of responsive relationships corresponds with Pool's [9] description of care, concepts of relational autonomy [20, 32-34], and autonomy as symbiosis of family members [8].

Examination of the processes underlying the dimensions of competency in shaping one's life shows that our findings partly align with theories developed by ethicists and nursing scholars, as well as empirical findings. Identification corresponds with actual autonomy as a process [12]. People develop in an integrative process of accommodating themselves to new circumstances [12]. The processes shaping self-management, especially the interrelation of cognitive and practical phases, correspond with Orem's [25] concept of self-care agency. Self-care agency relates to physical, cognitive and psychosocial development and is demonstrated through the ability to engage in the investigative and decision-making phase and in self-care action [25]. Interestingly, the process of preventive self-management has not yet been conceptualized in the literature. The process of selfdetermination, however, corresponds with the procedure of informed consent [24], the process of informed decision-making in the professional-patient relationship [27, 35], self-care [25], and isolation from the nurse [13]. In the family-patient context, self-determination has rarely been considered in relation to patient autonomy. The process underlying shared decision making within the nurse-patient relationship aligns with the processes described in shared decision making [27, 35], dialogical ethics [28], negotiated consent [29], negotiated interaction with nurses [31], and interdependence with the nurse [13]. The process 
underlying shared decision-making in the family-patient context, meanwhile, has been described as deliberative consent [36] and within family systems nursing $[18,19]$, where care is not delivered but actively shaped together with the family system $[18,19]$. The process underlying welcomed paternalism is comparable to paternalistic decision-making [24, 27, 35] and dependence upon the nurse [13], while that underlying planned surveillance corresponds with several theories and models. Being the wrong patient corresponds with paternalistic decision-making $[24,27,35]$. The process of integrating various concerns, too, is comparable to shared decision-making [27, 35] and negotiated consent [29]. Moody [29] focuses on negotiations among stakeholders: professionals, family members, and patients. This is in line with our findings, given that people with diabetes integrate their own concerns with those of DSN and family members. The processes underlying responsive relationships rest on being in a caring relationship and a combination of care traits and care activities. Some scholars centre on these aspects separately: on either the caring relationship [37, 38], care traits [39, 40], or care activities [41, 42]. Tronto's approach [30], however, which states that caring relationships are fundamental and that caring is both a disposition and a practice, is more congruent with our findings.

\subsection{Patients' autonomy competencies}

Because autonomy is a skill and not an attribute, people with diabetes can develop their autonomy. Peplau [13] notes that patients do develop skills but, in her view, only in the nurse-patient context. This view is too narrow, however, given that people with diabetes acquire many autonomy competencies outside the nurse-patient encounter. Our findings correspond with Meyers [43], who claims that "as with other competencies, one learns through practice and practice augments proficiency" ( $p$ 175). In line with our findings, both authors advocate a developmental view of autonomy competencies. Not every person with diabetes possesses the same level of competencies: some may have all the necessary competencies, while others might need to develop some of them further. For some, sufficient autonomy competencies are related to a fixed routine of diabetes care activities, while others have or develop a series of competencies that allow them sophisticated situational alterations. This fits with Meyers [43], who indicates that "on a competency-based view of autonomy, it is not necessary to plot out every detail of one's life in advance, for one's autonomy skills enable one to address situations on a case-by-case basis" ( $p$ 174).

People with diabetes need several competencies to realize autonomy: practical, cognitive, social and relational, and adaptive competencies. Practical competen- 
cies are functional skills for carrying out diabetes care activities, such as injecting insulin, and daily living activities, such as skin care and preparing diet meals (Chapters 4, 5, 6 and 8). These autonomy competencies are comparable to selfcare action as part of self-care agency [25].

Cognitive competencies include knowledge about diabetes and intellectual skills. People with diabetes acquire theoretical information from the DSN and knowledge through personal experience about diabetes-related issues. They are able to use that information and knowledge in subsequent comparable situations by comprehending and memorizing it. People with diabetes are also skilled at reasoning about decisions that have to be made. In doing so, they consider different options and/or viewpoints and make personal judgements about them. Further, they are able to evaluate their decisions, actions and health (Chapters 4, 5, 6, and 7). This autonomy competency is congruent with the decisional capacities required for the informed consent procedure [24], self-care agency related to the capacity to engage in the investigative and decision-making phase [25], and analytical and reasoning, introspective and memory skills [43].

Social and relational competencies require that people with diabetes are capable of interacting with others and maintaining a good rapport to achieve their autonomy. They are competent at preserving relationships, given that they receive long-term care by DSN, and they establish collaborative communication with DSN and family members. Social competency also involves people with diabetes being able to request and receive social support, and consider support from DSN and family members as resource to achieve their autonomy (Chapters 4, 5, 6, 7 and 8). This autonomy competency corresponds with communication and interpersonal skills [43].

Adaptive competencies, finally, entail that people with diabetes respond to situations to realize their autonomy. This may concern dealing with novel situations of any kind, familiarizing oneself with diabetes-related circumstances, and continuing with recognizable situations and the related changes. In this regard, patients respond to a variety of diabetes-related factors (e.g. changing glucose levels or health deterioration) over the course of years, as well as to modified medi$\mathrm{cal} /$ nursing treatment and lifestyle. Adaptive competencies also involve health professionals and family members. They mean that people with diabetes posses the faculty and strengths to gain perspective on their diabetes-related situations and conditions and to bring together all these responses to achieve autonomy as competency in shaping their lives (Chapter 2). 


\subsection{The family}

As our findings show, several contextual factors are relevant to the patient's realization of autonomy. We want to pay special attention here to the role of family. Diabetes is an intrusive illness and this means the illness itself can become a family affair. People with diabetes therefore need support from family members to realize autonomy which, clearly, will not come about during a half-hour consultation with the DNS. Family involvement with regard to patient autonomy affects all facets of life with diabetes, though in traditional ethics, it is mostly discussed in relation to surrogate decision making $[11,44]$. Several scholars in nursing and philosophy $[12,17-19,32,36,45,46]$ consider good relations with family members a precondition for autonomy. Few empirical studies, however, focus on the family's role in supporting people with diabetes. Some examine the role of family members in diabetes care from the patient's perspective [47] and from the family member's perspective $[48,49]$, and confirm that family members are attentive to the person with diabetes. They want to be involved with the patient and the health professionals, and by the same token, the patient wants to involve them.

Family caregiving is becoming increasingly important, and the number of chronically ill people receiving assistance at home is set to increase tremendously. Though often invisible, the family's contribution to carrying out diabetes care activities and supporting patient autonomy should not be undervalued. The different treatment options may have a serious impact on the patient's family. The involvement of family caregivers has a different meaning for each patient, and family members can participate in diabetes care in various ways. For some patients, the interests of their families are also their interests - yet not all patients feel this way. Family members should assist their loved one to a degree that they view themselves as autonomous and are able to maintain a balance between autonomy and dependency. Patients are still autonomous if they identify with the things and people they are dependent on [12]. However, family members should ensure that the patient's autonomy remains the focal point. In addition, family caregivers should ask for support and answers to their care questions from DSN in order to contribute effectively to patient autonomy.

\subsection{The changing healthcare landscape}

The implementation of the DSN in shared care was one of the first examples in the Netherlands of the handover of tasks from medical professionals to nurses. In recent years, a number of functions within the nursing profession have been developed to advance that policy. In particular, practice nurses (PN) $[50,51]$ and 
nurse practitioners (ANP) $[52,53]$ have been introduced in the care for chronically ill people. PN are either nurses with a bachelor's degree or practice assistants who work for family physicians. Their tasks in primary diabetes care are to carry out the three-monthly follow-ups and yearly health checks, assess patients who have not been seen by the physician, prescribe and/or change the insulin dosage, regulate the glucose and cholesterol levels as well as blood pressure, and cooperate with the DSN [50]. ANP have a master's degree in advanced nursing practice and work in primary and hospital settings [53], with an expanded scope of duties that include diagnosing, prescribing medications and treating medical conditions within specific settings [54]. Because there is substantial overlap of tasks between DSN, PN and ANP, our model is especially useful for the three professions in supporting patient autonomy. In addition, PN and ANP are employed in the family physician context, which enables them to develop long-term relationships with chronically ill patients and understand patients' social context, which in turn is important in supporting patient autonomy.

Another aspect of a changing healthcare landscape is that people with chronic conditions increasingly use the internet for health purposes [55]. In the Netherlands several sites have been launched for chronically ill people in general and people with diabetes in particular. The Diagnostics Association Nederland [56], for example, focuses on tests for the prevention, diagnosis, prognosis and treatment of all kinds of conditions. It offers a special diabetes mellitus subsection with information on self-monitoring of glucose parameters. Another website is the Diabetes Interactive Education Programme [57], whose key goal is to provide diabetes education to increase self-management. Features of its educational material are background information as well as information on hyper- and hypoglycaemia, lifestyle, treatment, management, self-monitoring and living with diabetes, and useful addresses and links. Many aspects are supported by spoken fragments from fellow patients. Clearly, e-health services are becoming increasingly available to supplement patient autonomy in general and self-management in particular.

\subsection{Theory testing and development}

Today, more and more nursing scientists are developing theories within the qualitative paradigm. Polit and Beck [58] propose the following steps for theory testing: Researchers use a particular theory as guiding framework. They deduce propositions and develop research hypotheses, which are predictions about how certain variables would be interrelated if the theory were correct. The hypotheses are subjected to empirical testing, which involves comparing observed outcomes 
and those predicted by the hypothesis. If studies repeatedly fail to disconfirm the theory, it gains support and acceptance [58]. In nursing, it is customary to associate theory testing with quantitative methods $[22,23,59,60]$, though qualitative methods may also be suitable $[61,62]$.

The goal of qualitative methods is not primarily to test the theory for measureable outcomes or for generalisation to a wide population, but to systematically evaluate the theory [63] and develop it further [7]. Strauss and Corbin [7] state that "If one is interested in extending an already existing theory, then one might begin with the existing theory and attempt to uncover how it applies to new and varied situations, as differentiated from those situations to which it was originally applied"(p. 51). In line with this, researchers who want to develop our theory further might apply the general framework of competency in shaping one's life to various situations and contexts. These might be illness specific, such as diabetes mellitus type 1, chronic heart and lung problems, chronic neurological and functional difficulties, etc. Alternatively, they might be contexts where patients interact with healthcare professionals, such as DSN and specialist nurses in other settings, nurse practitioners, practice nurses, health visitors, nursing and medical professionals working inside and outside the hospital, and so on. Other situations might involve patient autonomy within family relationships or professional-patientfamily relationships. Our theory then provides a set of sensitizing concepts and relationships [7] which researchers might verify against their own data. With the findings of subsequent studies, our theory can be amended, added to or modified to fit those particular situations [7]. It is imperative that these subsequent findings support meaning-in-context [63] in relation to the theoretical ideas of competency in shaping one's life. However, we suggest that the research questions should determine the appropriate research design.

\subsection{Some thoughts on method}

In Chapter 7 we discussed the use of literature as data in grounded theory. We now want to elaborate on the presentation of literature in grounded theory manuscripts. This dissertation began with the literature overview, which at first glance may seem at odds with the principles of grounded theory. However, Strauss and Corbin [7] state that researchers doing grounded theory studies read and use published literature during all phases of the project. While the authors do not specify the structure of grounded theory manuscripts, they do provide a broad rhetorical structure and writing parameters, and their approach involves the literature being part of all sections of a manuscript (i.e. the introduction, findings and discussion). In most grounded theory studies in various nursing journals, 
however, the literature is organized in the introduction. The may be because most journals only accept grounded theory manuscripts written according to the traditional structure. Most chapters in this dissertation were published in such journals. For this reason, and because we wanted the presentation of this dissertation to remain consistent, we therefore opted for the traditional organisation and structure. The sequence of chapters does not exactly mirror the process of the literature reviews, partly due to the publication lag and iterative nature of grounded theory analysis. We performed an initial but not exhaustive literature review to write the proposal and to meet the requirements for ethical approval. During and after the principal data collection and analysis, we turned to the literature again, reviewing the theoretical and empirical literature on patient autonomy (Chapter 3). Because this led us to perceive the need to elaborate on the literature in depth, we decided to write a separate publication (Chapter 2). Subsequently, we worked out the various dimensions and again turned to the literature, this time related to the processes of realizing autonomy in relation to each specific dimension (chapters 4-8). Finally, at the end of the study we used the literature to link existing theoretical and empirical findings to the model as a whole (Chapter 9). Although we organized the dissertation in the traditional style, we remained loyal to the use of the literature in grounded theory as advocated by Strauss and Corbin.

Theoretical sensitivity refers to "the attribute of having insight, the ability to give meaning to data, the capacity to separate the pertinent from that which isn't" (p. 43) [7]. Our understanding of patient autonomy increased through long and thorough interaction with the data. Shortly after the principal data analysis we developed the core category of autonomy, dimensions and sub-dimensions. Writing then centred on the processes that shape these dimensions. Both before and during the writing of the subsequent papers, we returned to the principal analysis and critically reviewed the process and findings, asking: does what we conceptualized fit with the data? In doing so, we refined some conceptual labels to better cover the behavioural variations they represent, though the processes underlying them remained unchanged. We also relabelled some of the concepts of the subdimensions; for example, in the dimension of self-determination we relabelled the sub-dimension self-care (Chapter 3 ) as self-determination within the familypatient context (Chapter 5). During this lengthy study, we continually monitored the theoretical and scientific literature on patient autonomy, as well as the methodological discussion surrounding grounded theory. The increasing amount of background information thus sensitized us to what was going on in the data, helped us formulate the theory, and allowed us to validate the data and analysis against the existing literature. We were also familiarized with conceptual issues that we might otherwise have overlooked; for example, after reading the litera- 
ture on care and care ethics we discovered the sub-dimension nurturing collaborative responsibilities in the interview data (Chapter 8 ). Bringing together these sources of theoretical sensitivity shows that in a grounded theory study analysis continues until the end of drafting a manuscript.

In this study we interviewed 15 people with type 2 diabetes mellitus. Qualitative research almost always uses small [64, 65], non-random [58] samples. In grounded theory the criteria for determining the sample size is theoretical saturation [7]; that is, sampling to the point at which no new theoretical information is being obtained and theoretical redundancy has been achieved [66]. The number of participants needed to reach saturation depends on various factors [67]: the scope of the study, nature of the topic, quality of the data, study design and research method. In a grounded theory study the sample size is determined by the provision of rich data (i.e. that covers many behavioural variations [7]), which guides the unfolding theoretical analysis [68]. Participants in our study provided rich accounts of their personal experiences with and perspectives on autonomy. One reason for this might be that the interview strategy was to ask participants to talk about experiences in their daily lives rather than elaborate on autonomy as an abstract term. The 15 interviews provided 191 pages of written data.

Naturally, qualitative researchers encounter some practical difficulties when planning their research given that the point of saturation cannot be known beforehand. Patton [69] recommends specifying a minimum sample size that would be adequate for understanding the phenomenon in question. We chose to use this strategy, and at the onset of the study considered 15 participants as sufficient. This number was also based on Guba and Lincoln's [70] recommendation of 1220 data sources to reach saturation in a natural setting. We were aware that 15 interviews might be inadequate to gain a full understanding of patient autonomy; were this the case, however, we would have performed additional interviews to achieve saturation. This proved unnecessary as we reached saturation after 12 interviews, indicating that the sample of 15 respondents was adequate. We used the remaining three interviews, which added no new theoretical information, to validate, strengthen and deepen our theory.

Strauss and Corbin [7] define theoretical sampling as "sampling on the basis of concepts that have proven theoretical relevance to the evolving theory" (p. 177). The aim is to sample events, experiences and the like that can further develop and conceptually relate categories $[65,71]$. The basic question is: What people or events can provide rich information to develop the theory further, in order to cover behavioural variation in the context under study? Thus, researchers are faced with multiple sampling decisions during data collection. We refrained from 
interviewing people who did not conform to the follow-up regime; we did not consider their information theoretically relevant as we wanted to develop a theory of autonomy for patients who are treated by DSN. We also did not interview people with severe health problems. First, these people usually receive care from various care professionals such as a family physician or public health nurse. They might have had difficulties distinguishing autonomy issues among the various health professionals when reflecting on their experiences and behaviours. We are aware that these experiences are particularly important for this group to realize autonomy but we think they are less relevant to the scope of the emergent theory. Second, an in-depth interview requires certain physical, emotional and cognitive strengths. We refrained from interviewing people with severe health problems although we are aware that autonomy issues for this group are particularly at stake. We asked DSN who were employed at the nurse-led clinic to select the participants. This was necessary because the ethics committee required that DSN first approached respondents if they were willing to participate and, second, if the data could be passed on to the researcher. Thus, it may be the case that we received consent more readily from patients who were satisfied with the care they had received. This would imply a selection bias; yet this was preferable to interfering with ethical standards.

We used in-depth interviews, which are the most prominent type of data collection in grounded theory studies $[68,72]$. Although participant observations are increasingly used [58], they do not enjoy widespread appeal within nursing research [73], and we did not make use of this data collection method. We aimed to study patient autonomy from the broadest perspective, focusing on life as a whole. Participant observation would have required us to collect observational data in various situations, for example at participants' homes. This would entail practical difficulties, given that observations are bound by the time in the field. Moreover, it is difficult to say in advance what might be useful to observe, and whether the situation one wants to observe will actually occur because observations in grounded theory studies should have theoretical relevance, and not be observed in very general terms. We could have made observations in the nursepatient interaction which would have yielded a richer account of patient autonomy in that context. However, at the time of data collection the researcher was working as a nurse herself, which made it impossible to perform participant observations. 


\subsection{A personal note}

I had worked as a nurse for several years before I started this study. In fact, the topic of my research stemmed from that experience. Also, the work experience and nursing background helped me to understand the data more easily. One could argue that my professional experience made me blind to certain elements in the data given that I still worked as a public health nurse during the study. However, working in a different country under new circumstances made me more sensitive to conceptual issues as I underwent the process of learning the Dutch approach to nursing and healthcare. I also drew on my experiences of becoming a researcher in my work: I suppose I became more 'autonomy aware' in the field (which does not automatically mean that I was the most autonomy-supporting nurse). I also recognized things in my patients that I had found in the data, while at the same time, these interactions made me more sensitive to things in the data, and thus contributed to the evolving theory. I am certain that working in the field while doing research has a cross-fertilizing effect.

\subsection{The publication process}

We have published a series of articles based on one sample in the same study period. The analysis of the interviews resulted in several dimensions, subdimensions and process steps. In fact, we were surprised that a relatively small sample generated such a large quantity of findings. As it is common in qualitative research, where the research purpose is more open, we did not expect this prior to the fieldwork. We wrote a concept manuscript including all underlying processes of each (sub-)dimension of autonomy. We experienced some dilemmas, such as: how can we communicate all these findings in depth - and do justice to them - when publication space is restricted? How can we do justice to the participants they represent? If we divide the findings up, how can we avoid duplicate publications and 'salami slicing'? Finally, how can we preserve the integrity of the researchers if we divide the publication of the findings?

Duplicate publication is defined as the "publication of a paper that overlaps substantially with one already published in print or electronic media" (International Committee of Medical Journal Editors [ICMJE], 2004, cited in Hegyvary [74]). Morse [75] classifies substantial overlap as the duplication of 500 words in the method section of qualitative papers where the data collection (including sample, design, and analysis) is the same but the article presents different findings from one study. 'Salami slicing' refers to submitting different manuscripts drawn from data collected from a single study or data collection period [76]. In qualitative 
research, scholars are cautious about salami slicing but are aware that volumes of data can necessitate multiple publications $[75,77,78]$. There are several possibilities to divide data while avoiding duplication and salami slicing. For example, if research on one topic is conducted in different settings or populations, from different perspectives or using different methods [75], the findings can be spliced. Findings can also be divided along temporal, thematic, event, or subject lines [77], emphasizing methods over findings [77] and focusing on theoretical synthesis [78]. However, Morse [75] warns that the resulting publication may be too thin.

The research team considered the various possibilities and agreed to divide the presentation of the findings. We decided to make thematic cuts [77], which necessitates that the understanding of one concept or dimension of autonomy does not require understanding of the others. We also decided to write one methodological paper emphasizing method over findings [77]. Next, we considered the authors' responsibilities. We informed all potential authors [79] about the context of particular articles within the publication series, and all authors gave permission for publication [74, 76, 79]. We informed readers of every article (published, accepted or submitted) stemming from our study. We cross-referenced all related articles and manuscripts [74, 76-78, 80]. We avoided using more than 500 words of the same phrasing in the method section $[75,80]$. We refrained from using literature relating generally to patient autonomy, but rather to the specific dimension of autonomy in each article. In this way, we safeguarded new contributions to the scientific body of knowledge. We also detailed why we chose to explain only one part of the findings [77]. Finally, we considered additional aspects in every subsequent article; for example, we supplemented one article with a hermeneutic text interpretation (Chapter 6).

Throughout the publication process we remained cautious about our responsibilities. Once, during the editing process, some of our cross-references were deleted. In another case, the editor preferred to place the conceptual definitions of some dimensions of autonomy under the findings heading although they had already been published elsewhere. Because we published in different journals, certain repetitions were unavoidable.

\subsection{Evidence-based practice}

Evidence-based practice (EBP) involves making clinical decisions on the basis of the best possible evidence [81]. It is defined as "the conscious, explicit, and judicious use of current best evidence in making decisions about the care for individual patient" (p. 71) [82]. If nurses want to glean practice from research findings, 
they must take into account as much of the evidence as possible, organized and synthesized in a diligent manner [58]. Many consider systematic reviews of quantitative evidence as cornerstones of EBP [83]. In recent years, several scholars have developed methods to integrate qualitative findings: methasynthesis [84, 85], metasummary [86], aggregation of qualitative findings [87] and formal theory development [88]. Logically, an integration of qualitative findings can only be carried out on a phenomenon that has been well researched. However, qualitative research such as ours is often carried out when little is known about a phenomenon $[7,64,89]$.

Personal experience is frequently characterized as being anecdotal, not generalisable, and a poor basis for making scientific decisions [90]; yet we are convinced that our findings represent evidence based on patients' experiences. We systematically gathered, analysed, and critically reviewed the data [91], and this process ultimately resulted in our theory. Our findings contribute to EBP, given that they bring the patient perspective into play.

In clinical practice, the use of EBP guidelines is seen as the basis for clinical decision making [92]. The overemphasis on EBP guidelines may result in standardized templates of care that neglect the patient perspective [92]. Problems may thus arise when nurses make clinical decisions based on EBP guidelines that do not match patients' preferences. When using EBP guidelines, nurses should always be aware that any patient could be the exception to the rule [93]. Moreover, EBP guidelines are just one of the three types of evidence that constitute EBP: research evidence, professional experience and patient experience. These types are influenced by the healthcare context [91]. Practitioners are beginning to ask whether staff should be held hostage by the evidence, rather than combining the evidence with their own experience of what works best in local circumstances with the wishes and needs of the patient and [94]. The patient's preferences are not an alternative to the scientific evidence base - rather, they are part of EBP.

\subsection{Practical applications}

The model of competency in shaping one's life provides a description of the various analytical steps in the processes of the different dimensions of autonomy. It can be used to educate DSN about what autonomy is, and about the characteristics and process steps of each dimension. In addition, the different dimensions and the distinct process steps help to clarify what kind of autonomy people with diabetes actually pursue. A single nurse-patient interaction can combine several components from different dimensions of autonomy at different process phases. 
The model can also be used by DSN to assess individual patients' way(s) of exercising autonomy. Our model makes explicit that the patient's approach to realizing autonomy may change, either during an interaction, in the next meeting, or over time. The model may help DSN to identify the changes required of them to shift between the autonomy dimensions to support patient autonomy most effectively. Changes may be small within the context of one dimension, or larger, putting a different dimension on the agenda. Our model could serve as an analytical tool to sensitize nurses to which dimension of autonomy is at stake, what the differences and nuances are, and also what the changes are over time. And as an analytical tool it may help to create awareness of the diversity in patient autonomy.

The actions and interventions needed from DSN to support patient autonomy can be worked out individually in every analytical step of each dimension of autonomy. In this way, practice theories can be developed bottom up to provide concrete interventions to support patient autonomy that are suitable to the specific care and nursing setting. This will help scientific language be translated into professional language which is familiar with actual nursing practice.

One goal of the Maastricht shared care model is to improve patient autonomy in the organisation of their own diabetes care. Our model might be a helpful tool to initiate a theory-based quality improvement agenda to improve patient autonomy. However, the theory involved itself is practise based. As already mentioned, practice-based theories can be developed and integrated into autonomysupporting counselling programmes.

The use of our model could also be extended to or include other professionals who participate in the Maastricht shared care setting, such as family physicians and medical specialists, to truly reach the goal of improving patient autonomy. These professionals could use the theoretical ideas of our model to become more sensitized to their patients' autonomy issues in view of their own work context and its particularities. This would entail their application of our model in the sense of theoretical transferability. They could make use of the concept of competency in shaping one's life, applying the dimensions of autonomy relevant to their own practice situations and to a degree that reflects the meaning of our findings for their context. Our model might also be transferable to health professionals who work with diabetes patients but who are not located in a shared care setting.

National DSN networks could use our model as a tool to develop a shared view of patient autonomy. This might lead to a collective understanding among DSN. In addition, national networks like the Dutch Association of Diabetes Nurses could 
make use of our model to formulate the competencies DSN need to support patient autonomy. This might help guide the development of such competencies at an individual as well as a national level, which in turn might generate situations to meet the patients' autonomy wants and needs more effectively.

Patient associations can use the model to inform their members about patient autonomy: which dimensions of autonomy are relevant and how they can be realized. The model might also help people with diabetes to become aware of their autonomy preference and individual autonomy-related actions and achievements, and to clarify what approach they can expect from their DNS and family members. In addition, family members can use it to learn how best to support the autonomy of their loved one.

Group or peer support such as group consultation, internet, telephone-based peer support and social support groups assist diabetes patients in adjusting to life with diabetes and making better decisions [95]. Our findings can be used by peer support groups to inform 'future' peers about patient autonomy. Since our model is based on the actual experiences of diabetes patients, it may complement but also confirm knowledge based on personal experiences. We also recommend that peer support groups pay attention to informal caregivers and include that aspect in their peer support activities, for example in family peer support groups. Informational, educational and training material should be developed bottom up in order to translate scientific language to lay discourse.

The makers of diabetes e-health sites could use our model to extend the scope of e-health services. While current Dutch e-health sites focus primarily on selfmanagement and self-monitoring of glucose levels, our findings show that preventive self-management has a broader meaning to people with diabetes. Ehealth services can develop self-management and self-monitoring further by including preventive self-management as an integral part of self-management. They may also want offer educational material on and self-monitoring tools for long-term complications to support patient autonomy.

Our model also provides a tool to support learning of DSN in the sense of lifelong learning [96], reflection-on-action, reflection-in-action [97] and group reflection, and case analysis [98] in clinical practice. Lifelong learning refers to all forms of learning (personal development, educational training and professional development [96]) that follows initial education and training [99]. This implies that DSN's learning about patient autonomy is never finished, but rather a process that is open to the future. Reflection-on-action means that DSN reflect afterward on the actions they have performed [97]. In this case, the model can serve as a tool that 
helps clarify which dimension of autonomy was dominant in what specific patient situation. Reflection-in-action, on the other hand, means that DSN reflect during actual nursing practice and modify their behaviour immediately [97]. In this case, DSN know the model of autonomy and have the capacities to change their approach to support patient autonomy in their interaction with the patient. In addition, DSN might also use the model as a guide to reflect together with others on patient autonomy. In this case, our model may help to improve patient care by implementing evidence-based practice in patient care [91] and by cultivating certain moral capacities. A case-based approach might safeguard practice-based learning and reflection, and reflective case-based learning might integrate practice, ethics and several evidence sources, which in turn leads to evidence-based practice.

Our model can be used as an educational tool in nursing to foster the discussion about professional orientation towards patient autonomy. In early nursing education at bachelor's level, we recommend using the model to teach the theoretical baseline about patient autonomy based on personal experiences. This will help students to link theory with practice. In later nursing education at bachelor's level and at master's level, we suggest using the model to theoretically underpin students' reflection on cases from practice situations either individually or in groups. Additionally, the model could be used at both educational levels to foster the development of moral and professional capacities by raising awareness of and teaching the ethical dimension of nursing care. For example, how can nurses support patient autonomy in a healthcare environment dominated by economic concerns, personnel shortages or institutional rules? And how can nurses' moral (and other) capacities to support patient autonomy best be developed and maintained?

Finally, as mentioned previously, for both educational and professional learning courses we recommend that our model be implemented primarily as an analytical tool. Vocational and training courses should use the concepts of lifelong learning, individual and group reflection and practice-based cases as their teaching strategies. The goal should be for students and professionals to understand what is relevant for individual patients to realize autonomy in view of their particular circumstances, what the differences and nuances are, and what questions need to be asked about the various elements of the situation. There is no simple answer as our model does not presume to offer a single concept of patient autonomy. As the model is complex, vocational and professional courses should safeguard its applicability, for instance by using no more than two or three dimensions of autonomy within one context to reflect on a particular practice situation and 
taking the complexity of the practice situation to be reflected on into consideration.

\section{Epilogue: Let us return to Mr Limpens}

Autonomy for Mr Limpens means having the competency to shape his own life. Competency is the individual repertoire of skills that allows him to do so. Shaping his life with diabetes means that Mr Limpens actively strives towards an autonomy that is right for him; it is based on characteristics unique to him, and is flexible in the face of changing health conditions and life situations. He is autonomous in the sense that he carries out self-management activities, makes decisions about certain diabetes care issues, identifies with the diabetes as part of his life, is under the surveillance of the DSN, and receives help from his wife. The multi-dimensional and dynamic character of Mr Limpens's autonomy implies that various dimensions of autonomy are simultaneously relevant, interrelated in an interactive process, and one or more dimensions may dominate at the same time. How can DSN best support Mr Limpens's autonomy in situations where he exercises several dimensions of autonomy?

Given that Mr Limpens's autonomy is multi-dimensional and flexible, there are movements between dimensions and within sub-dimensions. Short-term selfmanagement strategies might turn into long-term ones if Mr Limpens experiences the outcome as positive. His DSN might start a consultation using an informed consent approach but then switch to shared decision-making if Mr Limpens hesitates in making a decision or wants to discuss it first. How exactly are the sub-dimensions and dimensions of autonomy related? At what phases of a particular dimension does the shift occur? What are the multiple facets of autonomy that lie between the dimensions?

How Mr Limpens exercises his autonomy is not fixed; rather, it varies depending on several contextual factors. In the context of consultation with the DSN, Mr Limpens is, in some instances, determined to have it his own way. At other times he takes on the DNS's advice or discusses diabetes issues with the DSN. In the context of his family life, many factors influence how Mr Limpens exercises his autonomy. If he wants to sleep longer on the weekend or is occupied with other things and forgets to inject himself with insulin, his wife reminds him. In all, he is able to master his diabetes very well, but at times he experiences setbacks. His autonomy is thus a shifting process. For him, different dimensions of autonomy are relevant at different times and situations. Which specific contextual factors cause a shift in what particular dimension(s) of autonomy? 
Further, Mr Limpens's autonomy is not a yes-or-no phenomenon. Interaction with and support from the DSN and his wife are necessary for him. He perceives diabetes as a risky disease, and as he has grown older he has become more aware about future health problems, which implies increased reliance on others. He might fear increasing dependence on his wife's support. What assistance will Mrs Limpens need from the DSN to support her husband's autonomy most effectively in times of increased dependency?

Mr Limpens's autonomy provokes a number of new research questions. However, DSN can best support his autonomy by facilitating opportunities in which $\mathrm{Mr}$ Limpens has both the possibility to make his own independent decisions and resources in terms of support from others. 


\section{References}

1. Vrijhoef, H.J.M., C. Spreeuwenberg, I.M.J.G. Eijkelberg, B.H.R. Wolffenbuttel and G.G. Van Merode, Adoption of disease management model for diabetes in the region of Maastricht. British Medical Journal, 2001. 323: p. 983-985.

2. Spreeuwenberg, C. and P. Pop, Transmurale zorg, in Handboek tansmurale zorg., C. Spreeuwenberg, et al., Editors. 2000, Elsevier Gezondheidszorg: Maarssen. p. 17-36.

3. Wolffenbuttel, B., Het Matador-project (Maastrichtse transmurale diabetesorganisatie), in Transmurale zorgvormen van diabetes mellitus: een verkenning van de situatie anno 2000, $\mathrm{H}$. Bilo, et al., Editors. 2000, Isala Klinieken: Zwolle.

4. Barlow, J., C. Wright, J. Sheasby, A. Turner and J. Hainsworth, Self-management approaches for people with chronic conditions: a review. Patient Education and Counseling, 2002. 48: p. 177-187.

5. Reed, J.A., J.M. Lawrence, S. Hollinghurst and E.R. Higgs, Diabetes self-management: how are we doing? Practical Diabetes International, 2003. 20(9): p. 318-322.

6. Blumer, H., Symbolic interactionism. 1969, New York: Englewood Cliffs.

7. Strauss, A. and J. Corbin, Basics of qualitative research: grounded theory procedures and techniques. 1990, Newbury Park: Sage.

8. Heimerl, K. and I. Berlach-Pobitzer, Autonomie erhalten: Eine qualitative PatientInnenbefragung in der Hauskrankenpflege, in Autonomie im Alter: Studien zur Verbesserung der Lebensqualität durch professionelle Pflege, E. Seidl, M. Stankova, and I. Walter, Editors. 2000, Verlag Wilhelm Maudrich: Wien. p. 102-165.

9. Pool, A., Autonomie, afhankelijkheid en langdurige zorgverlening. 1995, Utrecht: Lemma BV.

10. Stuessgen, R.A.J., De nieuwe patient op weg naar autonomie. 1997, Amsterdam: Thesis Publishers.

11. Proot, I., Changing autonomy: new perspectives on the care for stroke patients in nursing homes. 2000, Maastricht: University Press Maastricht.

12. Agich, G., Dependence and autonomy in old age. 2003, Cambridge: Cambridge University Press.

13. Peplau, H., Interpersonal relations in nursing. 1988, Hampshire and London: Macmillan Education Ltd.

14. Husted, J., Autonomy and the right not to know., in The right to know and the right not to know., R. Chadwick, M. Levitt, and D. Shickle, Editors. 1997, Aldershot: Avevury. p. 55-68.

15. Berlin, I., Twee opvattingen van vrijheid. 1996, Amsterdam/Meppel: Boom.

16. Ingadottir, B. and S. Halldorsdottir, To discipline a "dog": the essential structure of mastering diabetes. Qualitative Health Research, 2008. 18(5): p. 606-619.

17. Mackenzie, C. and N. Stoljar, Relational autonomy: feminist perspectives on autonomy, agency, and social self. 2000, Oxford: Oxford University Press.

18. Friedemann, M.-L., The concept of family nursing. Journal of Advanced Nursing, 1989. 14: p. 211 216.

19. Friedemann, M.-L. and C. Köhlen, Familien- und umweltbezogene Pflege. 2003, Bern: Hans Huber Verlag.

20. Tronto, J.C., Moral boundaries: a political argument of an ethic of care. 1993, New York: Routledge.

21. Im, E.O., Development of situation-specific theories: an integrated approach. Advances in Nursing Science, 2005. 28(2): p. 137-151.

22. Walker, O.L. and K.C. Avant, Strategies for theory construction in nursing. 4 th ed. 2005, Upper Saddle River, NJ: Person Education, Inc.

23. Fawcett, J., Contemporary nursing knowledge. Analysis and evaluation of nursing models and theories. 2nd ed. 2005, Philadelphia: F.A. Davis Company.

24. Beauchamp, T.L. and J.F. Childress, Principles of biomedical ethics. 5 th ed. 2001, New York: Oxford University Press.

25. Orem, D.E., Nursing: concepts and practice. 2001, St. Louis: Mosby.

26. Emanuel, E.J. and L.L. Emanuel, Four models of the physician-patient relationship. Journal of the American Medical Association, 1992. 267(16): p. 2221-2226. 
27. Charles, C., A. Gafni and T. Whelan, Decision-making in the physician-patient encounter: revisiting the shared treatment decision-making model. Patient Education Counseling, 1999. 49: p. 651-661.

28. Widdershoven, G.A.M., Care, cure and interpersonal understanding. Journal of Advanced Nursing, 1999. 29(5): p. 1163-1169.

29. Moody, H.R., From informed consent to negotiated consent. The Gerontologist, 1988. 28(Supplement): p. 64-70.

30. Stüssgen, R.A.J., De nieuwe patient op weg naar autonomie. 1997, Amsterdam: Thesis Publishers.

31. Roberts, S.J., H.J. Krouse and P. Michaud, Negotiated and nonnegotiated nurse-patient interactions. Clinical Nursing Research, 1995. 4(1): p. 67-77.

32. Donchin, A., Understanding autonomy relationally: towards a reconfiguration of bioethical principles. Journal of Medicine and Philosophy, 2001. 26(4): p. 365-386.

33. Verkerk, M., The care perspective and autonomy. Medicine, Health Care and Philosophy, 2001. 4: p. 289-294.

34. Donchin, A., Autonomy, interdependence, and assisted suicide: respecting boundaries/crossing lines. Bioethics, 2000. 14(3): p. 187-204.

35. Charles, C., A. Gafni and T. Whelan, Shared decision-making in the medical encounter: what does it mean? (or it takes at least two to tango). Social Science and Medicine, 1997. 44(5): p. 681-692.

36. Kuczewski, M.G., Reconceiving the family: the process of consent in medical decisionmaking. Hastings Center Report, 1996. March-April: p. 30-37.

37. Noddings, N., Caring - a feminine approach to ethics and moral education. 1984, Berkeley, CA: University of California Press.

38. Tschudin, V., Ethics in nursing: the caring relationship. 3rd ed. 2003, London: Butterworth Heinemann.

39. Gastmans, C., B. Dierckx de Casterle and P. Schotsmans, Nursing considered as moral practice: $a$ philosophical-ethical interpretation of nursing. Kennedy Institute of Ethics Journal, 1998. 8(1): p. 43-69.

40. Mayeroff, M., On caring. 1972, New York: Harper \& Row Publishers.

41. Mol, A., De logica van het zorgen: actieve patienten en de grenzen van het kiezen. 2006, Amsterdam: Van Gennep.

42. Struhkamp, R.M., Patient autonomy: a view from the kitchen. Medicine, Health Care and Philosophy, 2005. 8: p. 105-114.

43. Meyers, D., Intersectional identity and the authentic self. Opposites attract, in Relational autonomy: Feminist perspectives on autonomy, agency and the social self. , C. MacKenzie and N. Stoljar, Editors. 2000, Oxford University Press: New York. p. 151-180.

44. Schermer, M., The different faces of autonomy. 2002, Dordrecht: Kluwer Academic Publishers.

45. Hardwig, J., What about the family? Hastings Center Report, 1990. Mar-Apr: p. 5-10.

46. Moody, H.R., Ethics in an aging society. 1992, Baltimore: The Johns Hopkins University Press.

47. Bailey, B. and A. Kahn, Apportioning illness management authority: how diabetes individuals evaluate and respond to spousal help. Qualitative Health Research, 1993. 3(1): p. 55-73.

48. Silliman, R.a., S. Bhatti, A. Khan, K.A. Dukes and L.M. Sullivan, The care of older persons with diabetes mellitus: families and primary care physicians. Journal of the American Geriatrics Society., 1996. 44: p. 1314-1321.

49. Stödberg, R., H. Sunvisson and G. Ahlström, Lived experience of significant others of persons with diabetes. Journal of Nursing and Healthcare of Chronic Illness in association with Journal of Clinical Nursing, 2007. 16(7b): p. 215-222.

50. Houwling, S.T., E. Van Ballegooie, S. Verhoeven, H.J.G. Bilo and B. Meyboom-de Jong, Taakenverschuiving in de eerstelijns diabeteszorg. Huisarts \& Wetenschap, 2006. 49(3): p. 118-122.

51. Van Son, L., H. Crebolder, L. Van Hoef and G. Beusmans, De huisarts ondersteund. Huisarts \& Wetenschap, 2004. 47(1): p. 15-21. 
52. Dierick-van Daela, A.T.M., J.F.M. Metsemakers, E.W.C.C. Derckx, C. Spreeuwenberg and H.J.M. Vrijhoef, Nurse practitioners substituting for general practitioners: randomized controlled trial. Journal of Advanced Nursing, 2009. 65(2): p. 391-401.

53. Gezondheidsraad, Taakherschikking in de gezondheidszorg. 2008: Den Haag.

54. Reay, T., K. Golden-Biddle and K. German, Challenges and leadership strategies for managers of nurse practitioners. Journal of Advanced Nursing, 2003. 11: p. 396-403.

55. Andreassen, H.K., R.C. Cumitru, I. Pudule, S. Santana, H. Voss, and R. Wynn, European citizens' use of e-health services: a study of seven countries. BMC Public Health, 2007. 10(53).

56. www.diagned.nl. [cited 21.05.2009].

57. www.diep.nl. [cited 22.05.2009].

58. Polit, D.F. and C.T. Beck, Nursing Research. Generating and assessing evidence for nursing practice. 8 th ed. 2008, Philadelphia: Wolters Kluwer Lippincot Williams \& Wilkins.

59. Meleis, A.l., Theoretical nursing. Development and progress. 3 rd ed. 2005, Philadelphica: Lippincott Williams \& Wilkings.

60. Chinn, P.L. and M.K. Kramer, Integrated knowledge development in nursing. 6th ed. 2004, St. Louis, MI: Mosby Inc.

61. Bitektine, A., Qualitative method for deductive theory testing. Organizational Research Methods, 2008. 11(1): p. 160-180.

62. Piper, S., Qualitative theory testing as mixed-method research. Journal of Research in Nursing, 2006. 11(3): p. 183-193.

63. Leininger, M.M., Culture care diversity \& universality: a theory of nursing. 1991, New York, NY: National League for Nursing Press.

64. Silverman, D., Doing qualitative research: a practical handbook. 2000, London, Thousand Oaks, and New Delhi: Sage Publications.

65. Kuzel, A.J., Sampling in qualitative inquiry, in Doing qualitative research, B.F. Crabtree and W.L. Miller, Editors. 1999, Sage London. p. 33-46.

66. Bowen, G.A., Naturalistic inquiry and the saturation concept: a research note. Qualitative Research, 2008. 8(1): p. 137-152.

67. Morse, J.M., Determining sample size in qualitative health research (Editorial) Qualitative Health Research, 2000. 10: p. 205.

68. Tuckett, A., Qualitative research sampling: the very real complexities. Nurse Researcher, 2004. 12(1): p. 47-61.

69. Patton, M.R., Qualitative evaluation and research methods. 3 rd ed. 2002, Thousand Oaks, CA.: Sage.

70. Guba, E.G. and Y.S. Lincoln, Naturalistic Inquiry. 1985, Newbury Park: Sage.

71. Miles, M.B. and A.M. Huberman, Qualitative data analysis: an expanded sourcebook. 2 nd ed. 1994, Thousand Oaks, London and New Delhi: Sage Publications.

72. MacDougall, C. and E. Fudge, Planning and recruiting the sample for focus groups and in-depth interviews. Qualitative Health Research, 2001. 11(1): p. 117-126.

73. Munhall, A., In the field: notes on observation in qualitative research. Journal of Advanced Nursing, 2003. 41(3): p. 306-313.

74. Hegyvary, S., What every author should know about redundant and duplicate publication (Editorial) Journal of Nursing Scholarship, 2005. Fourth Quarter: p. 295-297.

75. Morse, J.M., Duplicate Publication (Editorial). Qualitative Health Research, 2007. 17(10): p. 13071308.

76. Norham, I., Duplicate publication and 'salami slicing': ethical issues and practical solutions. International Journal of Nursing Studies, 2008. 45: p. 1257-1260.

77. Sandelowski, M., Divide and conquer: avoiding duplication in reporting of qualitative research (Editorial). Research in Nursing \& Health, 2006. 29: p. 371-373.

78. Parse, R.R., Data-based articles and duplicate publication. Nursing Science Quarterly, 2008. 20(4): p. 301. 
79. DeAngelis, C.D., Duplicate publication, multiple problems. Journal of the American Medical Association, 2004. 292(14): p. 1745-1746.

80. Baggs, J.G., Issues and rules for authors concerning authorship versus acknowledgements, dual publication, self plagiarism, and salami publishing (Editorial). Research in Nursing and Health, 2008. 31: p. 295-297.

81. Polit, D.F. and C.T. Beck, Nursing research: principles and methods. 7 th ed. 2004, Philadelphia: Lippincott Williams \& Wilkins.

82. Sackett, D.L., W.M. Rosenberg, J.A. Gray, R.B. Haynes and W.S. Richardon, Evidence-based medicine: what is it and what it isn't. British Medical Journal, 1996. 312(7023): p. 71-72.

83. Sandelowski, M., R. Trimble, E.K. Woodard and J. Barroso, From synthesis to script: transforming qualitative research findings for use in practice. Qualitative Health Research, 2006. 16(10): p. 13501370.

84. Thorne, S., L. Jensen, M.H. Kearney, G. Noblit and M. Sandelowski, Qualitative metasynthesis: reflections on methodological orientation and ideological agenda. Qualitative Health Research, 2004. 14(10): p. 1342-1365.

85. Sandelowski, M. and J. Barroso, Toward a metasynthesis of qualitative findings on motherhood in HIV-positive women. Research in Nursing \& Health, 2003. 26: p. 153-170.

86. Sandelowski, M. and J. Barroso, Creating metasummaries of qualitative findings. Qulitative Health Research, 2003. 52(4): p. 226-233.

87. Estabrooks, C.A., P.A. Field and J.A. Moorse, Aggregating qualitative findings: an approach to theory development. Qualitative Health Research, 1994. 4(4): p. 503-511.

88. Kearney, M.H., Ready-to-wear: discovering grounded formal theory. Research in Nursing \& Health, 1998. 21: p. 179-186.

89. Burns, N. and S.K. Grove, The practice of nursing research: conduct, critique, and utilization. 5th ed. 2005, St. Louis, Mi: Elsevier Saunders.

90. Green, J. and N. Britten, Qualitative research and evidence-based medicine. British Medical Journal, 1998. 316: p. 1230-1232.

91. Cox, K., C. Kuiper, J. Verhoef and D. de Louw, Het verkrijgen van evidence., in Evidence-based practice voor verpleegkundigen. Methoden en toepassing., K. Cox, et al., Editors. 2008, Lemma: Den Haag.

92. Hudson, K., G. Duke, B. Haas and G. Varnell, Navigating the evidence-based practice maze. Journal of Nursing Management, 2008. 16: p. 409-416.

93. Grypdonck, M., Qualitative health research in the era of evidence-based practice. Qualitative Health Research, 2006. 16(10): p. 1371-1385.

94. Nolan, P., Evidence-based practice: implications and concerns. Journal of Nursing Management, 2008. 16: p. 388-393.

95. Van Dam, H.A., F. Van der Horst , B. Van den Borne, R. Ryckman and H. Crebolder, Provider-patient interaction in diabetes care: effects on patient self-care and outcomes. A systematic review. Patient Education and Counseling, 2003. 51: p. 17-28.

96. Colardyn, D., Lifelong learning: which way forward? 2 nd ed. 2002, Utrecht: Lema.

97. Schön, D.A., The reflective practitioner. How professionals think in action. 1995, London: Ashgate.

98. Ashcroft, R., A. Lucassen, M. Parker, M. Verkerk and G.A.M. Widdershoven, Case analysis in clinical ethics. 2005, Cambridge: Cambridge University Press.

99. Comission of the European Communities, Report from the Commission. Adult learning: it is never too late to learn. 2006, COM: Brussels. 


\section{Summary}

Samenvatting

\section{Zusammenfassung}




\section{Summary}

This dissertation concerns a study into the autonomy of older adults with type 2 diabetes mellitus who are treated by diabetes specialist nurses in a nurse-led clinic. The main aims of this study were first, to develop a substantive theory of patient autonomy in diabetes care, second, to conceptualize the essence of complex interactional processes related to the patients' realization of autonomy, and third, to formulate recommendations for specialist nurses to promote patient autonomy on an individual as well as a policy level.

Diabetes mellitus, a chronic disease that affects many aspects of daily life, compels people to comply with a life-long treatment regime. The care of diabetes is complicated because of the multi-systemic and chronic nature of the illness. In the late 1990s diabetes specialist nurses (DNS) got an independent role in the care for people with diabetes. In the Maastricht shared care model nurse-led clinics have been implemented where DNS have taken over medical tasks from medical specialists and general practitioners. One assumption of this transformation was that these nurses are very well skilled to encourage people with diabetes to participate actively in the care for themselves. This means that the responsibility for day-to-day care shifts from the professional to the individual patient. It places a heavy burden on patients. This thesis examines the experience and realization of patient autonomy from the viewpoint of older adults with diabetes mellitus type 2 .

Chapter 1 provides an introduction to the concepts of patient autonomy, the nurse-led clinics as embedded in the Maastricht shared care model and the role of nurses in supporting patient autonomy. In this chapter the aims of the study, research questions, social interactionism as theoretical orientation and research design are introduced.

Chapter 2 presents a review of the theoretical and empirical literature addressing patient autonomy and how nurses can support patient autonomy. Two methods were used to identify literature: a search of several data-bases and ethical and nursing literature was selected on the basis of its identification of positive and negative freedom. We limited the review to qualitative empirical research because we focused on the patients' perception of autonomy. Negative freedom emphasizes freedom of action and freedom from interference by others. The most prominent theories fitting negative freedom are those defining autonomy as self-governance and self-care. Positive freedom stresses the idea that people should direct their lives according to their personal convictions and individual reasons and goals. Theories fitting positive freedom are those focusing on auton- 
omy in caring, autonomy as identification, autonomy in communication, and autonomy as goal achievement. In the empirical literature, two studies centred on patient autonomy in home care, one in nursing home care, and three in hospital settings. Patients prefer a mixed approach that combines features of negative and positive freedom. A variety of factors can support patient autonomy, including support from nurses and family. Nurses cannot rely exclusively on one model of autonomy to foster patient autonomy. Rather, it requires in-depth knowledge of, and interaction with, patients in the context of each particular nursing encounter. The patient's perspective of autonomy in the practice of nurse-led, shared care remains to be investigated.

Chapter 3 to 8 report the findings of a grounded theory study. The study has a qualitative descriptive and exploratory design and an inductive approach. The study population consisted of 15 people who are enrolled for at least 1 year at the nurse-led, shared care unit and who live independently at home. Data were collected by means of in-depth interviews and observational notes. Data were analysed according to the constant comparative analysis as used in grounded theory which is based on the theory of social interactionism.

Chapter 3 describes the concepts of autonomy people with type 2 diabetes use. The core category, 'competency in shaping one's life', describes how people with diabetes exercise their autonomy. Competency is the individual repertoire of skills that includes recognizing the possibilities and having the abilities, capacities, and expertise that allow people with diabetes to shape their own lives. To shape one's life with diabetes means that a person with diabetes actively strives towards an autonomy that is exactly right for this particular person; it is based on characteristics that are unique to this person, and it is flexible in changing health conditions and life situations. Competency implies that people with diabetes initiate and complete various actions daily. These courses of actions are conceptualised as dimensions of autonomy. These dimensions are: identification, self-management, self-determination, shared decision-making, welcomed paternalism, planned surveillance, and responsive relationship. Shaping one's life is a construct of joining various dimensions of autonomy. The synthesis of diverse dimensions of autonomy arises in various ways, depending on health conditions, treatment, social context, familial patterns, knowledge, experience and skills, type of relationship, life history, and personal approach. Thus, the combination of the dimensions of autonomy is not fixed, but rather a mix of what seems most appropriate at a given time. Patient autonomy is a multidimensional, dynamic and complex construct. Nurses can best support autonomy as competency in shaping one's life by tailoring their approach of autonomy to the needs and beliefs of each individual person with diabetes. 
In Chapter 4 we investigate the process of identification with diabetes as a dimension of autonomy. The phases of identification are comprehending, struggling, evaluating and mastering. Each phase has its own characteristics. Identification with the diabetes is a non-linear, cyclical and continuous process because people with diabetes have to deal with changing conditions. The dynamics of identification are directed to a process of identifying with diabetes and its care requirement. Recognizing identification as an element of autonomy enables nurses to adopt a more patient-oriented view of autonomy. Nurses should support autonomy as identification in a way that a person with diabetes is to identify with the diabetes care interventions. Hence it is vital that nurses build supportive partnerships to promote patient autonomy most effectively.

Chapter 5 reports of an empirically grounded conceptualization of selfmanagement in the context of autonomy of people with type 2 diabetes. They use three kinds of self-management processes: daily, off-course, and preventive. The steps for daily self-management are adhering, adapting, and acting routinely. The steps for off-course self-management are becoming aware, reasoning, deciding, acting, and evaluating. The steps for preventive self-management are experiencing, learning, being cautious, and putting into practice. These processes are interwoven and recurring. Self-management consists of a complex and dynamic set of processes and it is deeply embedded in one's unique life situation. Support from DSN and family caregivers is a necessity of self-managing diabetes. Nurses can best support patient autonomy by providing diabetes counselling that goes beyond generic and technical education. Such counselling includes providing patients with the necessary cognitive, social and practical skills needed for autonomous self-management.

In Chapter 6 we examine how people with diabetes type 2 perceive autonomous decision-making and which moral capacities they consider important in the diabetes nurses' support of autonomous decision-making. Here, the focus is on the dimensions self-determination, shared decision-making and welcomed paternalism. First, data were analyzed using the grounded theory method. Second, descriptions of the decision-making processes were analyzed using a hermeneutic text interpretation. From the hermeneutic text interpretation moral capacities nurses need to support patient autonomy from the patients' perspective were inferred. Participants described a variety of decision-making processes in the nurse and family-care giver context regarding self-determination, shared decision-making and welcomed paternalism. In the nurse-patient context self-determination consists of obtaining information from the nurse and deciding for oneself and in the family-patient context it contains of obtaining information through selfmonitoring, reasoning and deciding for oneself. In the nurse-patient context 
shared decision-making contains confiding, building consensus and reaching consensus and in the family-patient context it consists of expressing views, deliberating and agreeing. In the nurse-patient context welcomed paternalism includes giving information to the nurse, allowing the nurse to decide, and accepting the nurse's decision and in the family-patient context it consists of being supervised, being reminded and complying. In reality these processes occur together in a dynamic process and the nurse-patient and the family-patient contexts are interwoven. From the hermeneutic text interpretation we inferred firstand second-order moral capacities. First-order moral capacities are: commitment, sensitivity and flexibility. Second-order moral capacities are curiosity and comprehensiveness (self-determination), tactfulness, frankness and mediation (shared decision-making), and familiarity and inclusiveness (welcomed paternalism). Nurses should engage in ongoing, interactive reflective practice to further develop their moral capacities to support patient autonomy.

Chapter 7 describes how the literature as data was used and its integration in the grounded theory analysis. We used the concept of planned surveillance to illustrate how the literature as data was theoretically sampled and helped to develop the concept further in response to the emergent concept. The concept of planned surveillance consists of two sub-categories: being the wrong patient and integrating various considerations. Integrating various considerations contains the following process steps: getting to know: information gathering and relationship building, thinking it over and deciding. As conditional aspects, participants named five motivational factors to remain under planned surveillance: continuity of supervision, sustenance of care responsibility, safety, information supply and necessity. The integration of literature as data in the constant comparative analysis as used in grounded theory enhances and densifies theoretical concepts. Nurses can best support patient autonomy as planned surveillance by ensuring that patients are involved in the transfer process at an early stage and that they enabling them to be engaged in the development of agreed upon procedures within the shared care setting.

Chapter 8 reports of an ethical discussion concerning autonomy in responsive relationships based on the perception of older adults with type 2 diabetes mellitus. We performed a literature review on relational autonomy concerning care ethics, caring in nursing and publications that highlight relational aspects. The literature was classified in five strands: attitude-oriented, dialogue-oriented, activity-oriented, relationship-oriented and life-oriented. Three processes were conceptualized in which people with diabetes realize their autonomy in responsive relationships with others: preserving patterns of concerns and interactions, nurturing collaborative responsibilities, and being engaged in trustful and helpful 
family relations. People with diabetes realize autonomy in various responsive relationships in their unique life context. Most theories on care ethics, caring in nursing and relational aspects cover some aspects that are important to people with type 2 diabetes mellitus. Patients can best realize their autonomy in relationships with others when several essential aspects of care and caring are present in their lives. Nurses can support patient autonomy in responsive relationships by cultivating their relational care attitudes and expressing them in the daily practice of diabetes care.

Chapter 9 presents a summary of the main findings concerning how older adults with type 2 diabetes mellitus view their autonomy, how they realize their autonomy and how DSN can support patient autonomy. We describe the model of competency in shaping one's life which shows that patient autonomy is multidimensional, flexible, contextual and specific to people's unique life situations. The model is also compared with ethical, nursing and empirical literature. Patients need several competencies to realize their autonomy. These are practical, cognitive, social and relational, and adaptive autonomy-competencies. We also discuss the role of the family in relation to patient autonomy and evidence-based practice. We elaborate on methodological issues and the publication process. Finally, recommendations centre on the practical application of the model in relation to clinical practice, quality improvement, patient organisations and nursing education. The main conclusion of this dissertation is that nurses best support patient autonomy by facilitating opportunities where patients have both the possibilities to make their own independent decisions and in terms of resources support from others. 


\section{Samenvatting (Dutch summary)}

Dit proefschrift betreft een onderzoek naar de autonomie van oudere volwassenen met type 2 diabetes mellitus die behandeld worden door verpleegkundig specialisten op het gebied van diabetes die zelfstandig praktijk houden. De hoofddoelen van deze studie waren in de eerste plaats om een substantieve theorie te ontwikkelen over autonomie van patiënten in de diabetische zorg, ten tweede om de essentie te conceptualiseren van complexe interactieprocessen die te maken hebben met de verwezenlijking door patiënten van hun autonomie, en ten derde om aanbevelingen te formuleren voor verpleegkundig specialisten om autonomie van patiënten te bevorderen zowel op individueel als op beleidsniveau.

Diabetes mellitus, een chronische ziekte die veel aspecten van het dagelijks leven beïnvloedt, dwingt mensen om zich aan een levenslang behandelregime te houden. De zorg op het gebied van diabetes in gecompliceerd aangezien het meerdere lichamelijke stelsels beïnvloedt en chronisch van aard is. In de late jaren '90 kregen de verpleegkundig specialisten een onafhankelijke rol in de zorg voor mensen met diabetes. In het Maastrichtse shared care model zijn door verpleegkundigen geleide praktijken geïmplementeerd waar zij taken van medisch specialisten en huisartsen hebben overgenomen. Een van de aannamen van deze omschakeling was dat verpleegkundigen zeer bekwaam zijn om mensen met diabetes aan te moedigen om actief deel te nemen in hun eigen zorg. Dit betekent dat de verantwoordelijkheid voor alledaagse zorg verschuift van de deskundige naar de individuele patiënt. Dat legt een zware last op de patiënten. Dit proefschrift bestudeert de ervaring en verwezenlijking van de autonomie van patiënten vanuit het oogpunt van oudere volwassenen met type 2 diabetes mellitus.

Hoofdstuk 1 geeft een introductie in de concepten van de autonomie van patiënten, de door verpleegkundig specialisten zelfstandig gehouden spreekuren zoals ingebed in het Maastrichtse shared care model en de rol van verpleegkundigen in het ondersteunen van de autonomie van patiënten. In dit hoofdstuk worden de studiedoelen, onderzoeksvragen, het sociaal interactionisme als theoretische oriëntatie en het onderzoeksontwerp beschreven.

Hoofdstuk 2 presenteert een overzicht van de theoretische en empirische literatuur met betrekking tot de autonomie van patiënten en manieren waarop verpleegkundigen de autonomie van patiënten kunnen ondersteunen. Twee methoden werden gebruikt om de literatuur te identificeren: het doorzoeken van verscheidene databases en het identificeren van ethische en verpleegkundige literatuur of het gaat om positieve of negatieve vrijheid. We hebben het overzicht 
beperkt tot kwalitatief empirisch onderzoek omdat we ons hebben gericht op het perspectief van de patiënt. Negatieve vrijheid benadrukt vrijheid van handelen en vrijheid van ingrijpen van derden. De bekendste theorieën die bij negatieve vrijheid passen zijn die welke autonomie definiëren als zelfbepaling en zelfzorg. Positieve vrijheid benadrukt het idee dat mensen hun leven richting zouden moeten geven volgens hun persoonlijke overtuigingen en individuele doelen. Theorieën die passen bij positieve vrijheid richten zich op autonomie in de zorg, autonomie als identificatie, autonomie in communicatie en autonomie in het bereiken van doelen. In de empirische literatuur werden twee studies gevonden in de thuiszorg, een in de verpleeghuiszorg en drie in algemene ziekenhuizen. Patiënten geven de voorkeur aan een gemengde benadering waarin kenmerken van negatieve en positieve vrijheid worden gecombineerd. Verschillende factoren ondersteunen de autonomie, waaronder steun van verpleegkundigen en familieleden. Verpleegkundigen kunnen niet uitsluitend vertrouwen op één model om autonomie van patiënten te bevorderen. Daarentegen vereist het diepgaande kennis van en interactie met patiënten in de context van iedere specifieke verpleegkundige contact. Het perspectief van de patiënt aangaande zijn autonomie in het zelfstandig spreekuur met de verpleegkundig specialist dient verder onderzocht te worden.

Hoofdstuk 3 tot en met 8 beschrijven de resultaten van een gefundeerde theoriebenadering. De onderzoeksontwerp is kwalitatief, descriptief en exploratief en de benadering is inductief. De studiepopulatie bestond uit 15 mensen die tenminste een jaar onder de hoede van een verpleegkundig specialist waren en die zelfstandig thuis wonen. Gegevens werden verzameld door middel van diepteinterviews en observationele aantekeningen. De gegevens werden geanalyseerd volgens de constant vergelijkende analyse zoals gebruikt in de gefundeerde theoriebenadering die gebaseerd is op de theorie van het sociaal interactionisme.

Hoofdstuk 3 beschrijft de autonomieconcepten zoals gebruikt door mensen met diabetes mellitus type 2 . De kerncategorie, 'de competentie het leven vorm te geven', beschrijft hoe mensen met diabetes hun autonomie uitoefenen. Competentie is het individuele repertoire van vaardigheden die inhouden het herkennen van de mogelijkheden en het hebben van het vermogen, de capaciteiten en de expertise die de mensen met diabetes in staat stellen hun eigen leven vorm te geven. Het leven met diabetes vormgeven betekent dat een persoon met diabetes actief streeft naar een autonomie die precies juist is voor deze specifieke persoon. Deze is gebaseerd op kenmerken die uniek zijn voor deze persoon en ze is flexibel in het veranderen van gezondheidscondities en leefsituaties. Competentie impliceert dat mensen met diabetes dagelijks het initiatief nemen tot verscheidene handelingen en ze voltooien. Deze handelingen worden geconceptua- 
liseerd als dimensies van autonomie. Deze dimensies zijn: identificatie, zelfmanagement, zelfbeschikking, gezamenlijke besluitvorming, gewenst paternalisme, geplande bewaking en responsieve relaties. Het leven vormgeven is een construct waarin verscheidene dimensies van autonomie verbonden worden. De synthese van verschillende dimensies van autonomie komt op diverse manieren tot stand, afhankelijk van gezondheidstoestand, behandeling, sociale context, familiepatronen, kennis, ervaring en vaardigheden, aard van de relatie, levensloop en persoonlijke benadering. Derhalve staat de combinatie van de dimensies van autonomie niet vast, maar is veeleer een mix van wat het meest geschikt lijkt op een bepaald moment. Autonomie is een multidimensioneel, dynamisch en complex construct. Verpleegkundigen kunnen autonomie als de competentie het leven vorm te geven het best ondersteunen door hun benadering van de autonomie toe te snijden op de behoeftes en overtuigingen van iedere individuele persoon met diabetes.

In hoofdstuk 4 onderzoeken we het proces van identificatie met diabetes als een dimensie van autonomie. De fasen van identificatie zijn begrijpen, worstelen, evalueren en zich eigen maken. Elke fase heeft zijn eigen kenmerken. Identificatie met diabetes is een non-lineair, cyclisch en continu proces omdat mensen met diabetes om moeten kunnen gaan met veranderende omstandigheden. De dynamiek van identificatie is gericht op een proces van zich identificeren met diabetes en de zorgvereisten daarvan. Het erkennen dat identificatie een onderdeel is van autonomie stelt verpleegkundigen in staat een meer patiëntgerichte kijk op autonomie aan te nemen. Verpleegkundigen zouden autonomie als identificatie moeten ondersteunen zodanig dat een persoon met diabetes in staat is om zich te identificeren met de zorginterventies die horen bij diabetes. Vandaar is het essentieel dat verpleegkundigen een ondersteunende partnerschap tot stand brengen om de autonomie van de patiënt op meest effectieve wijze te bevorderen.

Hoofdstuk 5 rapporteert over een empirisch onderbouwde conceptualisering van zelfmanagement in de context van autonomie van personen met type 2 diabetes. Zij gebruiken drie soorten zelfmanagement processen: dagelijkse, afwijkende en preventieve. De stappen voor dagelijks zelfmanagement zijn: zich houden aan de therapie, zich aanpassen, en routinematig handelen. De stappen voor afwijkend zelfmanagement zijn: bewustwording, beredeneren, beslissen, handelen en evalueren. De stappen voor preventief zelfmanagement zijn: ervaren, leren, voorzichtig zijn en toepassen. Deze processen zijn met elkaar verweven en terugkerend. Zelfmanagement bestaat uit dynamische en complexe processen en is diep geworteld in iemands unieke leefsituatie. Steun van verpleegkundigen en familieleden is noodzakelijk voor het zelfmanagement van diabetes. Verpleegkundigen 
kunnen autonomie het beste ondersteunen door spreekuren te verzorgen die verder gaan dan algemene en technische instructie. In zulke spreekuren worden patiënten ook cognitieve, sociale en praktische vaardigheden aangeleerd die nodig zijn voor het autonome zelfmanagement van diabetes.

In hoofdstuk 6 onderzoeken we hoe mensen met diabetes autonome besluitvorming waarnemen en welke morele capaciteiten zij belangrijk vinden in de ondersteuning door diabetesverpleegkundigen van autonome besluitvorming. Hier ligt de aandacht bij de dimensies zelfbeschikking, gezamenlijke besluitvorming en gewenst paternalisme. Ten eerste werden gegevens geanalyseerd met gebruik van de gefundeerde theoriebenadering. Ten tweede werden beschrijvingen van besluitvormingsprocessen geanalyseerd met behulp van een hermeneutische tekstinterpretatie. Vanuit de hermeneutische tekstinterpretatie werden morele capaciteiten afgeleid die verpleegkundigen nodig hebben om de autonomie van de patiënt te ondersteunen vanuit het gezichtspunt van de patiënt. Deelnemers beschreven uiteenlopende besluitvormingsprocessen in de context van zorg door de verpleegkundige en door familieleden met betrekking tot zelfbeschikking, gezamenlijke besluitvorming en gewenst paternalisme. In de relatie verpleegkundige-patiënt bestaat zelfbeschikking uit het verkrijgen van informatie van de verpleegkundige en het voor zichzelf beslissen. In de relatie familieledenpatiënt bestaat zij uit het verkrijgen van informatie uit observatie van zichzelf, beredeneren en voor zichzelf beslissen. In de relatie verpleegkundige-patiënt bevat gezamenlijke besluitvorming het in vertrouwen nemen, het werken aan consensus en het bereiken van consensus. In de relatie familieleden-patiënt bestaat zij het uitdrukken van standpunten, overleggen en tot overeenstemming komen. In de relatie verpleegkundige-patiënt houdt gewenst paternalisme in: het geven van informatie aan de verpleegkundige, de verpleegkundige toelaten te beslissen en het accepteren van de beslissing van de verpleegkundige. In de relatie familieleden-patiënt bestaat het uit supervisie, herinnerd worden en zich houden aan de therapie. In werkelijkheid vinden deze processen tegelijkertijd plaats in een dynamisch proces en zijn de relaties verpleegkundige-patiënt en familieleden-patiënt met elkaar verweven. Vanuit de hermeneutische tekstinterpretatie hebben we eerste en tweede orde morele capaciteiten afgeleid. Eerste orde morele capaciteiten zijn: betrokkenheid, sensitiviteit en flexibiliteit. Tweede orde morele capaciteiten zijn: nieuwsgierigheid en veelomvattendheid (zelfbeschikking), takt, openheid en bemiddeling (gezamenlijke besluitvorming) en bekendheid met de situatie en inclusiviteit (gewenst paternalisme). Verpleegkundigen zouden zich continu bezig moeten houden met interactief reflecteren in de praktijk om hun morele capaciteiten verder te ontwikkelen om autonomie van patiënten te ondersteunen. 
Hoofdstuk 7 beschrijft hoe de literatuur als gegevens is gebruikt en hoe zij geïntegreerd is in de analyse van de gefundeerde theoriebenadering. We gebruikten het concept van geplande bewaking om te illustreren hoe uit de literatuur als gegevens theoretisch werd gekozen en het concept verder werd ontwikkeld als antwoord op het zich ontwikkelende concept. Het concept van geplande bewaking bestaat uit twee subcategorieën: de verkeerde patiënt zijn en het samenbrengen van diverse afwegingen. Het samenbrengen van diverse afwegingen bevat de volgende processtappen: leren kennen: informatie verzamelen en relatie bouwen, overdenken en een besluit nemen. Als conditionele aspecten noemden de deelnemers vijf motiverende factoren om onder geplande bewaking te blijven: continuïteit van de supervisie, het volhouden van de zorgverantwoordelijkheid, veiligheid, informatievoorziening en noodzaak. De integratie van literatuur als gegevens in de constante vergelijkende analyse zoals gangbaar in de gefundeerde theoriebenadering verrijkt en verdicht theoretische concepten. Verpleegkundigen kunnen autonomie van de patiënt in de dimensie geplande bewaking het beste ondersteunen door zeker te stellen dat patiënten in een vroeg stadium betrokken worden in het verwijsproces en door patiënten in staat te stellen om betrokken te zijn in de ontwikkeling van overeengekomen procedures in het kader van shared care.

Hoofdstuk 8 rapporteert een ethische discussie met betrekking tot autonomie in responsieve relaties gebaseerd op de waarneming van oudere volwassenen met type 2 diabetes mellitus. We hebben een literatuurstudie gedaan over de relationele autonomie betreffende zorgethiek, verpleegkundige zorg en publicaties die relationele aspecten benadrukken. De literatuur werd in vijf stromen geclassificeerd: houdingsgericht, dialooggericht, handelingsgericht, relatiegericht en levensgericht. Drie processen werden geconceptualiseerd waarin mensen met diabetes zich bewust zijn van hun autonomie in responsieve relaties met anderen: het instandhouden van patronen van betrokkenheid en interacties, het bevorderen van samenwerking en verantwoordelijkheden, en het betrokken zijn in vertrouwvolle en behulpzame familierelaties. Mensen met diabetes zijn zich hun autonomie bewust in diverse responsieve relaties in hun leefsituatie. De meeste theorieën over zorgethiek, verpleegkundige zorg en relationele aspecten behandelen bepaalde aspecten die van belang zijn voor mensen met diabetes. Patiënten kunnen hun autonomie in relaties met anderen het best tot stand brengen wanneer verscheidene essentiële aspecten van zorg aanwezig zijn in hun leven. Verpleegkundigen kunnen autonomie in responsieve relaties het beste ondersteunen door het tot ontwikkeling brengen van hun houding ten aanzien van relationele zorg en deze tot uitdrukking brengen in de dagelijkse zorgpraktijk. 
Hoofdstuk 9 presenteert een samenvatting van de belangrijkste bevindingen omtrent hoe oudere volwassenen met type 2 diabetes mellitus hun autonomie bezien, hoe zij hun autonomie tot stand brengen en hoe verpleegkundigen de autonomie van patiënten kunnen ondersteunen. We beschrijven een model van de competentie het leven vorm te geven die laat zien dat autonomie van de patient multidimensioneel, flexibel, context afhankelijk en specifiek aan de unieke leefsituatie van mensen is. Het model wordt ook vergeleken met ethische, verpleegkundige en empirische literatuur. Patiënten hebben verscheidene competenties nodig om hun autonomie tot stand te brengen. Deze zijn praktisch, cognitief, sociaal en relationeel, en adaptieve competenties betreffende autonomie. We bespreken ook de rol van de familie met betrekking tot autonomie en het evidentiegebaseerde werken. We gaan verder in op de methodologische kwesties en het publicatieproces. Ten slotte worden aanbevelingen gedaan betreffende de praktische toepassing van het model in de klinische praktijk, kwaliteitsverbetering, patiëntenorganisaties en verpleegkundigenopleiding. De belangrijkste conclusie van dit proefschrift is dat verpleegkundigen de autonomie van patiënten het beste kunnen ondersteunen door mogelijkheden te faciliteren waarbij mensen met diabetes zowel de kansen krijgen om hun eigen beslissingen te nemen als de hulpbronnen in termen van ondersteuning door anderen. 


\section{Zusammenfassung (German summary)}

Bei dieser Dissertation handelt es sich um eine Studie über die Autonomie älterer Erwachsener mit Diabetes mellitus Typ 2, die von spezialisierten DiabetesPflegekräften in einer pflegerisch geleiteten Klinik behandelt werden. Die Hauptziele dieser Studie waren erstens: eine substanzielle Theorie der PatientenAutonomie in der Diabetes-Pflege zu entwickeln, zweitens: die Essenz komplexer interaktionaler Prozesse bezogen auf die Verwirklichung der Autonomie der Patienten begrifflich zu fassen, und drittens: Empfehlungen für DiabetesSpezialpflegekräfte zu formulieren, um die Patienten-Autonomie sowohl auf individueller als auch auf politischer Ebene zu fördern.

Diabetes mellitus, eine chronische Krankheit, die viele Aspekte des täglichen Lebens betrifft, zwingt die betroffenen Menschen, ein lebenslanges Behandlungssystem einzuhalten. Die Behandlung von Diabetes ist wegen der multisystemischen und chronischen Eigenschaft der Krankheit kompliziert. In den späten 1990er Jahren erhielten spezialisierte Diabetes-Pflegekräfte eine unabhängige Rolle in der Behandlung von Menschen mit Diabetes. Im Maastrichter SharedCare-Modell wurden pflegerisch geleitete Kliniken eingeführt, in denen spezialisierte Diabetes-Pflegekräfte medizinische Aufgaben von medizinischen Spezialisten und Hausärzten haben. Eine Voraussetzung dieser Übertragung war, dass diese Krankenschwestern sehr gut befähigt sind, Menschen mit Diabetes zu ermuntern, aktiv an ihrer eigenen Pflege und Behandlung teilzuhaben. Das heißt, dass die Verantwortung für die tägliche Pflege sich von der professionellen Ebene auf den individuellen Patienten verlagert. Dies bürdet den Patienten eine schwere Last auf. Diese Doktorarbeit untersucht die Erfahrungen und die Umsetzung der Patienten-Autonomie aus dem Blickpunkt älterer Menschen mit Diabetes mellitus Typ 2.

Kapitel 1 bietet eine Einführung in die Konzepte der Patienten-Autonomie, in die pflegerisch geleiteten Kliniken, wie sie im Maastrichter Shared-Care-Modell eingebettet sind, und in die Rolle der Diabetes-Krankenschwestern bei der Förderung der Patienten-Autonomie. In diesem Kapitel werden die Ziele der Studie, Forschungsfragen, Symbolischer Interactionismus als theoretische Orientierung und die Forschungsmethodik vorgestellt.

Kapitel 2 bietet einen Überblick der theoretischen und empirischen Literatur, die sich mit der Patienten-Autonomie und der Frage, wie Krankenschwestern die Patienten-Autonomie unterstützen können, auseinandersetzt. Um diese Literatur zu ermitteln, wurden zwei Methoden angewandt: eine Recherche in mehreren Datenbanken und auf deren Grundlage die Ermittlung positiver und negativer 
Freiheit. Wir begrenzten den Überblick auf qualitativ empirische Untersuchungen, weil die Sichtweise der Patienten zur Autonomie im Mittelpunkt stand. Negative Freiheit betont die Handlungsfreiheit und die Freiheit von Beeinflussung durch andere. Die bedeutendsten Theorien, die negative Freiheit thematisieren, sind jene, die Autonomie als Selbstbestimmung und Selbstpflege definieren. Positive Freiheit betont die Vorstellung, dass Menschen ihr Leben nach ihren persönlichen Überzeugungen sowie individuellen Beweggründen und Zielen führen sollten. Theorien, die positive Freiheit thematisieren, sind jene, die Autonomie des Füreinander-Sorge-Tragens, Autonomie als Identifikation, Autonomie in der Kommunikation und Autonomie als Erreichen von Zielen in den Mittelpunkt stellen. In der empirischen Literatur konzentrieren sich zwei Studien auf die PatientenAutonomie in der häuslichen Pflege, eine Studie widmet sich der PatientenAutonomie in der Heimpflege und drei Studien setzen sich mit der PatientenAutonomie im klinischen Umfeld auseinander. Patienten bevorzugen einen gemischten Ansatz, der Merkmale negativer und positiver Freiheit kombiniert. Vielfältige Faktoren können die Patienten-Autonomie fördern, einschließlich der Unterstützung durch Krankenschwestern und Familie. Pflegekräfte können sich nicht ausschließlich auf ein Autonomie-Modell verlassen, um PatientenAutonomie zu fördern. Es bedarf vielmehr gründlicher Fachkenntnisse über Patienten und Interaktion mit Patienten im Kontext jedes spezifischen Pflegekontakts. Die Perspektive des Patienten zur Autonomie in der Praxis der pflegerisch geleiteten Shared-Care bleibt zu erforschen.

Kapitel 3 bis 8 stellen die Ergebnisse einer Grounded Theory Studie dar. Die Studie hat eine qualitativ deskriptive und untersuchende Methode sowie einen induktiven Ansatz. Die Teilnehmergruppe der Studie bestand aus 15 Personen, die sich für mindestens ein Jahr zur Teilnahme am pflegerisch geleiteten SharedCare-Modell verpflichtet haben und die unabgängig zu Hause leben. Das Datenmaterial wurde durch detaillierte Befragungen und Beobachtungsprotokolle ermittelt. Die Daten wurden analysiert gemäß der konstanten vergleichenden Analyse, die in der Grounded Theory, basierend auf der interaktionistischen Sozialtheorie, Anwendung findet.

Kapitel 3 beschreibt die Autonomie-Konzepte, die Menschen mit Typ-2-Diabetes anwenden. Die zentrale Kategorie „Kompetenz zur eigenen Lebensgestaltung” beschreibt, wie Menschen mit Diabetes ihre Autonomie praktizieren. Kompetenz ist das individuelle Repertoire an Fertigkeiten, welche das Erkennen der Möglichkeiten und die Verfügung über die Fähigkeiten, Kapazitäten und das Sachwissen beinhaltet, die es den Menschen mit Diabetes ermöglichen, ihr eigenes Leben zu gestalten. Sein eigenes Leben mit Diabetes zu gestalten, bedeutet, dass ein Mensch mit Diabetes sich aktiv um eine Autonomie bemüht, die für seine indivi- 
duelle Persönlichkeit genau richtig ist. Diese Autonomie basiert auf Merkmalen, die einzigartig für diese Person sind, und sie ist flexibel in der Veränderung von Gesundheitsbedingungen und Lebenssituationen. Kompetenz impliziert, dass Menschen mit Diabetes täglich unterschiedliche Handlungen initiieren und ausführen. Diese Handlungsabläufe sind als Autonomie-Dimensionen begrifflich gefasst. Es handelt sich um folgende Dimensionen: Identifikation, SelbstManagement, Selbstbestimmung, gemeinsame Entscheidungsfindung, erwünschter Paternalismus, geplante Beobachtung und zuwendungsvolle Beziehungen. Die eigene Lebensgestaltung ist ein Konstrukt, das verschiedene Autonomie-Dimensionen verbindet. Die Synthese verschiedener AutonomieDimensionen entsteht auf unterschiedliche Art und Weise, und zwar abhängig von folgenden Faktoren: gesundheitliche Bedingungen, Behandlung, sozialer Kontext, familiäre Strukturen, Wissen, Erfahrung und Fertigkeiten, Art der Beziehung, Lebenslauf und persönliche Einstellung. Demzufolge ist die Kombination der Autonomie-Dimensionen nicht unveränderlich, sondern vielmehr eine Mischung aus dem, was zu einer bestimmten Zeit am zweckmäßigsten erscheint. Diabetes-Krankenschwestern können Autonomie als Kompetenz zur eigenen Lebensgestaltung am besten fördern, indem sie ihren Autonomie-Ansatz auf die Bedürfnisse und Vorstellungen jeder einzelnen Person mit Diabetes abstimmen.

In Kapitel 4 untersuchen wir den Prozess der Identifikation mit Diabetes als eine Autonomie-Dimension. Die Phasen der Identifikation sind: Begreifen, Kämpfen, Beurteilung und Bewältigung. Jede Phase hat ihre eigene Besonderheit. Identifikation mit Diabetes ist ein nicht-linearer, zyklischer und kontinuierlicher Prozess, weil Menschen mit Diabetes mit wechselnden Bedingungen umgehen müssen. Die Dynamik der Identifikation führt zu einem Prozess der Identifizierung mit Diabetes und dessen Behandlungsanforderungen. Das Verständnis von Identifikation als Element der Autonomie befähigt Pflegekräfte, eine Sichtweise zur Autonomie einzunehmen, die sich verstärkt am Patienten orientiert. Krankenschwestern sollten Autonomie als Identifikation in der Weise unterstützen, dass ein Diabetes-Patient sich mit den Diabetes-Behandlungseingriffen identifizieren kann. Deshalb ist es unerlässlich, dass Diabetes-Krankenschwestern eine unterstützende Partnerschaft aufbauen, um Patienten-Autonomie am effektivsten zu fördern.

Kapitel 5 setzt sich mit einer empirisch fundierten Konzeptualisierung von SelbstManagement auseinander im Kontext der Autonomie von Menschen mit Diabetes Typ 2. Man gebraucht drei Arten von Selbst-Management-Prozessen: täglich, abweichend und präventiv. Die Schritte für tägliches Selbst-Management sind: Befolgen der Behandlung, Gewöhnung und routinemäßiges Handeln. Die Schritte für abweichendes Selbst-Management sind: Bewusstwerdung, Schlussfolgerung, 
Entscheidung, Handeln und Auswertung. Die Schritte für präventives SelbstManagement sind: Erfahrung, Lernen, Vorsicht zeigen und Umsetzung in die Praxis. Diese Prozesse sind miteinander verwoben und periodisch wiederkehrend. Selbst-Management besteht aus einer komplexen und dynamischen Prozessreihe und ist tief verankert in der jeweils einzigartigen Lebenssituation. Die Unterstützung durch spezialisierte Diabetes-Krankenschwestern und Familienangehörige ist eine Notwendigkeit für das Diabetes-Selbst-Management. Pflegkräfte können die Patienten-Autonomie am besten fördern, indem sie eine Diabetes-Beratung anbieten, die über eine allgemeine und fachliche Beratung hinausgeht. Eine solche Beratung beinhaltet, dass den Patienten die notwendigen kognitiven, sozialen und praktischen Fertigkeiten zur Verfügung gestellt werden.

In Kapitel 6 untersuchen wir, wie Menschen mit Diabetes Typ 2 autonome Entscheidungsfindung wahrnehmen und welche moralischen Kompetenzen sie für wichtig halten, wenn es um die Unterstützung von Diabetes-Krankenschwestern bei autonomer Entscheidungsfindung geht. Hierbei liegt der Schwerpunkt auf den Dimensionen Selbstbestimmung, gemeinsame Entscheidungsfindung, erwünschter Paternalismus. Zunächst wurden Daten mit der Grounded Theory analysiert. Dann wurden Beschreibungen der Entscheidungsfindungsprozesse mit einer hermeneutischen Textinterpretation analysiert. Aus der hermeneutischen Textinterpretation wurden moralische Kompetenzen ermittelt, die Pflegekräfte benötigen, um Patienten-Autonomie aus der Patienten-Perspektive zu unterstützen. Die Teilnehmer beschrieben vielfältige Entscheidungsfindungsprozesse im Kontext der Pflege durch Pflegekräfte und Familienangehörige in Bezug auf Selbstbestimmung, gemeinsame Entscheidungsfindung und erwünschten Paternalismus. Im Kontext Krankenschwester-Patient besteht Selbstbestimmung darin, Informationen von der Pflegekraft zu erhalten und dann selbständig zu entscheiden, und im Kontext Familie-Patient besteht Selbstbestimmung darin, Informationen durch Selbstbeobachtung zu erhalten, Schlussfolgerungen zu ziehen und selbständig zu entscheiden. Im Krankenschwester-Patient-Kontext beinhaltet gemeinsame Entscheidungsfindung sich Anvertrauen, Konsensbildung und Konsensvereinbarung und im Familie-Patient-Kontext beinhaltet sie Ansichten verdeutlichen, Erörterung und Zustimmung. Im Krankenschwester-Patient-Kontext besteht erwünschter Paternalismus darin, der Pflegekraft Informationen zu vermitteln, der Krankenschwester zu erlauben, Entscheidungen zu treffen und die Entscheidung der Pflegekraft zu akzeptieren, und im Familie-Patient-Kontext besteht erwünschter Paternalismus darin, beaufsichtigt zu werden, erinnert zu werden und sich zu fügen. In der Realität finden diese Abläufe gemeinsam in einem dynamischen Prozess statt und die Kontexte Krankenschwester-Patient sowie Familie-Patient sind miteinander verwoben. Aus der hermeneutischen Textinterpretation ermittelten wir erst- und zweitrangige moralische Kompeten- 
zen. Zu den erstrangigen moralischen Kompetenzen gehören: Engagement, Sensibilität und Flexibilität. Die zweitrangigen moralischen Kompetenzen sind Wissbegier und Gesamtheitlichkeit (Selbstbestimmung), Taktgefühl, Offenheit und Vermittlung (gemeinsame Entscheidungsfindung) sowie Vertraulichkeit und Eingebundenheit (erwünschter Paternalismus). Diabetes-Krankenschwester sollten sich an fortlaufender interaktiver, reflektierender Tätigkeit beteiligen, um ihre moralischen Kompetenzen zur Förderung der Patienten-Autonomie weiterzuentwickeln.

Kapitel 7 beschreibt, wie die Literatur als Datenmaterial verwendet wurde, und es beschreibt deren Integration in die Grounded Theory Analyse. Wir benutzten das Konzept der geplanten Beobachtung, um zu veranschaulichen, wie die Literatur als Datenmaterial theoretisch erprobt wurde und dabei half, das Konzept als Antwort auf das sich entwickelnde und entstehende Konzept weiterzuentwickeln. Das Konzept der geplanten Beobachtung besteht aus zwei Sub-Kategorien: der unpassende Patient zu sein und Integration unterschiedlicher Gesichtspunkte. Die Integration unterschiedlicher Gesichtspunkte beinhaltet folgende Ablaufschritte: kennenlernen: Informationen sammeln und Verbindungen herstellen, darüber nachdenken und sich entscheiden. Als bedingte Aspekte nannten die Teilnehmer fünf motivierende Faktoren, um unter geplanter Beobachtung zu bleiben: Kontinuität der Aufsicht, Unterstützung der Pflege-Verantwortung, Sicherheit, Informationsbereitstellung und Notwendigkeit. Die Integration der Literatur als Datenmaterial in der konstanten vergleichenden Analyse, wie sie in der Grounded Theory Anwendung findet, verbessert und verdichtet theoretische Konzepte. DiabetesKrankenschwestern können Patienten-Autonomie als geplante Beobachtung am besten unterstützen, indem sie sicherstellen, dass die Patienten in einem frühen Stadium in den empfohlenen Prozess einbezogen werden und indem sie die Patienten befähigen, an der Entwicklung von Behandlungsrichtlinien innerhalb des Shared-Care-Umfelds teilzuhaben.

Kapitel 8 setzt sich mit einer ethischen Diskussion auseinander. Diese Diskussion betrifft die Autonomie in zuwendungsvollen Beziehungen basierend auf der Wahrnehmung älterer Erwachsener mit Diabetes mellitus Typ 2. Wir erstellten eine Literaturübersicht zur relationalen Autonomie bezüglich Ethik des FüreinanderSorge-Tragens, sowie in der Krankenpflege und sichteten Publikationen, die relationale Aspekte hervorheben. Die Literatur wurde in fünf Bereiche eingeteilt: haltungsorientiert, dialogorientiert, handlungsorientiert, beziehungsorientiert und lebensorientiert. Begrifflich erfasst wurden drei Prozesse, in denen Menschen mit Diabetes ihre Autonomie in zuwendungsvollen Beziehungen mit anderen ausführen: Muster der Pflege und Interaktion bewahren, gemeinschaftliche Verpflichtungen pflegen und an vertrauensvollen und hilfsbereiten familiären Bezie- 
hungen teilhaben. Menschen mit Diabetes setzen Autonomie in verschiedenen zuwendungsvollen Beziehungen ihres einzigartigen Lebensumfelds um. Die meisten Theorien zur Ethik des Füreinander-Sorge-Tragens, Krankenpflege und zu relationalen Aspekten behandeln einige Gesichtspunkte, die für Menschen mit Diabetes mellitus Typ 2 wichtig sind. Patienten können ihre Autonomie in Beziehungen mit anderen am besten verwirklichen, wenn mehrere wesentliche Aspekte des Füreinander-Sorge-Tragens vorhanden sind. Diabetes- Krankenschwestern können die Patienten-Autonomie in zuwendungsvollen Beziehungen fördern, indem sie ihre relationalen Pflege-Haltung entwickeln und sie in der täglichen Praxis der Diabetes-Pflege zum Ausdruck bringen.

Kapitel 9 stellt eine Zusammenfassung der wichtigsten Ergebnisse vor, und zwar in Bezug darauf, wie ältere Erwachsene mit Diabetes Mellitus Typ 2 ihre Autonomie sehen, wie sie ihre Autonomie umsetzen und wie spezialisierte DiabetesKrankenschwestern die Patienten-Autonomie unterstützen können. Wir beschreiben das Model der Kompetenz der eigenen Lebensgestaltung, welches zeigt, dass Patienten-Autonomie multidimensional, flexibel, kontextabhängig und spezifisch für die einzigartigen Lebenssituationen der Menschen ist. Darüber hinaus wird das Modell mit ethischer, pflegerischer und empirischer Literatur verglichen. Patienten benötigen mehrere Kompetenzen, um ihre Autonomie zu verwirklichen. Es handelt sich um praktische, kognitive, soziale, relationale und adaptive Autonomie-Kompetenzen. Wir diskutieren auch die Rolle der Familie in Beziehung zur Patienten-Autonomie und die evidenzbasierte Ausübung der Pflege. Wir führen die methodischen Kernpunkte und den Publikationsprozess näher aus. Schließlich gehen wir noch auf folgende Aspekte ein: Empfehlungen, die sich auf die praktische Anwendbarkeit des Modells in Beziehung zur klinischen Praxis konzentrieren, Qualitätsförderung, Patienten-Organisationen und Ausbildung und Schulung der Krankenpflegkräfte. Die zentrale Schlussfolgerung dieser Dissertation ist, dass Krankenschwestern die Patienten-Autonomie am besten unterstützen, indem sie Gelegenheiten ermöglichen, in denen Menschen mit Diabetes sowohl die Möglichkeiten haben, ihre eigenen unabhängigen Entscheidungen zu treffen, als auch über Mittel verfügen im Hinblick auf Unterstützung durch andere. 



\section{Acknowledgements Dankwoord Dankwort}


Rudern zwei in einem Boot

Der Eine kundig der Sterne

Der Andere kundig der Stürme

Wird der Eine führen durch die Sterne

Wird der Andere führen durch die Stürme

Und am Ende, ganz am Ende

Wird das Meer in der Erinnerung blau sein.

R. Kunze

... Mein Meer ist blau.

Allereerst wil ik de mensen met diabetes die meededen aan het onderzoek bedanken. Ik mocht bij u thuis komen en heel wat (soms nare) vragen stellen. Dankzij uw rijkdom aan ervaring heeft dit boek inhoud en kleur gekregen.

Ik wil ook de leescommissie bedanken: prof. dr. J. Hamers, dr. S. Beurskens, prof. dr. C. Gastmans, prof. dr. N. Schapper en dr. T. van der Weijden voor hun deelname aan de commissie.

I thank my supervisors prof. dr. Guy Widdershoven, prof. dr. Cor Spreeuwenberg and dr. Karen Cox.

Guy, I would like to thank you for the possibility to work the last 3 years at the department of Metamedica next to my work as nurse. Also thank you for your sharp comments on conceptual and theoretical issues, especially the chapters concerning ethical aspects of patient autonomy.

Ik wil Cor bedanken. $U$ heeft tijdens het onderzoek vaak op de achtergrond gestaan maar als het ging over het klaar maken van een publicatie dan was ik altijd blij met uw redactionele adviezen. Dit kwam ook het afmaken van de laatste hoofdstukken ten goede. Vooral tijdens het schrijven van de algemene discussie heeft u mij geholpen de hoofdlijnen niet uit het oog te verliezen. Bovendien heeft $\mathrm{u}$ voor mij de deur naar de transmurale praktijk geopend. Ik wil u ook bedanken voor uw rol in de aanstelling bij de vakgroep Metamedica.

Karen, je bent pas later in het traject mijn copromotor geworden. Jij bent op een rijdende trein gesprongen. Met jou reed de trein door, maar met heel wat nieuwe inzichten, ideeën en kennis. Jouw eerste vraag was altijd "Wat is er nieuw aan?" Je aan- en opmerkingen waren erg waardevol voor mij.

Er zijn twee mensen die heel bijzonder voor me zijn: dr. Harry van der Bruggen en $\mathrm{dr}$. Rob Houtepen. Beste Harry, jammer dat $\mathrm{u}$ aan het einde niet meer betrokken was als begeleider van dit proefschrift. Er zijn veel dingen waarvoor ik u graag wil bedanken -uw steun, uw kennis van kwalitatief onderzoek, uw passie voor de 
verpleging, voor de discussies van de dagelijkse kwalen. Bedankt dat u er voor mij was en er nog steeds bent.

Rob, ook met jou mocht ik aan een aantal stukken werken. Vooral tijdens onze allereerste samenwerkingsperiode heb je mij op vlakken, die minder met het promotietraject te maken hadden, houvast gegeven. Bedankt voor je ideeën: inhoudelijk, persoonlijk, deugdachtig, zorgethisch of filmmatig. Een ding wilde ik je al lang zeggen: je bent de meest waarachtige persoon die ik ken.

Ik wil Marianne Frederix, Marcel Bruysten, Annemie van Haarlem, Sylvia Martens, en Yvonne Wils van BZE VII bedanken voor hun steun.

Ik wil ook dr. Ingrid Mur-Veeman en dr. Arno van Raak bedanken voor hun indirecte maar zeer belangrijke hulp.

I would like to thank Sylvia van Rosmalen, Martha Tuninga and Alison Edwards who edited all the chapters and made easy-to-read pieces of what I delivered.

Mijn dank gaat ook uit naar Helen Heutz voor haar administratieve bijdrage aan mijn promotietraject.

Ik wil ook mijn oud-collega's van het Groene Kruis bedanken, vooral team Nazareth en team Zuid 3. Het was niet altijd makkelijk een promotie traject met een baan als wijkverpleegkundige te combineren maar met een beetje duwen hier, een beetje schuiven daar, is het gelukt.

Ik wil ook mijn collega's van de planning bedanken: Marie-Jose, Floor, Lieve en Anne. Wij hadden het niet makkelijk (vooral aan het begin), wij hadden het druk soms te druk, maar we konden altijd op de ander steunen. Wij blijven regelmatig uit eten gaan!

De tijd die ik bij de vakgroep Metamedika gewerkt heb was een bijzondere periode met speciale mensen. Ik had ook een werkplek naast de koffiezetapparaat (zoals het hoort voor een verpleegkundige) en een praatje houden bij de koffie kon nooit geen kwaad. Bovendien hadden wij ook een leuk lunch clubje waar allerlei dingen boven tafel kwamen. Enkele mensen wil ik graag noemen: Sandra van Dam, Vivianne Baur, Yolanda Truksema en Sander Welie. Mijn kamergenote Antina, bedankt voor de prettige (vrouwen)gesprekken.

Het is fijn zo hartelijk opgenomen te zijn in de opleiding Master of Advanced Nurse Practice aan de Hogeschool Zuyd. Mijn collega's Gerrie, Magda, Renee, Ton, Paula, Tineke, Rob, Herbert en Erik van de opleiding wil ik bedanken voor hun belangstelling, discussies en gezelligheid! Ook mijn kamergenoten waarmee ik leuke, inhoudelijke, en ook privé conversaties heb.

Tijdens mijn promotietraject heb ik ook bij de vakgroep huisartsgeneeskunde gewerkt. Ik wil dr. Irene Korstjens, dr. Huibert Tange en dr. Trudy van der Weijden 
voor de prettige samenwerking bedanken. Huibert, ik vind het fijn, dat ik met jou samen blijf werken. Een kort kwalitatief project vergt toch andere onderzoeksvaardigheden dan een promotietraject. Irene, als een "kwantitativeling" met een "kwalitativeling" samenwerkt dan zijn "scientific debates" best wel bevorderend voor de wetenschappelijke vorming van onderzoekers.

Ich danke meinen Freunden zu hause - besonders Anni, Angelika und Familie, Rosy und Familie und Cecile und Familie, und Julia. Sie alle haben mich begleitet in all den Jahren die ich von zu Hause weg bin.

I also would like to thank my friends around the globe. Dear Amira, Aisha, Jossie, Irene, Julietta. Thank you for your attentiveness. It is so nice to be still in contact with my colleagues from the MPH especially Monika, Tina, Bahaa, and Mutaz. You really care. Also, thanks to my "San Diego" friends - Isabelle, Corinne, Tove, Katarina, Simon, Fabian and Nebi.

I would also like to thank the ladies from the International Women's Club South Limburg, especially Pam Falger for her support.

Liebe Susanne, ich möchte mich bei dir ganz herzlich bedanken, dass du mir so oft und immer wieder unter die Arme gegriffen hast. Gleichzeitig hat dein kritischer Blick mir so manche Dingen vor Augen geführt, aber immer wohlwollend gemeint!

Lieve Marlou, bedankt dat je er voor me bent - no matter what! Dank je wel voor je schouder, de vele serieuze gesprekken maar ook voor de gezellige bijklets avonden. Lieve Halime, het is makkelijk door het (privé, verpleegkundig en academisch) leven te gaan samen met een mens als jij. Jullie tweeën zijn bijzonder. Fijn dat jullie mijn paranimfen zijn.

Ich möchte meiner Familie danken. Ich bin meinen ganz eigenen Weg gegangen, aber immer mit der Unterstützung und Aufmerksamkeit von Mutti und Vati, Michaela, Sieglinde, Anni, Brigitte und Peter. Es ist ein gutes Gefühl immer wieder in die "Hoamat" zu kommen und bei euch zu sein. 


\section{Curriculum vitae}

Albine Moser was born on 4 November 1972 in Tamsweg, in the federal state of Salzburg, Austria. She grew up in Krakauebene, a village in the federal state of Styria. In 1992, she earned a bachelor's degree in General and Children's Nursing at the School of Nursing in Mödling, near Vienna. From 1992 to 2000 she worked as a registered nurse at the General and Orthopaedic Hospital on the Stolzalpe, in a septic surgical ward with mentally handicapped children as well as in an orthopaedic surgical ward. She took part in a project to implement the nursing process and nursing documentation, was engaged in quality management activities, and served as a member of the quality management commission. During this time she also undertook a one-year internship at the Sharp Mary Birch Hospital in San Diego, California.

In 2001, she earned her master's degree in Public Health at Maastricht University, the Netherlands. Around the same time, she also began working in home care. After having her nursing diploma accredited she worked part time as a public health nurse at Groene Kruis in Maastricht, providing bedside care to home-care patients until 2007. She set up the Nursing and Nursing Auxiliary Advisory Council (Verpleegkundige en verzorgende adviesraad), and chaired it for several years. She was also involved in a project on central patient planning.

In 2002, she started her PhD research at Maastricht University as an external candidate. Subsequently, she held a part-time position as a junior researcher at the university's Department of Health, Ethics and Philosophy from 2006 to 2009, and as a researcher at the Department of General Practice from 2007 to mid 2008. She was also involved in a joint project on how people use comparative consumer information to choose a hospital for elective surgery.

Since September 2008 she has been working part time as a senior lecturer at Zuyd University in Heerlen, where she teaches and coordinates several courses for the Master of Advanced Nursing Practice programme. Further, since January 2009 she has been working once again as a part-time researcher in the Department of General Practice at Maastricht University. Her part of the joint project centres on how people with COPD and health professionals evaluate the use of a digital selfmanagement tool. 


\section{List of publications}

Moser, A., I. Korstjens, T. Van der Weijden, and H. Tange, Patient's decision making in selecting a hospital for elective orthopaedic surgery. Journal of Evaluation in Clinical Practice. Accepted.

Moser, A., R. Houtepen, H. Van der Bruggen, C. Spreeuwenberg and G.A.M. Widdershoven, Autonomous decision making and moral capacities. Nursing Ethics, 2009. 16(2): p. 203-218.

Moser, A., H. Van der Bruggen, G.A.M. Widdershoven and C. Spreeuwenberg, Selfmanagement of type 2 diabetes mellitus: a qualitative investigation from the perspective of participants in a nurse-led, shared-care programme in the Netherlands. BMC Public Health 2008. 8: p. 91.

Moser, A., H. Van der Bruggen, G.A.M. Widdershoven and C. Spreeuwenberg, Autonomy through identification: a qualitative study of the process of identification used by people with type 2 diabetes. Journal of Clinical Nursing, 2008. 17(17 (7b)): p. 209-216.

Moser, A., Autonomy through identification: a qualitative study of the process of identification Verpleegkunde, 2008. 23(1): p. 85.

Tange, H., A. Moser, I. Korstjens and T. Van der Weijden, Gebruikersparticipatie bij het ontwerp van een CQI-keuzewebsite. Tijdschrift voor Sociale Geneeskunde, 2008. 86(8): p. 494-500.

Moser, A., R. Houtepen and G.A.M. Widdershoven, Patient autonomy in nurse-led shared care: a review of theoretical and empirical literature. Journal of Advanced Nursing, 2007. 57(4): p. 357-365.

Moser, A., H. Van der Bruggen and G.A.M. Widdershoven, Competency in shaping one's life: Autonomy of people with type 2 diabetes mellitus in a nurse-led, sharecare setting; a qualitative study. International Journal of Nursing Studies, 2006. 43: p. 417-427. 
Um weise leise Wege finden Weil selbst Wunden Blumen bringen Bunt und brennend Berge schauen Und dort Wege auf zu bauen

C. Creux 